\title{
DETECÇÃO DE VOZ CANTADA EM SINAIS DE ÁUDIO POLIFÔNICOS
}

\author{
Shayenne Luz Moura Corrêa \\ DISSERTAÇÃO APRESENTADA \\ $\mathrm{AO}$ \\ Instituto De Matemática e EstatísticA \\ DA \\ UNIVERSIDADE DE SÃo PAUlo \\ PARA \\ OBTENÇÃO DO TÍTULO \\ $\mathrm{DE}$ \\ Mestre EM CiênCIAS \\ Programa: Ciência da Computação \\ Orientador: Prof. Dr. Marcelo Queiroz
}

Durante o desenvolvimento deste trabalho a autora recebeu auxílio financeiro do CNPq

São Paulo, outubro de 2020 


\section{Detecção de Voz Cantada em Sinais de Áudio Polifônicos}

Esta versão da dissertação contém as correções e alterações sugeridas pela Comissão Julgadora durante a defesa da versão original do trabalho, realizada em 01/10/2020. Uma cópia da versão original está disponível no

Instituto de Matemática e Estatística da Universidade de São Paulo.

Comissão Julgadora:

- Prof. Dr. Marcelo Gomes de Queiroz (orientador) - IME-USP

- Prof. Dr. Martin Rocamora Martinez - UDELAR

- Prof. Dr. Rodrigo Schramm - UFRGS 


\section{Agradecimentos}

Poemas e canções

a Deus sejam escritos

Por todos os peritos

a quem concedeu os dons.

Poemas e Canções

- Stênio M. B. Nogueira

Deus concede dons aos homens, graças e oportunidades.

Eu tive a oportunidade de trabalhar nesta dissertação com um tema que sempre me motivou e inspirou: a música!

Agradecer é expressar a realidade de que nada fazemos se não houver quem ajude. O trabalho que você lê agora é fruto de muito esforço e dedicação de muitas pessoas, direta ou indiretamente. Esforço e dedicação que me permitiram escrever essas palavras, realizar experimentos, e crescer pessoal e profissionalmente. Não poderia escrever o nome de todos os que me ajudaram neste processo (seria injusto com muitos) mas quero destacar pessoas que estiveram ao meu lado e me fortaleceram neste período.

Antes de tudo, o Senhor Jesus, que se mostrou maior e melhor que tudo que eu imaginava enquanto eu trabalhei na redação deste trabalho.

Minha família: mãe, pai e irmã, que estavam sempre torcendo por mim (e se desesperando quando eu tinha que viajar para longe para alguma conferência).

Meu amigo, namorado, noivo, e agora, marido Willian Corrêa (passamos por todos estas etapas desde o início do mestrado até hoje) que sempre me inspirou a fazer o meu melhor.

Meus irmãos da ABU (Aliança Bíblica Universitária) que se tornaram uma brisa suave em meio ao caos da vida acadêmica. Suas orações e conselhos me foram extremamente importantes.

Meus amigos e colegas de graduação e mestrado, que venceram comigo as batalhas das disciplinas e estiveram presentes em minha defesa.

A comunidade do ISMIR, com seus projetos de inclusão e mentoria, que me permitiram ter mais profundidade nos estudos e contato com pesquisadores experientes, dentre eles Justin Salamon, que me incentivou a trabalhar com detecção de voz cantada.

Ao meu orientador Marcelo Queiroz e aos professores membros da banca avaliadora Martin Rocamora e Rodrigo Schramm, que me incentivaram ao longo de todo o processo de desenvolvimento do trabalho e me mostraram que o resultado do meu trabalho era bom.

Por fim, dedico este trabalho a Deus, afinal de contas "Porque dEle e por Ele, e para Ele, são todas as coisas; glória, pois, a Ele eternamente. Amém." (Romanos 11:36) 


\section{Resumo}

MOURA-CORRÊA, S. L. Detecção de voz cantada em sinais de áudio polifônicos. 2020. 54 f. Dissertação (Mestrado) - Instituto de Matemática e Estatística, Universidade de São Paulo, São Paulo, 2020.

Detecção de voz cantada em sinais de áudio polifônicos é o problema que trata de determinar quais trechos de um sinal musical com diversas fontes sonoras contêm voz cantada. Este é um tópico de pesquisa ativo na área de Recuperação de Informação Musical (MIR) e possui muitas aplicações, incluindo reconhecimento automático de cantor, alinhamento de letra e música, separação de voz cantada e extração de melodias.

Neste projeto, o problema de detecção de voz cantada é abordado através do levantamento das técnicas utilizadas na literatura, com o desenvolvimento de um sistema capaz de classificar os segmentos de sinais de áudio em duas classes (os trechos que contêm e os trechos que não contêm voz cantada) e também pela comparação dos resultados de detecção de voz cantada utilizando ferramentas baseadas em aprendizado profundo.

Os objetivos gerais são: apresentar a revisão da literatura e construir experimentos a fim de analisar os métodos de classificação e descritores de áudio. Os objetivos específicos são: avaliar as restrições presentes na classificação dos trechos cantados, usar descritores de áudio baseados em aprendizado profundo ainda não aplicados na tarefa e comparar o uso de métodos tradicionais de aprendizado de máquina com as possibilidades apresentadas pelas representações aprendidas automaticamente.

A partir de uma série de experimentos, enfrentamos a complexidade do tema e as limitações apresentadas por descritores comumente usados. Ao usar um descritor baseado em aprendizado profundo, observa-se espaço para melhorias na abordagem clássica de aprendizado de máquinas baseada na seleção e combinação de representações tradicionais dos dados musicais na entrada dos algoritmos de aprendizado.

Palavras-chave: recuperação de informação musical, detecção de voz cantada, computação musical, aprendizado de máquina, representações aprendidas automaticamente. 


\section{Abstract}

MOURA-CORREAA, S. L. Singing voice detection on polyphonic audio signals. 2020. 54 p. Dissertation (Master Degree) - Instituto de Matemática e Estatística, Universidade de São Paulo, São Paulo, 2020.

Singing voice detection in polyphonic audio signals is the problem that deals with determining which segments of a musical signal (with several sound sources) contain singing voice. This is an active topic of research in the field of Music Information Retrieval (MIR) and has various applications, including automatic singer recognition, lyrics alignment, singing voice separation and melody extraction.

In this project, the problem of singing voice detection is addressed through the survey of the techniques used in the literature, the development of a system capable of classifying the segments of audio signals in two classes (the sections that contain and the sections that do not contain singing voice) and also by comparing the results of singing voice detection using tools based on deep learning.

The general objectives are: to present a literature review and to build experiments in order to analyze classification methods and audio descriptors. The specific objectives are: to evaluate the restrictions present in the classification of the sung excerpts, to use audio descriptors based on deep learning not yet applied to the task and to compare the use of traditional machine learning methods with the possibilities presented by automatically learned representations.

By a series of experiments we face the complexity of the theme and the limitations presented by commonly used descriptors. When using a descriptor based on deep learning, it was noticeable that there is room for improvement over classic machine learning approaches, which are based on selection and combination of traditional representations of the music data at the input of learning algorithms.

Keywords: music information retrieval, singing voice detection, computer music, machine learning, representation learning. 


\section{Sumário}

1 Introdução 1

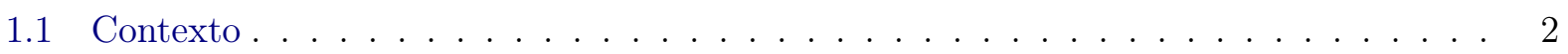

1.2 Motivação e aplicações . . . . . . . . . . . . . . . . . . . . . . . . . . . 3

1.3 Trabalhos relacionados ............................... 4

1.4 Objetivos ................................ . . . . . . . . .

1.5 Estrutura da dissertação . . . . . . . . . . . . . . . . . . . . . . . . . . . . . 8

2 Fundamentação Teórica $\quad 9$

2.1 Representações digitais de áudio . . . . . . . . . . . . . . . . . . . . . . . . . . . . . . . . 9

2.2 Descritores de áudio . . . . . . . . . . . . . . . . . . . . . . . . . . . . . . . . . . . . 11

2.3 Algoritmos de aprendizado de máquina . . . . . . . . . . . . . . . . . . . . . . . . . . . 14

2.4 Representações aprendidas automaticamente . . . . . . . . . . . . . . . . . . . 16

2.5 Métodos de separação de fontes . . . . . . . . . . . . . . . . . . . . . . . . . . . . . 17

2.6 Métodos de avaliação em MIR . . . . . . . . . . . . . . . . . . . . . . . . . . 18

3 Detecção de voz cantada usando descritores de áudio 21

3.1 Metodologia . . . . . . . . . . . . . . . . . . . . . . . . . . . . . 21

3.2 Conjunto de dados . . . . . . . . . . . . . . . . . . . . . . . . . . . . . . . 22

3.3 Experimentos preliminares . . . . . . . . . . . . . . . . . . . . . . . . . . . . . . 23

3.4 Experimento de comparação de descritores de áudio . . . . . . . . . . . . . . . . . . . . 29

3.5 Resultados ................................... 30

3.6 Discussão . . . . . . . . . . . . . . . . . . . . . . . . . . . . 33

4 Detecção de voz cantada usando separação de fontes 35

4.1 Metodologia . . . . . . . . . . . . . . . . . . . . . . . . . . . . . 35

4.2 Conjunto de dados . . . . . . . . . . . . . . . . . . . . . . . . . . . . . . . . . . . . . 36

4.3 Separação de fontes . . . . . . . . . . . . . . . . . . . . . . . . . . . . . . . . . . 36

4.4 Resultados . . . . . . . . . . . . . . . . . . . . . . . . . . . . . 37

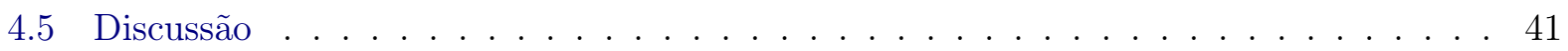

5 Conclusões $\quad 43$

5.1 Contribuições . . . . . . . . . . . . . . . . . . . . . . . . . . . . . . 43

5.2 Objetivos alcançados . . . . . . . . . . . . . . . . . . . . . . . . . . 44

5.3 Dificuldades encontradas . . . . . . . . . . . . . . . . . . . . . . . . . 45

5.4 Trabalhos futuros . . . . . . . . . . . . . . . . . . . . . . . 45 
A Sensibilidade à Instrumentação de um Detector de Voz Cantada baseado em Descritores Espectrais

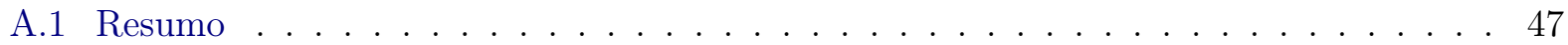

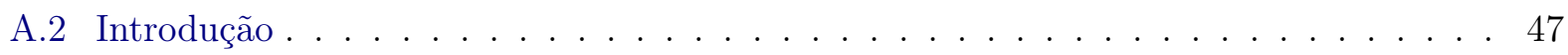

A.3 Metodologia . . . . . . . . . . . . . . . . . . . 47

A.4 Avaliação . . . . . . . . . . . . . . . . . . . . . . 48

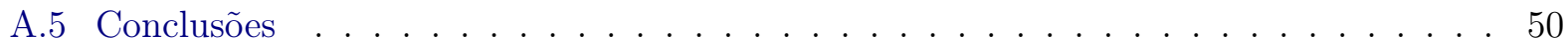

$\begin{array}{ll}\text { Referências Bibliográficas } & 51\end{array}$ 


\section{Capítulo 1}

\section{Introdução}

E então as vozes dos Ainur, semelhantes a harpas e alaúdes, a flautas e trombetas, a violas e órgãos, e a inúmeros coros cantando com palavras, começaram a dar forma ao tema de Ilúvatar, criando uma sinfonia magnífica; e surgiu um som de melodias em eterna mutação, entretecidas em harmonia, as quais, superando a audição, alcançaram as profundezas e as alturas; e as moradas de Ilúvatar encheram-se até transbordar; e a música e o eco da música saíram para o Vazio, e este não estava mais vazio

$\overline{\text { A música dos Ainur, Silmarillion }}$ - J. R. R. Tolkien

Na música ocidental, a voz cantada tem papel muito relevante no conteúdo musical. O retrato do som da voz como criador de elementos exuberantes, no trecho de "A música dos Ainur" do escritor J.R.R. Tolkien, representam o impacto emocional causado pelo som de vozes em música. A voz cantada expressa o humor, as características do intérprete, e, por isso, contextualiza, informa e atinge o ouvinte de diversas formas. Esse caráter comunicativo da voz cantada tem grande influência em diversos aspectos musicais, como a emoção, o significado e a intenção do compositor, implicando na extrema relevância da voz quando analisamos o conteúdo musical.

Seres humanos conseguem determinar trechos contendo voz cantada rapidamente quando ouvem uma música. Ouvintes conseguem distinguir quando o cantor inicia as frases, quando prolonga notas e liga novas palavras, até mesmo quando as palavras não são da língua nativa. Independentemente de qualquer processo externo, apenas a onda sonora que alcança os ouvidos é suficiente para a percepção de presença do conteúdo vocal. O som é processado pelos sistemas auditivo e cognitivo, permitindo identificar e distinguir os cantores favoritos, diferentes versões e performances das mesmas músicas.

Atualmente, sistemas computacionais são capazes de identificar objetos em imagens com alta precisão, devolver respostas coerentes para perguntas feitas por humanos, recriar imagens novas como se fossem de obras de pintores famosos, tomar decisões baseadas em experiências anteriores e muitas outras tarefas que, até pouco tempo atrás, apenas humanos eram capazes de realizar. Distinguir o conteúdo de sinais sonoros é apenas um desafio dentre tantos que têm influenciado pesquisadores a desenvolverem sistemas computacionais capazes de obter desempenho igual ou superior ao humano em tarefas do dia-a-dia. 
Dada a importância da voz cantada, reconhecê-la automaticamente por meio de sistemas computacionais é um passo essencial para diversas tarefas relacionadas ao conteúdo vocal em sinais musicais como, por exemplo, o reconhecimento automático de cantores, o alinhamento entre letra e música, a separação da voz cantada do acompanhamento e a transcrição de melodias vocais.

A identificação dos trechos de voz cantada pode ser feita destacando-se no sinal de áudio polifônico os instantes no tempo em que começam e terminam os trechos cantados (abordagem de segmentação) e pode também ser feita dividindo-se o sinal em pequenos trechos de um tamanho específico e rotulando-se os trechos com a presença ou ausência de voz cantada (abordagem de classificação). A Figura 1.1 apresenta um exemplo de segmentação dos trechos cantados (faixas azuis) com indicação de início (barras vermelhas) e fim dos trechos (barras cinzas). Identificar os trechos cantados a partir de segmentação demanda encontrar os instantes onde a voz inicia (onsets) e termina (offsets), o que é difícil de definir com precisão quando no conteúdo do sinal existem outras fontes sonoras que ocultam e/ou suavizam essas características da voz. Neste trabalho, portanto, utilizaremos a segunda abordagem: o problema de detecção automática de voz cantada é definido aqui como a classificação de segmentos de áudio que contêm ou não voz cantada.

Figura 1.1: Saída esperada de um detector automático de voz cantada

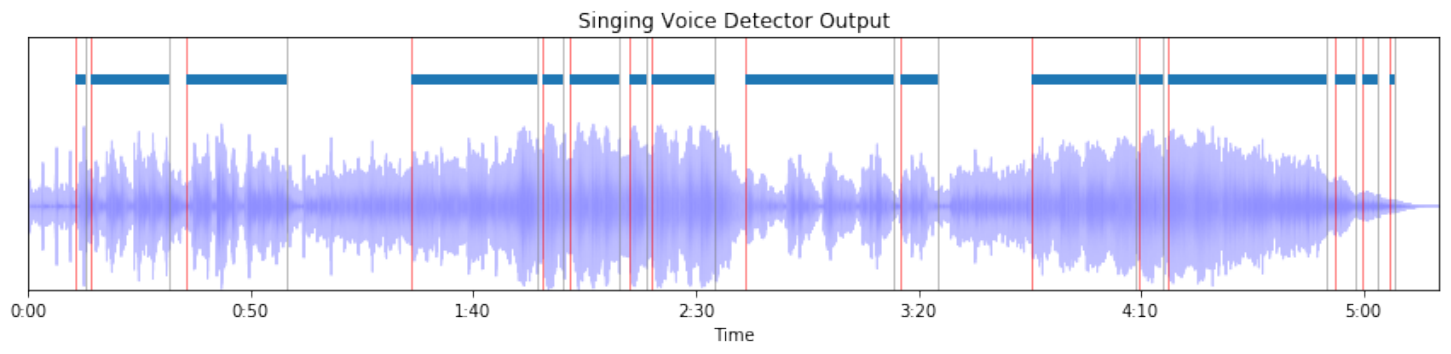

\subsection{Contexto}

O estudo da Análise de Cenas Sonoras (Auditory Scene Analysis - ASA) realizado por Bregman [1994] deu origem a uma área de pesquisa homônima, relacionada à modelagem da percepção sonora humana através do conceito de cenas sonoras. Como ocorreu em diversas outras áreas, adotou-se o uso do computador para se desenvolver sistemas capazes de processar e analisar cenas sonoras, de forma similar ao que é feito na área de Visão Computacional. Este campo ficou conhecido como Análise Computacional de Cenas Sonoras (Computational Auditory Scene Analysis - CASA) [Wang e Brown, 2006]. Em termos gerais, CASA trata do desenvolvimento de sistemas capazes de segregar fontes sonoras em meio a diversas outras fontes, como os humanos fazem, o que é denominado "cocktail party problem" [Cherry, 1953]. Esse nome é inspirado na ideia de que, mesmo em meio a uma profusão de eventos sonoros (pessoas conversando, ruído de máquinas, sons de instrumentos), uma pessoa é capaz de identificar e compreender a voz de outra e manter uma conversa.

A Recuperação de Informação Musical (Music Information Retrieval - MIR) é uma área de pesquisa que aborda diversos problemas relacionados ao uso de dados musicais através do desenvolvimento e aplicação de técnicas computacionais [Knees e Schedl, 2016]. A área é baseada na combinação do uso de teorias, conceitos e técnicas advindas da música, ciência da computação, processamento de sinais e cognição, entre outras.

O problema de detecção automática de voz cantada é estudado tanto em CASA [Li e Wang, 2007] quanto em MIR [Lehner et al., 2014]. A primeira, com o interesse de reproduzir a capacidade humana de identificar e segregar determinadas fontes sonoras em meio a outras e, a segunda, com interesse em recuperar informações relevantes sobre o conteúdo do sinal musical, como melodia, timbre, etc. Algumas abordagens na literatura buscam unir técnicas de ambas as áreas ([Li e Wang, 2007], [Regnier e Peeters, 2009],[Hsu e Jang, 2010]). 
A estrutura básica para construir um típico detector automático de voz cantada é baseada nos sistemas de classificação binária, como apresentado em Rocamora e Herrera [2007]: (1) segmentamos o áudio em trechos de tamanho fixo e resumimos a informação do sinal em descritores de áudio; (2) usamos estes descritores para alimentar um sistema de classificação; e (3) processamos a saída do classificador. O resultado é a atribuição dos rótulos cantado/não-cantado para cada trecho segmentado do áudio. A Figura 1.2 apresenta os elementos essenciais para a construção de um sistema de deteç̧ão de voz cantada.

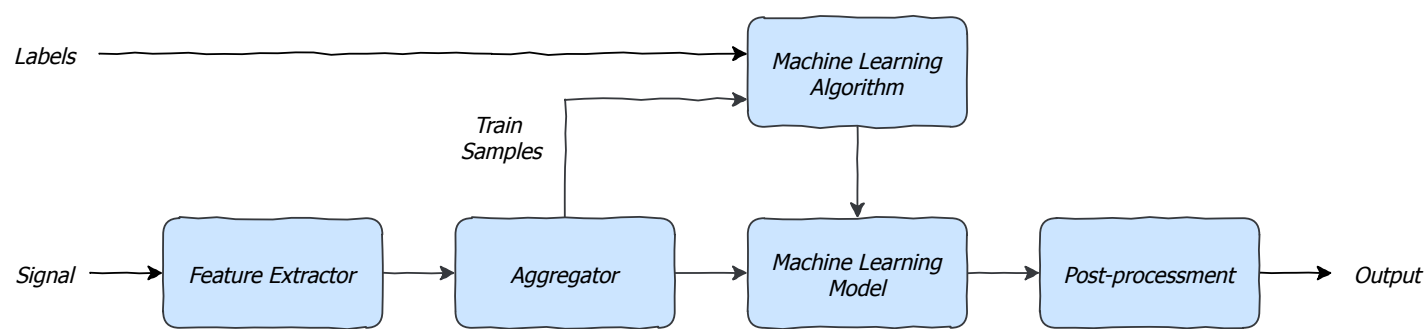

Figura 1.2: Estrutura básica de um detector de voz cantada típico

\subsection{Motivação e aplicações}

A detecção de voz cantada é um tópico importante em MIR porque é um passo necessário em diversas tarefas, como reconhecimento automático de cantor [Berenzweig et al., 2002], extração de melodias [Hsu e Jang, 2010] e alinhamento de letra [Li e Wang, 2007].

A voz cantada não possui uma definição formal na literatura. Numa revisão recente de métodos de detecção de voz cantada em sinais de áudio musicais, Lee et al. [2018] apontam algumas direções a seguir para melhorar os resultados desta tarefa, sendo uma delas a busca por uma definição formal de voz cantada. Uma preocupação citada por Lee et al. [2018] sobre a definição de voz cantada é considerar os trechos musicais contendo backing vocals como parte de trechos cantados. Os trabalhos anteriores que tratam deste assunto não se preocuparam com isso, possivelmente porque os conjuntos de dados eram limitados e não incluíam músicas com backing vocals.

Outra controvérsia sobre a caracterização de voz cantada deve-se à relação de similaridade entre voz falada e cantada. De acordo com Cook [1991], um sinal de voz seria considerado como de voz falada quando há pouca variação de altura musical (pitch) e uma taxa maior de ataques (consoantes) por segundo, isto é, o sinal de fala possuiria menos trechos vocalizados (cerca de 60\%) enquanto o sinal de voz cantada possuiria mais trechos vocalizados (cerca de 90\%). Uma tal caracterização dificultaria por exemplo a classificação da voz de um rapper em uma música como um exemplo de voz cantada.

Mesmo em se tratando de vozes com grande variação de altura musical, existem diferenças importantes de acordo com o estilo musical. Por exemplo, cantores populares não usam necessariamente os mesmos mecanismos de produção vocal que cantores líricos, o que influencia no timbre resultante e, consequentemente, no aprendizado realizado por um sistema de deteç̧ão.

Definir o que é considerado voz cantada é um passo importante para melhorar os resultados de detecção de voz nos sinais musicais. Sundberg [1977] apresenta uma caracterização da acústica da voz cantada, apresentando detalhes da geração da voz e frequências formantes. No entanto, pode ser necessário ajustar a definição de acordo com a aplicação desejada, como é o caso de identificar trechos cantados para karaokê ou para transcrição automática. No primeiro caso, deseja-se apenas encontrar a voz principal, enquanto no segundo, também seria importante detectar backing vocals.

Ter bancos de dados com as faixas de áudio separadas torna mais fácil tanto a definição do problema (a voz cantada está presente quando a faixa correspondente à voz possui atividade) quanto o treinamento do sistema de deteç̧ão (permitindo melhorar os resultados da classificação de acordo com a tarefa desejada). Para evitar inconsistências e definições não abrangentes, neste trabalho usaremos conjuntos de dados com faixas de áudio separadas, tendo como referência de voz 
cantada todas as faixas de áudio que contenham os rótulos (ou fontes sonoras) cantor feminino, cantor masculino, coral e vocalistas, e peças musicais que possuem a anotação destas fontes.

O último ponto a se considerar na geração de modelos de aprendizado de máquina é o contexto representado pelos dados de entrada. Em se tratando de áudio, as características do sinal normalmente são resumidas em pequenos trechos de intervalo definido. Quanto maior o intervalo, maior o contexto, e consequentemente, menor a capacidade de localização de informação específica. O estudo realizado por Belin et al. [2004] indica que conseguimos identificar a voz cantada em meio a outros instrumentos quando o tempo mínimo entre o ataque e a finalização da nota cantada tenha entre $300 \mathrm{~ms}$ e $400 \mathrm{~ms}$, havendo um pico de percepção normalmente em torno de $320 \mathrm{~ms}$. Para tratar a rotulação dos intervalos de áudio de modo a representar a realidade perceptual, usaremos um intervalo mínimo de $300 \mathrm{~ms}$ para indicar a presença de voz em um determinado trecho de áudio polifônico.

\subsection{Trabalhos relacionados}

Revisitando técnicas de deteç̧ão de voz cantada, Lee et al. [2018] dividem as abordagens para esta tarefa em três grupos: soluções que recorrem à similaridade entre voz cantada e falada; classificação por aprendizado de máquina; e aprendizado de descritores a partir de redes neurais profundas. Decidimos descrever os trabalhos relacionados da literatura agrupando-os segundo essas classes de abordagens. A Tabela 1.1 apresenta um resumo dos trabalhos, abordagens, descritores, classificadores e conjuntos de dados utilizados como referência.

Tabela 1.1: Resumo das técnicas aplicadas em detecção de voz cantada em ordem cronológica

\begin{tabular}{|r|c|c|c|}
\hline Autores & Descritores & Classificadores & Pós-processamento \\
\hline Berenzweig e Ellis [2001] & $\begin{array}{c}\text { PLP, PPF, Cepstral Coefficients, } \\
\text { Entropy }\end{array}$ & HMM & - \\
\hline Berenzweig et al. $[2002]$ & PLP, deltas and double deltas & MLP (130x2) & Moving-average \\
\hline Zhang [2003] & $\begin{array}{c}\text { LPC, Energy, ZCR, } \\
\text { Harmonic Coefficients, Spectral Flux }\end{array}$ & Thresholds & - \\
\hline Li e Wang [2007] & MFCC & GMM & - \\
\hline Rocamora e Herrera [2007] & MFCC, PLPC, LFPC, HC, ZCR & SVM, KNN, ANN, C4.5 & Re-classification \\
\hline Regnier e Peeters [2009] & Vibrato, Tremolo & Thresholds & Segments > 1sec \\
\hline Lehner et al. $[2014]$ & MFCC, Fluctogram, SF, SC, VV & Random Forest & Median Filter \\
\hline Dittmar et al. [2015] & MFCC, VOCVAR, FLUCT, & Random Forest & Bootstraping \\
\hline Leglaive et al. [2015] & NSD, FLAT, PSSC & BLSTM-RNN & Threshold \\
\hline Schlüter [2016] & STFT HPSS & CNN & - \\
\hline Lehner et al. [2018] & MFCC, Fluctogram, SF, SC & LSTM-RNN & - \\
\hline Swaminathan e Lerch [2019] & STFT & CNN & \\
\hline
\end{tabular}

\section{Similaridade com processamento de fala}

O primeiro trabalho que tratou de detecção de voz cantada foi apresentado por Berenzweig e Ellis [2001]. Com uma forte influência de abordagens de processamento de fala, eles implementaram um detector usando modelo oculto de Markov (Hidden Markov Model). As entradas para o modelo eram estatísticas baseadas em vetores de probabilidade saídos de uma rede neural artificial treinada para detectar trechos de fala em meio ao ruído.

Outra abordagem, apresentada por Zhang [2003], consistia em um sistema para classificação automática de cantor utilizando técnicas de classificação de falante, com estratégias para capturar os elementos da voz cantada em meio a outras fontes sonoras. Zhang treinou um modelo estatístico com músicas comuns de cada cantor, sendo que a classificação era feita usando trechos de áudio a partir de pontos onde iniciava a voz cantada. O autor usou uma série de descritores de energia do sinal e calculou limiares para determinar onde iniciavam os trechos de voz. Ele concluiu que estes descritores não foram suficientes para identificar os trechos de voz quando havia instrumentos fortes na música. 
Numa tentativa de explorar o conteúdo musical, Regnier e Peeters [2009] decidiram utilizar características sonoras da voz humana (harmonicidade, formantes, vibrato e tremolo) para identificar os trechos de voz cantada e treinaram limiares que caracterizassem os trechos cantados. Eles argumentam que seus resultados são próximos aos alcançados com outros mecanismos de aprendizado de máquina, dando espaço para combinar as abordagens, uma vez que elas são independentes.

\section{Classificação com aprendizado de máquina}

Em outro trabalho, Berenzweig et al. [2002] implementaram um classificador automático de artistas e fizeram experimentos comparando os resultados dessa classificação usando trechos cantados e trechos apenas instrumentais. Estes autores notaram que a classificação teve melhores resultados quando foram usados trechos estáveis de voz. No entanto, em outro experimento utilizando conjuntos de treino e teste com álbuns diferentes a fim de verificar a importância do álbum na identificação do artista, os mesmos autores notaram que a performance do classificador diminuiu. Concluíram, por isso, que os classificadores estavam aprendendo características específicas do álbum, possivelmente relacionadas aos elementos estilísticos e de instrumentação, ao invés de aprender as supostas regiões vocais estáveis.

Li e Wang [2007] desenvolveram um sistema de separação da voz cantada do acompanhamento musical. Esse sistema possuía três estágios: detecção dos trechos com voz, detecção da altura da voz e agrupamento dos elementos sonoros que faziam parte da voz. Eles utilizaram um descritor relacionado ao timbre e um classificador estatístico para detectar os trechos de voz cantada. Eles estavam preocupados em realizar um sistema baseado em CASA.

Em busca de comparar diferentes métodos, Rocamora e Herrera [2007] conduziram uma série de experimentos para identificar descritores de áudio e classificadores que melhor executassem a tarefa de detecção de voz cantada. Para selecionar os melhores descritores, os autores treinaram diversos modelos de aprendizado de máquina e verificaram os resultados após a classificação.

Lehner et al. [2014] definem um novo descritor de áudio (fluctogram) e apresentam técnicas para diminuir a quantidade de falsos positivos. O modelo de Lehner é considerado estado-da-arte em detecção de voz cantada utilizando a abordagem de uso de descritores vocais, segundo Lee et al. [2018].

Uma abordagem específica de Dittmar et al. [2015] apresenta um sistema de detecção de voz cantada para óperas, utilizando aprendizado de máquina. Neste artigo, os autores apresentam também um novo descritor de áudio que amplia o estado da arte em detecção de voz em músicas populares e métodos para melhorar os resultados da classificação.

\section{Redes neurais profundas}

Leglaive et al. [2015] propuseram um sistema utilizando redes neurais recorrentes BLSTM. O objetivo era encontrar trechos cantados utilizando informação temporal passada e futura. Como a rede neural possuía muitas camadas, era possível utilizar descritores de baixo nível, como STFT. Os resultados, segundo os autores, são significativamente melhores em relação ao estado da arte utilizando aprendizado de máquina.

Schlüter [2016] desenvolveu um sistema capaz de identificar trechos de voz cantada comparativamente ao estado da arte, além de mostrar em qual faixa de frequências a voz foi detectada. $\mathrm{O}$ sistema foi desenvolvido usando redes neurais convolucionais, aprendizado de múltipla instância e mapas de saliência. Neste trabalho, as músicas eram fracamente rotuladas, ou seja, cada música possuía apenas um rótulo dizendo se a música inteira continha ou não voz cantada, sem identificar precisamente os trechos de voz cantada.

Em uma tentativa de aumentar o conjunto de dados disponível para detecção de voz cantada, Humphrey et al. [2017] criaram um sistema de rede neural convolucional profunda capaz de identificar os trechos cantados comparando versões instrumentais e cantadas de uma mesma peça. Apesar de não ser um sistema perfeito, os autores relatam resultados de acurácia de anotação superiores aos humanos. 
Como uma evolução do seu trabalho anterior, Lehner et al. [2018] apresentam novas versões dos descritores vocais utilizados por ele anteriormente [Lehner et al., 2014] (os Fluctograms são pós-processados por indicadores de confiabilidade), e a estrutura de aprendizado de máquina usada é a rede neural recorrente com memória (LSTM-RNN). Segundo o autor, esta abordagem possui resultados superiores à anterior.

A abordagem mais recente de deteç̧ão de voz cantada de Swaminathan e Lerch [2019] volta às origens da representação de áudio, criando um detector de voz cantada com redes convolucionais tendo como entrada a STFT do sinal de áudio. O objetivo do artigo é avaliar a qualidade da separação da voz em uma mistura, adicionando ao sistema separador a informação de presença (ou atividade) da voz em cada trecho.

Usaremos como principal referência Lehner et al. [2014]. O foco deste artigo é apresentar features capazes de diminuir a quantidade de falsos positivos na deteç̧ão e que são leves e rápidas para serem calculadas, pois estes autores pretendem usá-las em um sistema de deteç̧ão de voz cantada on-line, i.e., em tempo real, com um modelo relativamente simples de aprendizado de máquina.

Até o momento da escrita do artigo, eles tomavam Mauch et al. [2011] como referência de melhor sistema de detecção de voz, porém este usava descritores complexos, extraindo F0 (frequência fundamental) mais evidente a cada instante, tendo como premissa que a voz cantada é a fonte predominante no sinal de áudio. Os autores de Lehner et al. [2014] apontam que o sistema de Mauch é a melhor estratégia até então, porém a sua complexidade inviabiliza a construção de um sistema de detecção em tempo real.

Em Lehner et al. [2014], os autores comparam os resultados do uso das novas features com os resultados de Mauch, além de outros três resultados: um sistema anterior que utilizava MFCCs otimizados, um sistema que eles puderam reproduzir [Vembu e Baumann, 2005] e os resultados relatados por Ramona et al. [2008]. As comparações dos resultados mostraram que o modelo superava a todos em todas as métricas, exceto as métricas de Mauch, por isso, os autores utilizaram como referência um baseline que atribuía a todos os frames o rótulo de cantado.

Para validar as novas features apresentadas, Lehner et al. [2014] testaram o classificador treinado sobre conjuntos de dados sem voz que continham fontes sonoras comumente confundidas com a voz cantada por serem altamente harmônicas (guitarras, cordas, flauta, etc). Em comparação com um modelo que utilizava apenas MFCCs otimizados, a porcentagem de falsos positivos caiu pela metade totalizando todos os conjuntos de teste. Os autores concluem então que as features novas conseguem minimizar o problema dos falsos positivos, além de serem leves o suficiente para serem utilizadas em sistemas de tempo real.

\subsection{Objetivos}

Como apresentado na contextualização, os trabalhos sobre deteç̧ão de voz cantada tratam do problema usando diferentes métodos e descritores. Este trabalho pretende levantar as abordagens utilizadas anteriormente e discutir as questões e limitações relativas aos descritores, realizando experimentos com o uso de descritores considerados estado da arte e utilizando ferramentas e descritores recentes na literatura. Podemos associar os objetivos gerais com as seguintes perguntas:

- Descritores tradicionais e perceptualmente motivados discriminam bem os trechos de voz cantada?

- A utilização de descritores de áudio aprendidos automaticamente contribui para melhores resultados nesta tarefa?

- O tipo de acompanhamento (fontes sonoras presentes no sinal) influencia na detecção dos trechos cantados?

- Qual seria a qualidade da detecção de voz cantada utilizando a saída de um separador de fontes treinado com aprendizado profundo? 


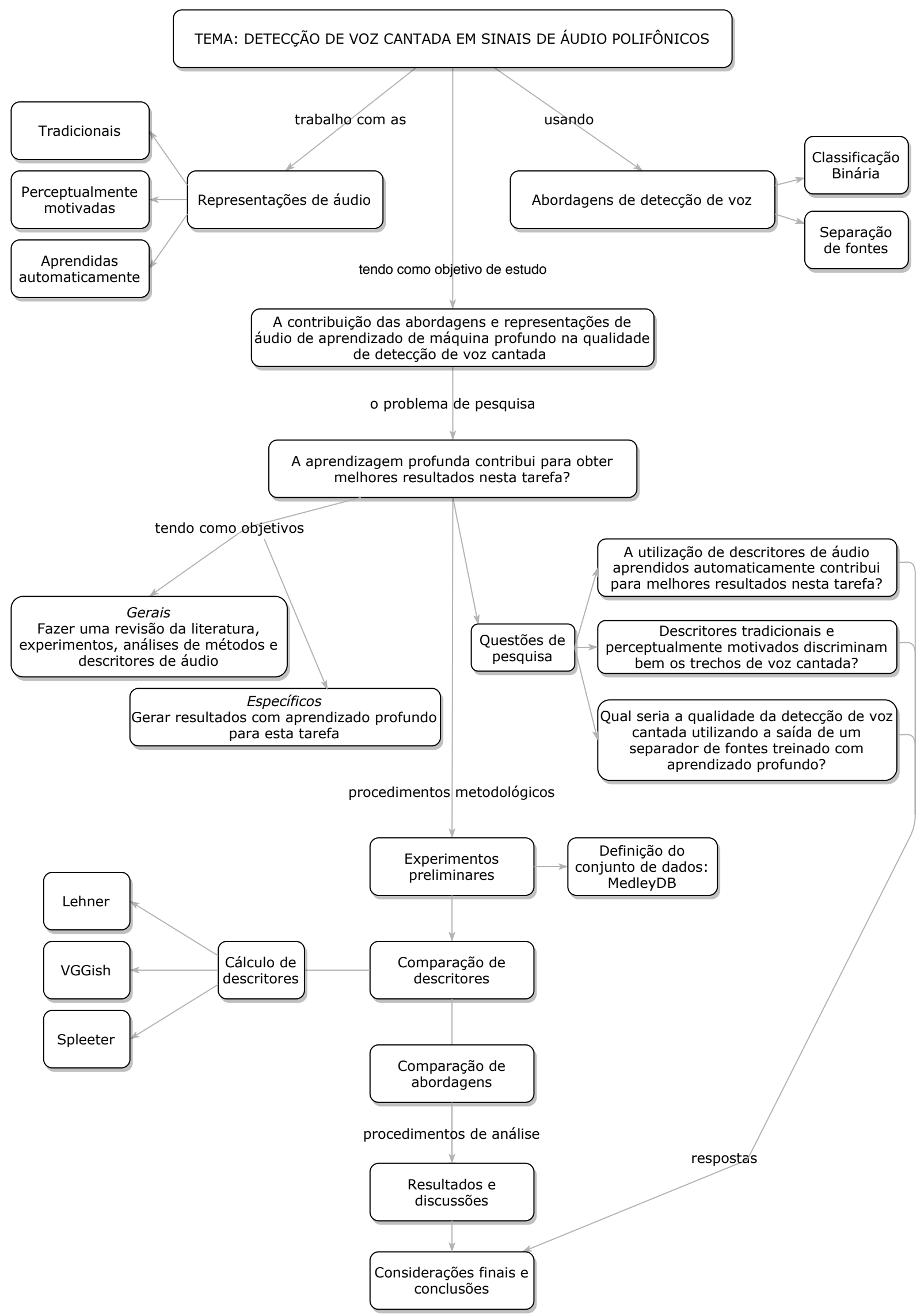




\subsection{Estrutura da dissertação}

Neste trabalho apresentamos diversos aspectos relacionados à tarefa de detecção de voz cantada. Estruturamos os capítulos de acordo com a descrição a seguir.

No Capítulo 2 apresentamos os conceitos básicos sobre representações digitais de áudio, descritores de áudio próprios para a identificação de voz cantada e algoritmos de aprendizado de máquina necessários para o desenvolvimento dos experimentos apresentados. Apresentamos também o modelo de aprendizado profundo que gera automaticamente descritores de áudio, um método de separação de fontes que serve como referência para os resultados de classificação de trechos cantados, e métricas de avaliação de qualidade para sistemas de classificação binária.

O capítulo 3 traz experimentos que visam apresentar e avaliar os descritores de áudio, tanto os comumente usados na detecção de voz quanto os mais recentes. Este capítulo contém experimentos preliminares, que serviram como base para reconhecimento da dificuldade da tarefa e para obtermos as primeiras considerações sobre o problema. Após as primeiras experiências, realizamos experimentos relacionados à reprodução do uso de descritores de áudio perceptualmente motivados e sua comparação com os resultados do uso de um descritor aprendido automaticamente. Nele discutimos as ferramentas, o banco de dados, a metodologia e o desenho dos experimentos, bem como seus resultados.

Para complementar a discussão, o capítulo 4 traz a comparação entre resultados de detecção de voz cantada alcançados com os detectores treinados anteriormente e os resultados obtidos pela separação de fontes, utilizando sistemas do estado da arte para essa última tarefa.

Por fim, no capítulo 5 apresentamos as contribuições deste trabalho e os objetivos alcançados, destacamos as dificuldades encontradas no decorrer do desenvolvimento bem como possíveis trabalhos futuros.

O apêndice traz resultados de experimentos preliminares em variações de conteúdos sonoros para a detecção de voz cantada, explorando a ideia de aumentação do conjunto de dados através da geração de mixagens alternativas. 


\section{Capítulo 2}

\section{Fundamentação Teórica}

A estrutura básica para a construção de um detector de voz cantada pode ser descrita da seguinte forma: transformação do sinal de áudio em representações digitais de baixo nível, cálculo de descritores que evidenciam elementos do conteúdo do sinal, geração de um modelo capaz de diferenciar descritores cujo conteúdo apresenta voz cantada, e avaliação da qualidade do sistema modelado.

Este capítulo contém a descrição dos fundamentos teóricos para os experimentos em detecção de voz cantada. Apresentamos como é feita a transformação do sinal de áudio digital em representações de aspectos semânticos, a relevância e justificativa de cada um dos descritores usados, algoritmos de aprendizado de máquina essenciais para a modelagem dos sistemas de detecção de voz cantada, e também métodos de avaliação de qualidade de sistemas de classificação.

\subsection{Representações digitais de áudio}

\section{Representação temporal}

Um sinal sonoro é representado digitalmente amostrando-se periodicamente a pressão da onda sonora, isto é, a cada intervalo de tempo $T$ (em segundos) é armazenado o valor $x_{n}=x(t)$ da pressão da onda no instante $t=n T$. O intervalo de tempo $T$ é denominado período de amostragem, e usamos o inverso deste valor $f=1 / T$ para denotar a frequência (ou taxa) de amostragem do sinal, que é medida em Hertz. Agrupamos todas essas medições $x_{n}$ em um vetor $x$ chamado de sinal de áudio no domínio temporal. A Figura 2.1 apresenta um exemplo de um sinal sonoro digitalizado.

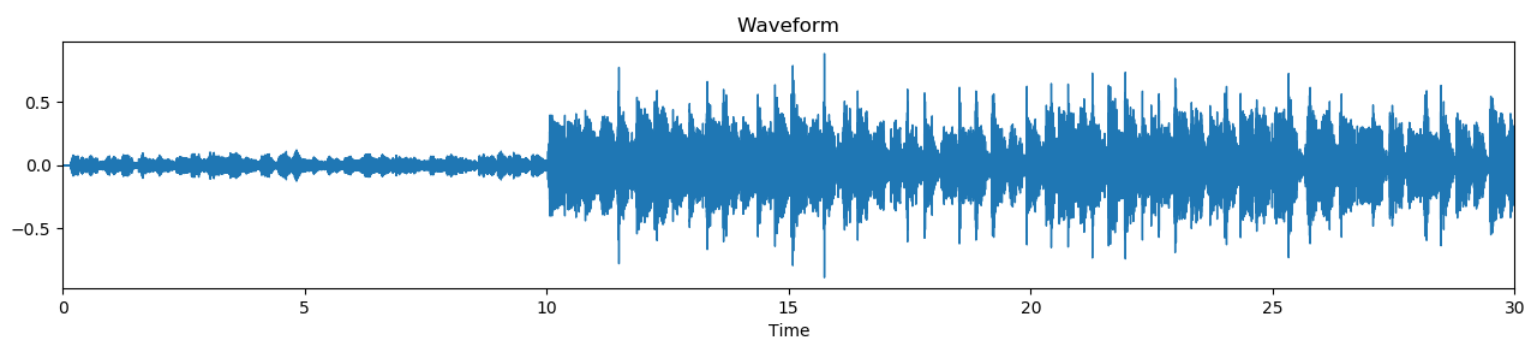

Figura 2.1: Sinal de áudio no domínio do tempo da peça Die For Us, Celestial Shore (30 segundos)

\section{RMS - Root Mean Square}

A energia de um sinal indica a magnitude de um sinal, isto é, quão intenso é esse sinal. O sinal de energia é definido como

$$
\text { Energy }=\sum_{n}|x(n)|^{2}
$$


Root Mean Square (RMS) é uma medida que descreve o valor médio de amplitude ${ }^{1}$ de um sinal:

$$
\operatorname{RMS}=\sqrt{\frac{1}{N} \sum_{n}|x(n)|^{2}} .
$$

O cálculo do RMS leva em consideração os valores do sinal de áudio ao longo de uma janela de tamanho $N$. Quanto maior o $N$, mais suavizada será a curva de RMS sobre o sinal de áudio. A Figura 2.2 apresenta um exemplo de um sinal de áudio com seus respectivos valores de energia e RMS, onde se pode notar que o sinal RMS acompanha razoavelmente bem os picos de amplitude do sinal de áudio.

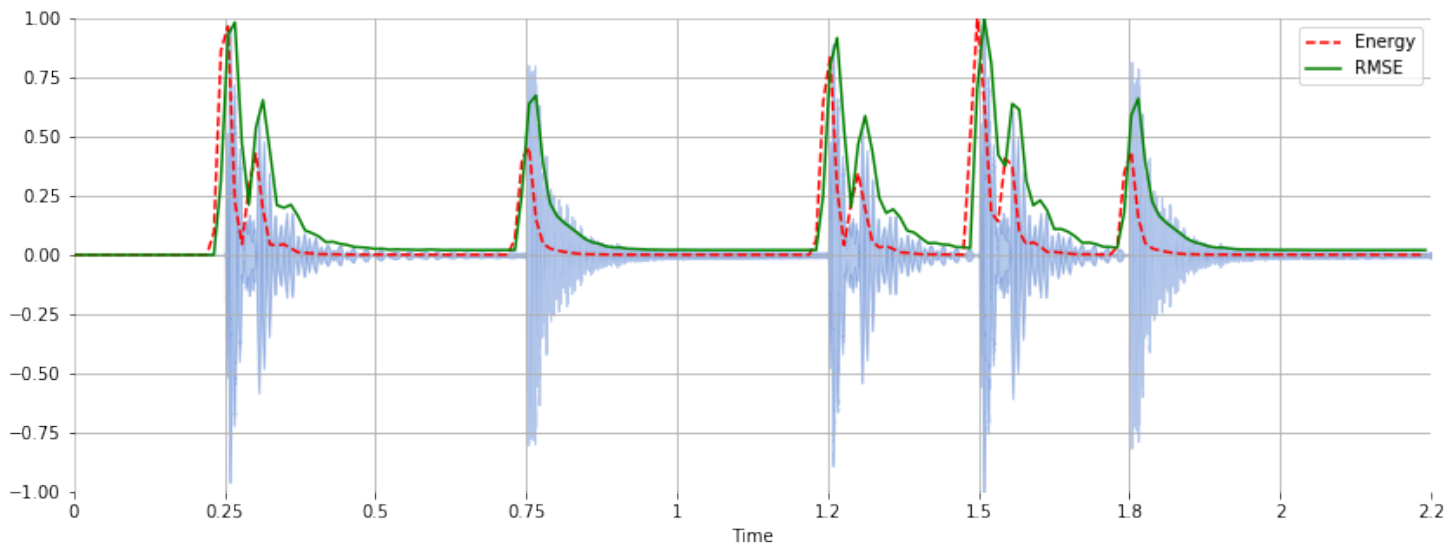

Figura 2.2: Exemplo de sinal de áudio com seus valores de energia e RMS

Observe que quanto mais próximo de zero o RMS, menor também a energia do sinal, isto é, menor seu conteúdo sonoro. Quando o valor de RMS é 0, o sinal de áudio contém apenas silêncio.

\section{Representação espectral}

Os sinais sonoros podem ser decompostos em diversas componentes mais simples; frequentemente se usa o modelo de componentes senoidais/cossenoidais, ou equivalentemente o modelo de funções exponenciais complexas, caracterizado por coeficientes obtidos pela transformada de Fourier:

$$
X_{k}=\sum_{n=0}^{N-1} x_{n} e^{-i 2 \pi k n / N},
$$

onde $\mathrm{N}$ é a resolução de amostragem e k define a frequência central do bin. Cada coeficiente complexo $X_{k}$ representa simultaneamente a amplitude e a fase inicial de uma onda senoidal pura, descrita como uma exponencial complexa que compõe o sinal $x$. O vetor $X$ formado pelos coeficientes $X_{k}$ obtidos pela transformada de Fourier é denominado espectro do sinal.

Para representar mais fielmente as variações temporais do conteúdo de um sinal de áudio, fazemos o cálculo do espectro em pequenos trechos do sinal, chamados de janelas ou quadros. O resultado disso é uma matriz de espectros denominada espectrograma, como ilustrado na Figura 2.3, uma transformada de Fourier discreta ou Short-time Fourier Transform (STFT).

Cada pixel desta imagem se refere a uma onda senoidal pura, ou bin do espectrograma. O eixo horizontal determina o instante no tempo, o eixo vertical determina o valor da altura em Hertz (a frequência central do bin) e a cor do pixel indica a magnitude do espectro em cada bin.

\footnotetext{
${ }^{1}$ Vale notar que a biblioteca librosa, usada aqui, denomina esse descritor como Root Mean Square Energy (RMSE), o que é problemático tanto por não se tratar de uma medida de energia e sim de amplitude, como por produzir uma confusão com o acrônimo RMSE também utilizado como Root Mean Square Error.
} 


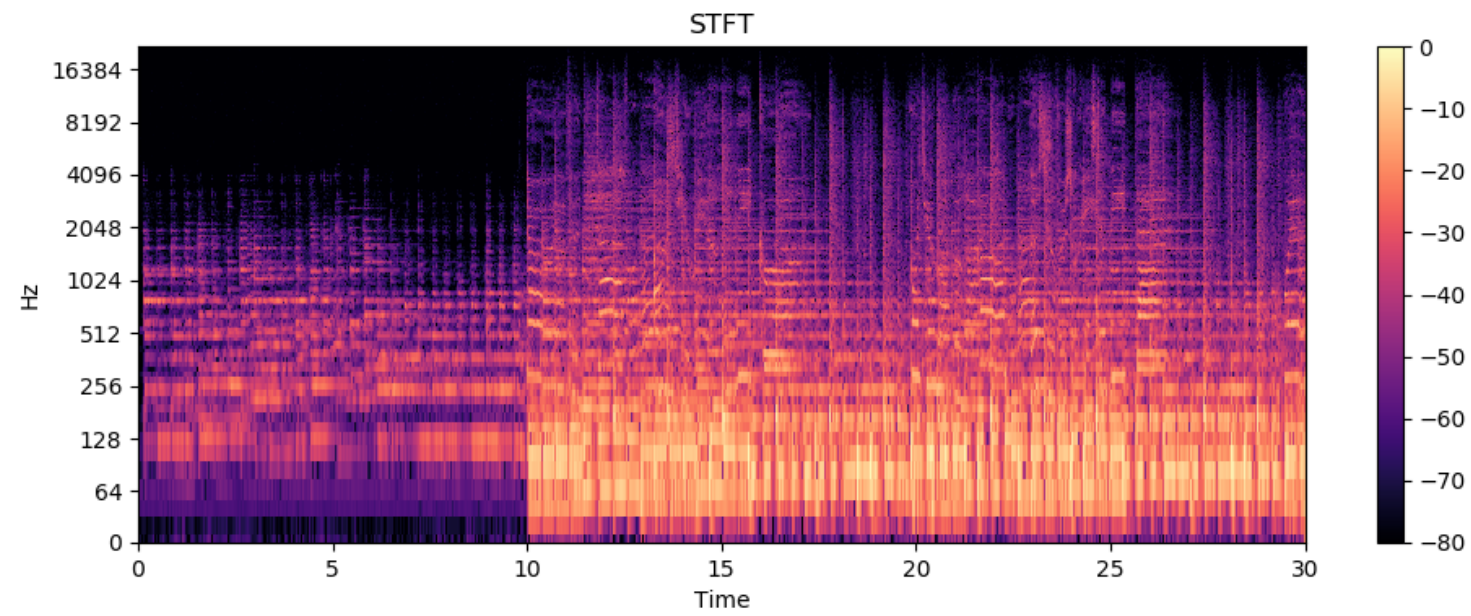

Figura 2.3: Sinal de áudio no dominio espectral da peça Die For Us, Celestial Shore (30 segundos)

O uso de janelas para o cálculo do espectrograma cria restrições na representação do sinal (ver, por exemplo, a referência Muller et al. [2011]). Quanto maior o intervalo de tempo coberto pela janela, melhor será a resolução no domínio das frequências, porém a resolução temporal é diminuída. Quanto menor o tamanho da janela, maior a resolução no tempo, tornando mais claro o momento do sinal onde cada evento ocorre, porém a representação no domínio das frequências é menos precisa.

\subsection{Descritores de áudio}

Descritores de áudio, segundo Peeters et al. [2011], são parâmetros acústicos extraídos do sinal que têm potencial de serem correlatos físicos das diferentes dimensões do conteúdo sonoro. Existem descritores temporais, espectrais, rítmicos. Os descritores podem ser locais (referentes a um trecho específico do sinal, e.g. um acorde em certo ponto da música) ou globais (representam características que se encontram por todo o sinal de áudio, e.g. a tonalidade da peça).

Os descritores podem ser obtidos por manipulações matemáticas/estatísticas dos sinais, ou podem ser baseados em modelos psicoacústicos específicos, a fim de destacar um certo elemento perceptual (timbre, frequência, ritmo) do conteúdo sonoro.

Os principais descritores usados em detecção de voz cantada são apresentados a seguir.

\subsubsection{MFCC}

Mel Frequency Cepstrum Coefficients (MFCC) [Logan et al., 2000] são os coeficientes do Cepstrum, uma representação do sinal que envolve a análise de seu espectro, e que são ajustados na escala perceptual de alturas denominada Mel.

Os MFCCs se tornaram dominantes na pesquisa em reconhecimento de fala. O sucesso deste descritor se deu devido à sua capacidade de representar o espectro de amplitude da fala de uma forma compacta. Cada passo para geração dos coeficientes MFCC é motivado por considerações perceptuais ou computacionais.

O processo para calcular os coeficientes MFCC está representado na Figura 2.4.

- Converte para frames: o sinal de áudio é analisado em pequenos trechos, que chamamos de janelas (frames)

- DFT: calcula-se a Discrete Fourier Transform (Transformada de Fourier Discreta)

- Log do espectro de amplitude: aplica-se a função logarítmo sobre os valores de amplitude do sinal resultantes da DFT 


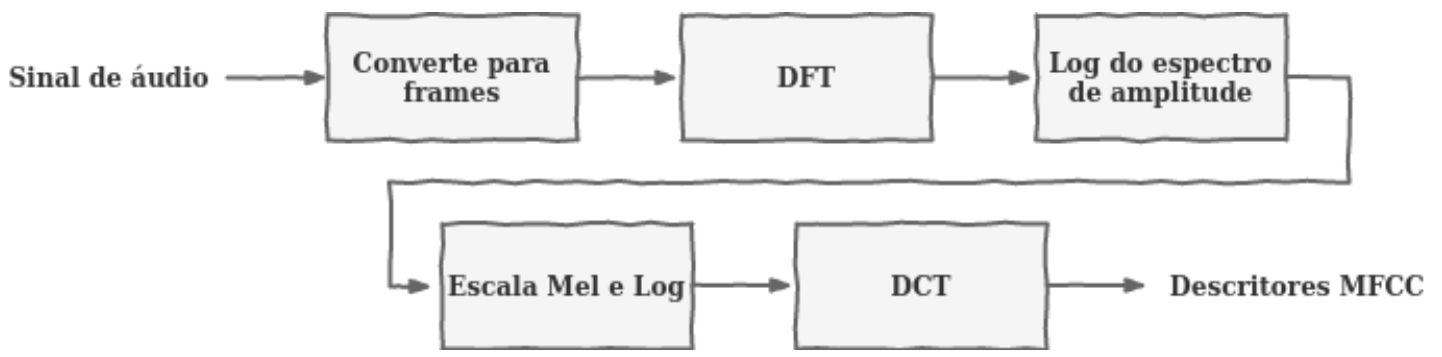

Figura 2.4: Cálculo dos Mel-Frequency Cepstrum Coeficients

- Escala Mel e Log: aplicar a escala Mel faz com o que os resultados sejam perceptualmente comparáveis, e outra vez aplicar a função logarítmo

- DCT: Discrete Cossine Transform (Transformada do Cosseno Discreta)

A Figura 2.5 apresenta os 30 primeiros coeficientes do Mel Frequency Cepstrum calculado para um trecho de sinal de áudio musical.

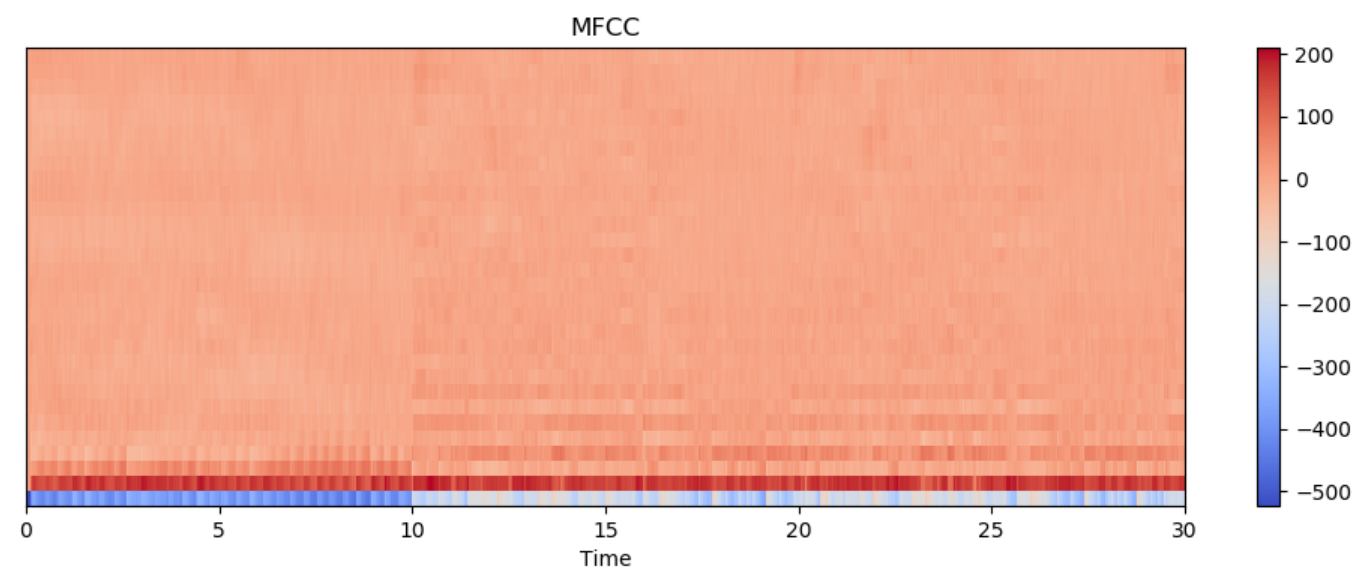

Figura 2.5: Primeiros 30 MFCC da peça Die For Us, Celestial Shore (30 segundos)

\subsubsection{Vocal Variance}

Vocal Variance (VV) é um descritor derivado dos coeficientes MFCC. Este descritor foi proposto por Lehner et al. [2014], com o objetivo de reduzir falsos positivos na deteç̧ão de voz cantada.

Para calcular o Vocal Variance, usa-se uma janela móvel de 11 frames sobre o MFCC com 30 coeficientes, tomando-se as medianas dos coeficientes de índices 1 a 5 (excluindo o índice 0). Dessa forma, a variância destes coeficientes são tomadas como descritores do áudio. Os autores argumentam que o último passo do cálculo dos coeficientes MFCC (DCT) faz com que os primeiros coeficientes representem as variações lentas no espectro do sinal, que por sua vez se relacionam com as mudanças morfológicas do trato vocal. Por isso, segundo os autores, o uso dos 5 primeiros coeficientes do MFCC para gerar este novo descritor aumenta a chance de diferenciar trechos cantados de trechos que contêm apenas acompanhamento instrumental.

\subsubsection{Fluctogram e indicadores de confiabilidade}

O fluctogram é também um descritor proposto por Lehner et al. [2014] como uma extensão de um outro descritor criado por Sonnleitner et al. [2012] para deteç̧ão de fala em sinais de áudio mixados. Ele se propõe a destacar os elementos de vibrato em diferentes faixas do espectrograma, dividindo o espectro em escala logarítmica em 17 faixas, e para cada faixa, detectando as flutuações menores que um tom usando correlação cruzada. 
Segundo o autor, o uso deste descritor permite a identificação de vibrato em diferentes bandas e com isso permite a identificação de padrões pertencentes à voz cantada em meio a outras fontes sonoras que não possuem o mesmo comportamento. No entanto, o vibrato é comum em diversas fontes musicais, e por este motivo a simples presença do vibrato não é suficiente para afirmar que um trecho de áudio possui voz. Desta forma, é necessário identificar as condições mais prováveis nas quais os padrões de vibrato encontrados provêm de voz cantada. Para isso, foram propostos também dois indicadores de confiabilidade: spectral flatness (inspirado na spectral dispersion) e spectral contraction, descritos abaixo.

A principal referência sobre cálculo e uso dos descritores Fluctogram, Spectral Contraction e Spectral Flatness está em Lehner et al. [2018]. Neste novo artigo, os autores utilizam os indicadores de confiabilidade como filtros para o Fluctogram.

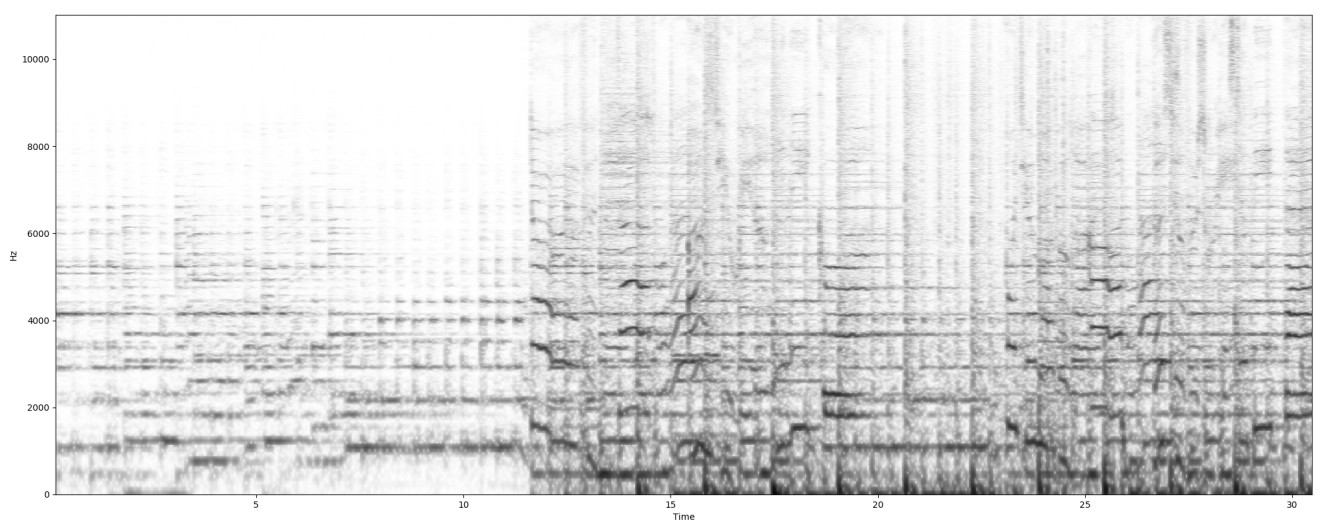

(a) Espectrograma

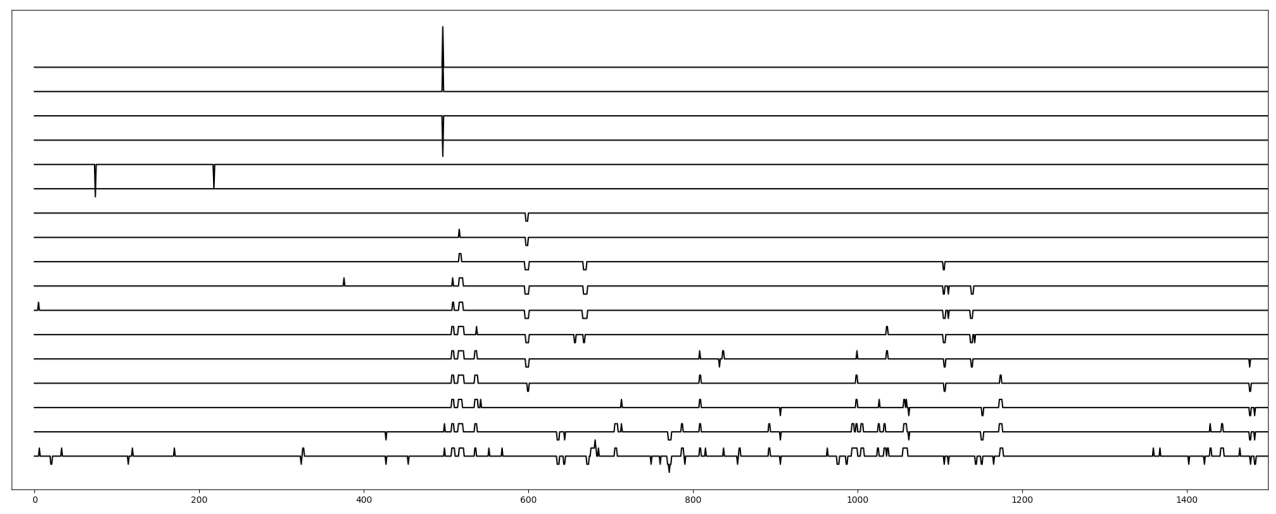

(b) Fluctogram

Figura 2.6: Fluctogram calculado a partir do espectrograma do trecho inicial da peça Die For Us, Celestial Shore, apresentando as 17 faixas de análise

\section{Spectral Flatness}

Spectral Flatness é um indicador de similaridade do sinal com o ruído branco (um sinal aleatório com a mesma intensidade em todas as faixas de frequência). Ele é calculado da seguinte forma:

$$
\operatorname{sf}[n]=\frac{\sqrt[N]{\prod_{j=0}^{N-1}\left|X_{n}[j]\right|}}{\frac{1}{N} \sum_{j=0}^{N-1}\left|X_{n}[j]\right|},
$$


onde $n$ é o índice do frame, $\mathrm{N}$ é o número de bins do espectro, $X_{n}$ é o espectro, $j$ é o índice de um bin, e pode assumir valores entre [0, 1]. Obter os valores de Spectral Flatness para cada valor de Fluctogram traz a informação de quanto aquele trecho é ruidoso com relação ao sinal como um todo. Quanto maior a presença de ruído, mais baixa é a probabilidade de haver conteúdo vocal neste trecho, pois a voz cantada possui frequências mais definidas e destacáveis em meio a outras fontes.

\section{Spectral Contraction}

Spectral Contraction indica quanto da energia reside no centro do espectro de energia $\left|X_{n}\right|^{2}$. Este indicador é calculado da seguinte forma:

$$
\operatorname{sc}[n]=\frac{\sqrt[N]{\sum_{j=0}^{N-1}\left|X_{n}[j]\right|^{2} w[j]}}{\frac{1}{N} \sum_{j=0}^{N-1}\left|X_{n}[j]\right|^{2}},
$$

onde $n$ é o índice do frame, $\mathrm{N}$ é o número de bins do espectro, $X_{n}$ é o espectro, $j$ é o índice de um bin, e $w$ é uma janela de ponderação (o autor utiliza uma janela de Chebyshev) e também pode assumir valores entre $[0,1]$. Como a voz cantada normalmente cria picos de energia no sinal, quanto menor o valor de Spectral Contraction, menor a probabilidade de haver voz naquele trecho.

O primeiro uso destes indicadores no artigo Lehner et al. [2014] adicionava os valores correspondentes de todos os frames de áudio no treinamento. Por sua vez, no segundo uso [Lehner et al., 2018] os autores utilizam os valores dos indicadores de confiabilidade correspondentes para filtrar os valores do Fluctogram.

\subsection{Algoritmos de aprendizado de máquina}

Técnicas de Aprendizado de Máquina empregam inferência por indução: a partir de um conjunto de treinamento, os algoritmos extraem informações úteis para a caracterização de novos dados.

\subsubsection{Support Vector Machines - SVM}

O SVM (Support Vector Machines, ou Máquinas de Vetores de Suporte [Lorena e de Carvalho, 2007]) é um método de separação de dados que utiliza hiperplanos e margens para classificar dados em duas classes linearmente separáveis. Existem SVM com margens rígidas e suaves. O SVM com margens rígidas define um hiperplano e classifica os dados de cada lado do hiperplano em uma única classe.

Como os dados reais podem não ser completamente linearmente separáveis (pode haver ruído ou outliers), o SVM pode ser modelado com margens suaves, que permite que os dados sejam classificados de um modo diferente entre dois hiperplanos marginais em relação a um hiperplano central.

Para dados que não são linearmente separáveis por natureza, é possível utilizar o SVM não linear, que transfere os dados do espaço original para um novo espaço de dimensão maior (também chamado de "feature space"). Encontrando uma transformação apropriada do espaço, os dados podem ser separados por uma SVM linear. Segundo o teorema de Cover [1965], é possível encontrar esta transformação mesmo que o espaço original não seja linear e as dimensões sejam suficientemente altas. A Figura 2.7 representa visualmente esta transformação

Para calcular as transformações, utiliza-se funções denominadas "Kernels". Os Kernels devem satisfazer as condições estabelecidas pelo teorema de Mercer $^{2}$. Kernels comumente utilizados são os Polinomiais, os Gaussianos ou RBF (Radial-Based-Function) e os Sigmoidais.

Existem vantagens em utilizar SVM pois este algoritmo funciona em grandes dimensões, está associado a um problema de otimização convexo (possui apenas um mínimo global), e as funções

\footnotetext{
${ }^{2}$ Para ver o conteúdo do Teorema de Mercer, visite https://www.encyclopediaofmath.org/index.php/Mercer theorem
} 


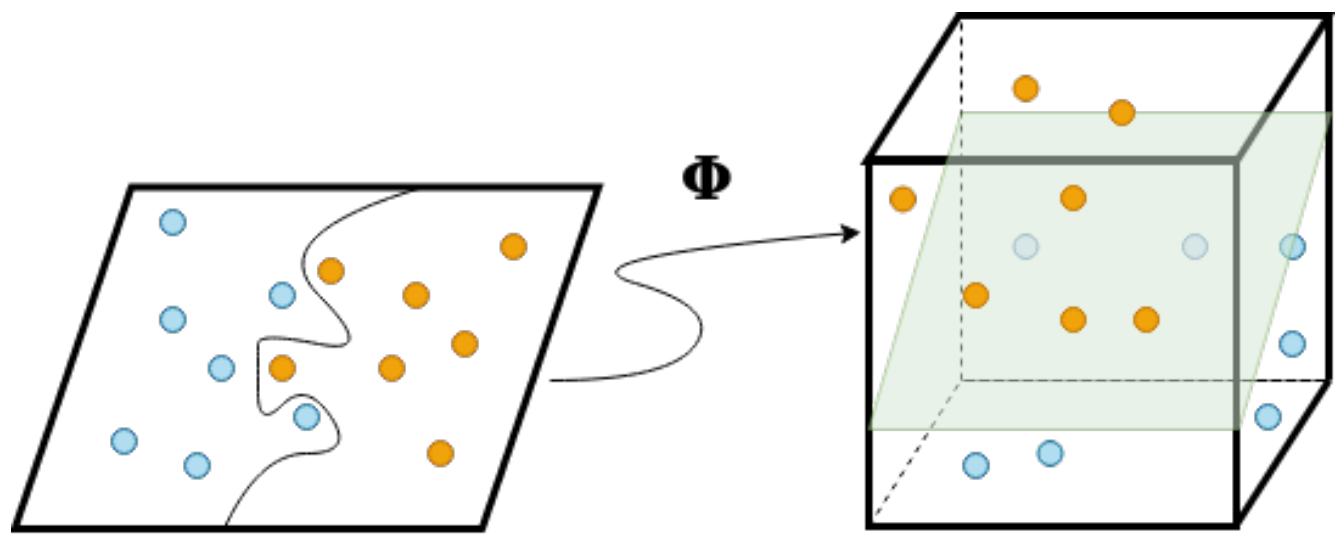

Figura 2.7: Transformação de espaço gerada pelo SVM

Kernel tornam o algoritmo eficiente, permitindo a construção de hiperparâmetros em espaços de alta-dimensão.

Em contrapartida, os modelos SVM são muito sensíveis aos parâmetros escolhidos e a interpretação dos modelos gerados é limitada.

\subsubsection{Random Forests - RF}

Uma Random Forest [Breiman, 2001], ou Floresta Aleatória, é um classificador composto de várias árvores de decisão. Cada árvore atribui um voto unitário para a classe que melhor representa o vetor de entrada.

As florestas aleatórias permitem medir a importância de cada feature para o modelo. Com isso, é possível reduzir o número de features utilizadas no treinamento e avaliação.

A Figura 2.8 a seguir representa um trecho de uma árvore de decisão que pertence a uma floresta aleatória.

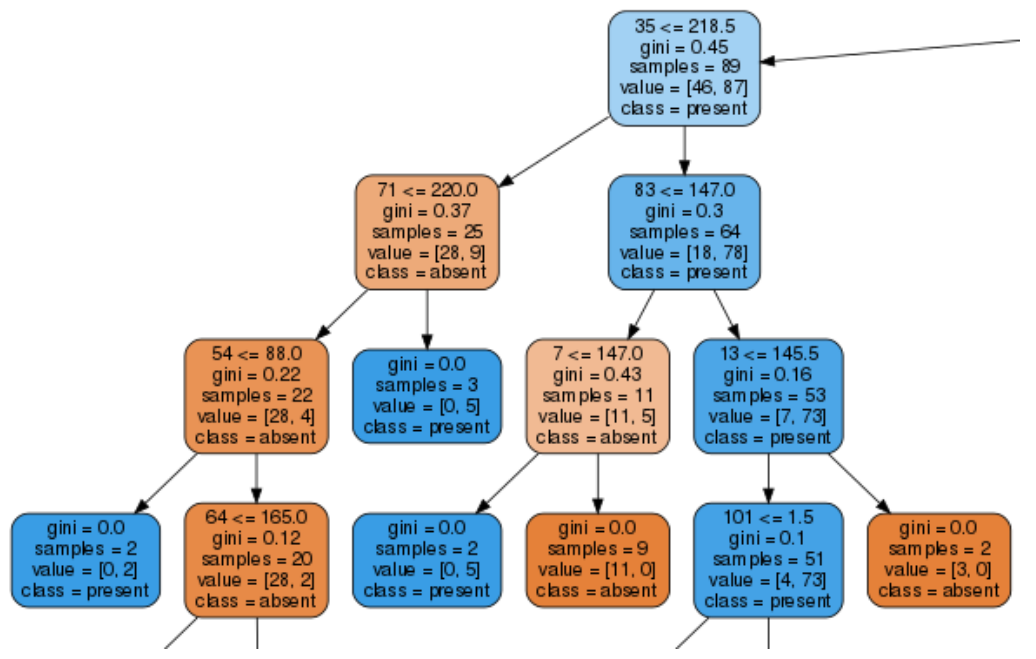

Figura 2.8: Trecho da árvore de decisão treinada com VGGish embeddings

Todos os nós, exceto as folhas, contêm 5 informações:

- feature question : Para cada questão, existem duas respostas possíveis (verdadeiro e falso) que levam aos nós filhos seguintes (esquerda e direita, respectivamente);

- gini : medida de impureza do nó, isto é, a probabilidade de que uma amostra aleatoriamente escolhida esteja incorretamente rotulada;

- samples : quantidade de exemplos únicos que passaram por este nó durante o treinamento; 
- value $e^{3}$ o número de amostras em cada classe (neste caso, as classes são "presente" e "ausente");

- class : classe atribuída à amostra

Normalmente as folhas das árvores de decisão possuem gini=0.0, o que pode indicar overfitting. Para evitar este fenômeno, as Random Forest treinam cada estimador com uma amostra aleatória do conjunto de treinamento, realizando uma operação chamada bagging. No momento do teste, o resultado da classificação é a média dos resultados de todos os estimadores treinados.

Outra característica importante do método de Random Forest é a subamostragem aleatória de features na divisão de cada nó. Isto é, ao selecionar a próxima feature mais relevante para a divisão do nó, o método seleciona aleatoriamente num conjunto pré-determinado das features qual delas será usada como referência.

\subsection{Representações aprendidas automaticamente}

O uso de redes neurais profundas para extrair informações relevantes (porém ainda não reconhecíveis ou interpretáveis) de um sinal tornou comum a produção de novas representações de áudio baseadas em aprendizado automático. O surgimento de descritores de áudio aprendidos automaticamente nos permite avaliar a qualidade das técnicas de detecção e classificação que fazem uso desta abordagem.

Por exemplo, pesquisadores da Google desenvolveram o Audio Set [Gemmeke et al., 2017], que é um conjunto de dados de áudio construído com o objetivo de anotar automaticamente 632 tipos de eventos de áudio diferentes. O propósito desta rotulação é permitir a busca por análise de conteúdo, especialmente conteúdo sonoro.

A proposta dos autores do Audio Set é criar um conjunto de dados para treinar um reconhecedor genérico de eventos de áudio que tenha a capacidade de reproduzir a maneira como humanos reconhecem e relacionam eventos sonoros. Para tanto, realizaram uma curadoria utilizando humanos como rotuladores de referência para os eventos de áudio. Durante a rotulação, os eventos foram estruturados em categorias hierárquicas chamadas de Audio Set Ontology.

A relevância do Audio Set neste trabalho se deve especialmente às categorias "Human sounds" e "Music". Dado que o reconhecedor genérico construído a partir do Audio Set tem capacidade de diferenciar estas classes de eventos sonoros, podemos utilizar o resultado do seu processamento como um descritor de áudio para deteç̧ão de voz cantada.

\section{Rede VGGish}

O reconhecedor genérico treinado é chamado de rede VGGish. Este nome faz referências às redes profundas criadas pelo Visual Geometry Group ${ }^{4}$, por ter estrutura parecida com as das famosas redes genéricas reconhecedoras de imagem (VGGnet). A Figura 2.9 apresenta a estrutura da rede VGGish.

Os vetores de saída da rede VGGish, ou simplesmente VGGish embeddings, podem ser usados como descritores de áudio em outras estruturas de aprendizado de máquinas. Os desenvolvedores do Audio Set disponibilizaram uma versão do modelo usado para treinar os VGGish embeddings disponíveis na primeira versão de lançamento do conjunto de dados ${ }^{5}$. Assim, para cada trecho de áudio de 960 milissegundos, obtemos um vetor de 128 valores (podendo ou não ser pós-processados para serem comparáveis aos resultados disponíveis no Audio Set). A Figura 2.10 representa visualmente o VGGish de uma música.

Trata-se de um descritor de áudio proposto recentemente e, segundo nosso conhecimento, está sendo usado pela primeira vez na tarefa de detecção de voz cantada (Moura [2018]). A principal

\footnotetext{
${ }^{3}$ Esta árvore foi gerada com bootstrap, o que permite que a mesma amostra apareça mais de uma vez no treinamento de uma árvore

${ }^{4}$ Mais sobre Visual Geometry Group, veja: http://www.robots.ox.ac.uk/ vgg/

${ }^{5}$ Mais sobre VGGish, veja: https://github.com/tensorflow/models/tree/master/research/audioset/vggish
} 


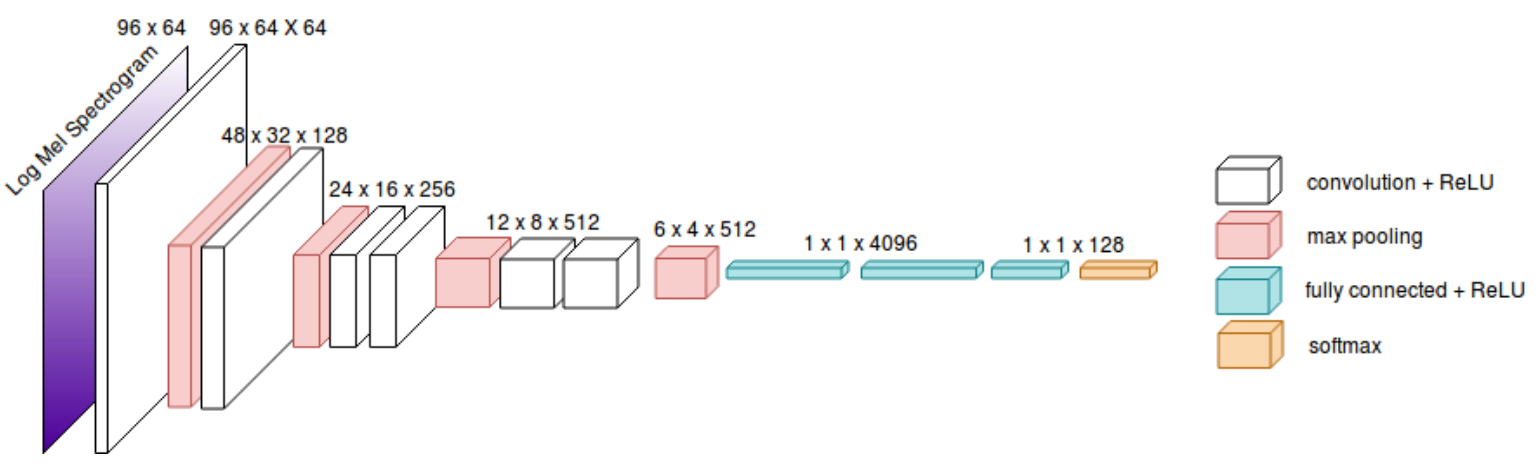

Figura 2.9: Estrutura da rede neural profunda VGGish

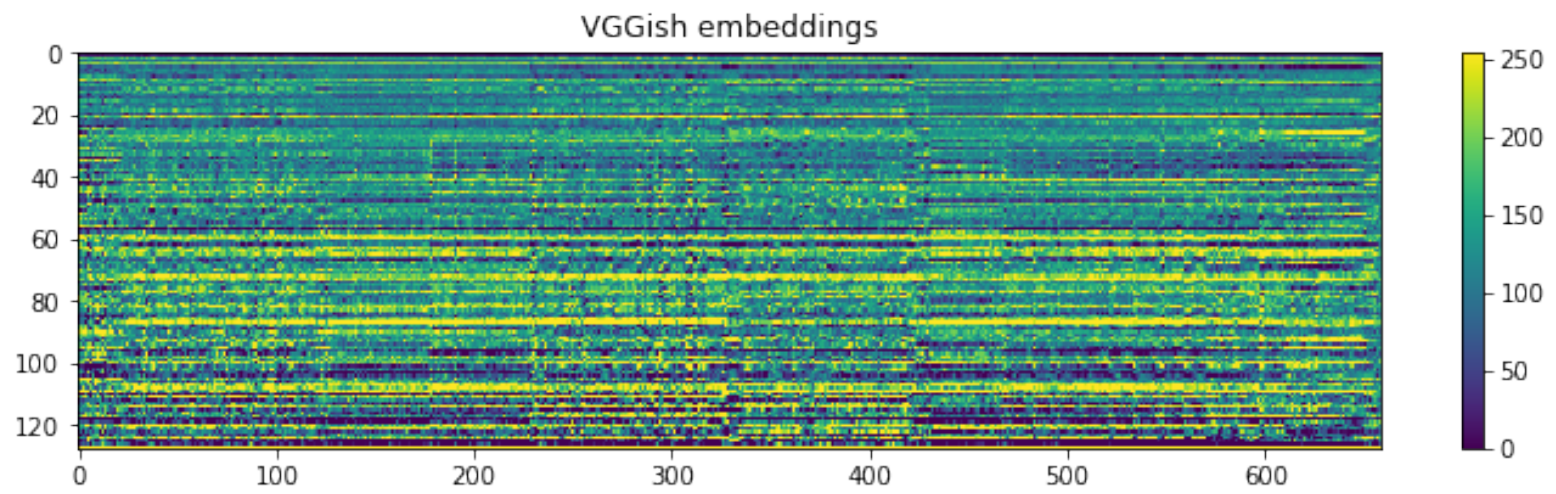

Figura 2.10: Representação visual do descritor VGGish embedding da peça Die For Us, Celestial Shore

justificativa do uso deste descritor é a capacidade de obter um warm start, isto é, alguma informação a priori para a tarefa de deteç̧ão de voz, uma vez que a rede da qual os descritores foram extraídos recebeu exemplos de sons humanos, fala, e música. De forma mais sucinta, a possibilidade da transferência de conhecimento amplia as oportunidades de melhoria na deteç̧ão de voz cantada.

\subsection{Métodos de separação de fontes}

A tarefa de separação de fontes tem sido estudada por mais de 50 anos, segundo Stöter et al. [2019]. O interesse em separar uma peça musical em seus elementos constitutivos é não só criativo, mas também comercial. Atualmente, a tecnologia de aprendizado baseado em dados e a maior disponibilidade de faixas de áudio musicais com fontes separadas permitiram a construção de sistemas capazes de realizar a separação de fontes de modos muito eficientes.

\section{Open-Unmix}

Open-Unmix [Stöter et al., 2019], por exemplo, é um software aberto que utiliza machine learning para realizar a tarefa de separação de fontes. Os objetivos dos autores na criação do software eram criar um sistema que tivesse boa performance, de fácil compreensão e que servisse de base aos pesquisadores futuros. Assim, novas representações e arquiteturas poderiam surgir deste software.

Open-Unmix é baseado em um modelo bidirecional LSTM e foi comparado com resultados da última competição SiSEC. Segundo os autores, o método possuia resultados equiparáveis ao estadoda-arte quando lançado, porém com a vantagem de ser software aberto.

\section{Spleeter}

A ferramenta Spleeter [Hennequin et al., 2019] contém modelos separadores de fontes desenvolvido por pesquisadores da empresa Deezer, com a intenção de obter boa performance de separação 
e velocidade de processamento computacional. Os modelos pré-treinados disponíveis podem separar arquivos de áudio em várias faixas de áudio. Também é possível treinar modelos de separação de fontes e aumentar a precisão de modelos pré-treinados com o TensorFlow ${ }^{6}$. A ferramenta Spleeter contém modelos para separação em:

- 2 faixas: vocais, acompanhamento;

- 4 faixas: vocais, baixo, percussão, e outros;

- 5 faixas: vocais, baixo, percussão, piano e outros.

Os modelos separadores de fontes são redes neurais convolucionais U-net, com 12 camadas (6 para encoder e 6 para decoder). Uma U-net é usada para estimar máscaras soft para cada fonte que se deseja separar. As redes foram treinadas com conjuntos de dados proprietários da empresa Deezer. O treinamento levou uma semana inteira usando apenas uma GPU (Graphics Processing Unit).

Com relação à performance, os modelos contidos em Spleeter são considerados como tendo resultados comparativamente superiores em separação de voz em relação ao único sistema disponível abertamente além deste, o Open-Unmix, segundo [Hennequin et al., 2019].

\subsection{Métodos de avaliação em MIR}

Uma vez construído um sistema de detecção de voz cantada, é importante avaliar quantitativamente seu desempenho. Nesta seção, apresentamos os métodos de avaliação comuns em tarefas de recuperação de informação musical que são aplicados à tarefa de deteç̧ão de voz cantada, pois os detectores normalmente são sistemas de respostas binários (classificação binária).

\section{Matriz de confusão}

Quando o sistema realiza a classificação, as possíveis respostas são: cantado e não cantado. Trataremos o cantado como $\mathbf{1}$ e o não cantado como $\mathbf{0}$ (presença e ausência de voz cantada). Para avaliar o sistema, necessitamos do ground truth, isto é, dos rótulos de cada segmento para verificar se o programa acertou a classificação. A visualização dos resultados da classificação é feita através da matriz de confusão, como ilustrado na Figura 2.11. Esta matriz relaciona os rótulos verdadeiros e os rótulos preditos pelo classificador, contabilizando esses últimos como positivos verdadeiros (TP - as siglas estão em inglês), positivos falsos (FP), negativos verdadeiros (TN) e negativos falsos $(\mathrm{FN})$.

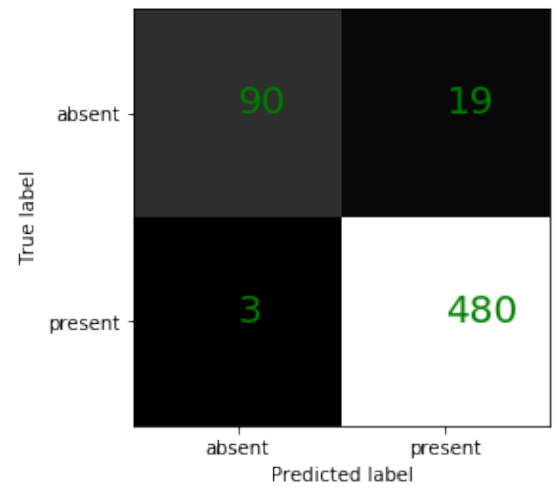

Figura 2.11: Exemplo de matriz de confusão: $T N=90, F P=19, F N=3$ e $T P=480$

\footnotetext{
${ }^{6}$ Mais sobre TensorFlow em: https://www.tensorflow.org/
} 


\section{Precision e Recall}

A imagem 2.12 apresenta duas métricas amplamente utilizadas em recuperação de informação, relacionadas às respostas de classificação. Os valores de Precision e Recall variam entre 0 e 1, sendo o Precision igual à quantidade de elementos da classe objetivo (verdadeiros positivos) corretamente classificados dentre elementos selecionados (verdadeiros + falsos positivos)

$$
P=\frac{T P}{T P+F P},
$$

e o Recall igual à quantidade de elementos da classe objetivo (verdadeiros positivos) que foram classificados corretamente dentre todos os elementos relevantes (verdadeiros positivos + falsos negativos)

$$
R=\frac{T P}{T P+F N} .
$$

Precision e Recall só são ambos iguais a 1 no caso de classificações perfeitas, sendo o Precision negativamente afetado pela presença de falsos positivos e o Recall negativamente afetado pela presença de falsos negativos.

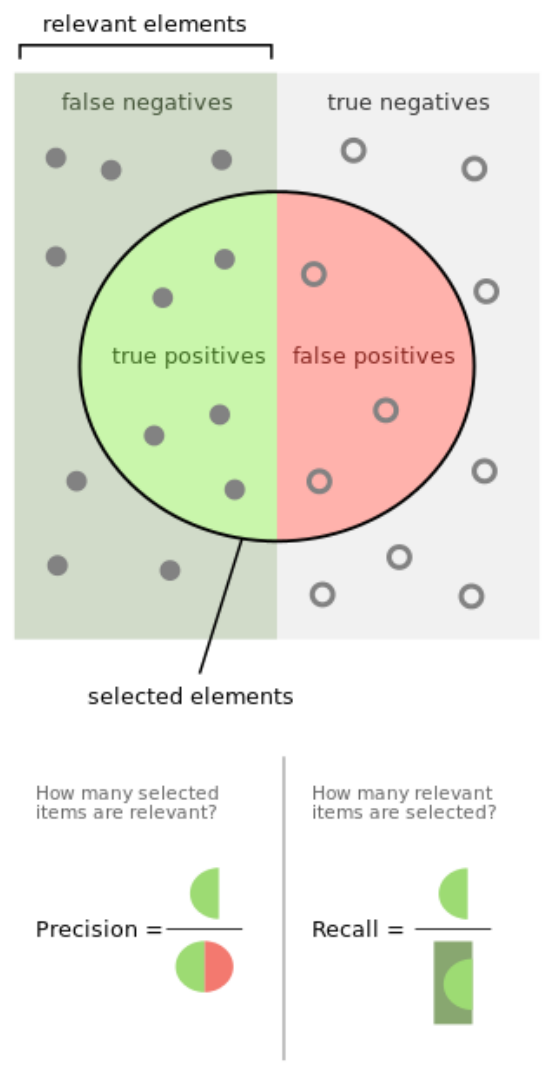

Figura 2.12: Métricas de Precision e Recall. Elementos relevantes são os elementos da classe objetivo. Elementos selecionados são os elementos classificados como pertencentes à classe objetivo. Imagem extraída de: https://en.wikipedia.org/wiki/File:Precisionrecall.svg

\section{Accuracy e F-measure}

A accuracy expressa a taxa de acerto do classificador, ou seja, a proporção de elementos corretamente classificados relativamente a todas as classes:

$$
\mathrm{Acc}=\frac{\mathrm{TP}+\mathrm{TN}}{\mathrm{TP}+\mathrm{TN}+\mathrm{FP}+\mathrm{FN}} ;
$$


essa medida não faz distinção entre erros do tipo falso positivo e falso negativo, que afetam diretamente as expressões de Precision e Recall.

A F-measure, por outro lado, busca combinar por meio da média harmônica os valores de Precision e Recall:

$$
\mathrm{F} 1=2 \cdot \frac{\mathrm{P} \cdot \mathrm{R}}{\mathrm{P}+\mathrm{R}}
$$

a média harmônica tende a se aproximar da menor dentre as medidas, o que faz com que a F-measure seja mais afetada pela pior performance relativamente aos falsos negativos e falsos positivos.

\section{Sensitivity e Specificity}

A sensitivity, outro nome para Recall ou taxa de verdadeiros positivos (true positive rate - TPR), indica a proporção de elementos classificados como positivos dentre todos os positivos:

$$
\mathrm{TPR}=\frac{\mathrm{TP}}{\mathrm{TP}+\mathrm{FN}} .
$$

Por outro lado, a specificity, ou taxa de verdadeiros negativos (true negative rate - TNR), indica a proporção de elementos classificados como negativos dentre todos os elementos negativos:

$$
\mathrm{TNR}=\frac{\mathrm{TN}}{\mathrm{TN}+\mathrm{FP}} .
$$

Valores altos em ambas as métricas indicam que o modelo está bem ajustado com a realidade.

O índice de Youden avalia a qualidade de evitar, com igual probabilidade, os dois tipos de erros de classificação. Para calcularmos os thresholds ótimos de uma classificação binária, utilizamos a maximização desse índice, definido como:

$$
J_{\max }=\max _{t}\{\operatorname{sensitivity}(t)+\operatorname{specificity}(t)-1\},
$$

onde $t$ é o threshold de classificação para o qual $J$ é máximo. 


\section{Capítulo 3}

\section{Detecção de voz cantada usando descritores de áudio}

Desejamos explorar técnicas de deteç̧ão de voz cantada em sinais de áudio polifônico. Para tanto, avaliamos a qualidade de discriminação (classificação correta de trechos contendo voz ou não) de detectores de voz cantada, explorando alguns fatores que causam confusão, i.e. outras fontes sonoras que atrapalham a identificação da voz (falso negativo) ou que são identificadas como voz (falso positivo), e discutimos estratégias para diminuir a confusão. Tendo isto em mente, realizamos uma série de experimentos com algoritmos de aprendizado de máquina para gerar modelos ajustados à deteç̧ão de voz, a partir de conjuntos de dados rotulados e descritores de áudio que destacam o conteúdo vocal. Em resumo, os objetivos deste capítulo são:

- Apresentar experimentos preliminares em deteç̧ão de voz cantada;

- Avaliar a qualidade dos resultados obtidos por meio de reprodução de abordagens do estado da arte;

- Avaliar um descritor de áudio gerado a partir de aprendizado profundo.

\subsection{Metodologia}

A tarefa de deteç̧ão de voz cantada proposta pode ser vista como a classificação binária de trechos de áudio musicais, onde os rótulos são: 1 para trechos que contêm voz cantada, e 0 para trechos que não contêm voz cantada.

Para realizar os experimentos, foram selecionados conjuntos de dados que contêm peças musicais polifônicas com voz cantada e as respectivas anotações indicando os trechos onde há presença de voz. Temos interesse em observar os trechos de áudio polifônico que apresentam confusão (falsos positivos e falsos negativos) na classificação.

Realizamos o cálculo dos descritores de áudio das peças do conjunto de dados e treinamos modelos de aprendizado de máquina com diferentes parametrizações, avaliando estes modelos por meio de métricas específicas para classificação binária.

Os modelos rotulam os trechos de áudio de acordo com a presença ou não de voz cantada, e por essa razão nos referiremos a eles como rotuladores. Comparamos também os resultados de classificação dos rotuladores treinados utilizando descritores tradicionais com um rotulador que utiliza um descritor gerado por aprendizado profundo (embedding). 


\subsection{Conjunto de dados}

Para realizar o treinamento e avaliação dos detectores de voz cantada apresentados neste trabalho, utilizamos o dataset MedleyDB [Bittner et al., 2014], que inclui um conjunto de dados de gravações multi-faixas (multitracks) livres de direito autoral e uma API $^{1}$. Este conjunto de dados possui as seguintes características:

- Tamanho: 122 multi-faixas (mixagem final + faixas processadas + áudio puro + meta-dados);

- Anotações: frequência fundamental da melodia principal (para 108 faixas), ativação dos instrumentos e gênero musical (para 122 faixas);

- Formato de áudio: WAV (44.1 kHz, 16 bits);

- Gêneros musicais: Singer/Songwriter, Classical, Rock, World/Folk, Fusion, Jazz, Pop, Musical Theatre, Rap;

- Duração das músicas: 105 faixas inteiras (3 a 5 minutos de duração) e 17 excertos (com menos de 1 minuto), totalizando 7 horas e 17 minutos;

- Instrumentação: 52 faixas instrumentais e 70 faixas contendo voz humana, das quais 61 possuem conteúdo vocal cantado (fontes listadas como "vocals" na API do MedleyDB) e foram selecionadas para os experimentos.

A fim de obter uma caracterização estatística preliminar do conjunto de dados, fizemos um levantamento das durações dos trechos contíguos de áudio contendo ou não voz cantada. A Tabela 3.1 apresenta um resumo da distribuição destas durações e a Figura 3.1 apresenta as estatísticas em formato boxplot. As anotações de presença de voz foram feitas a partir de todas as fontes vocais presentes na peça, o que pode ocasionar intersecções entre fontes e trechos extremamente curtos sem voz cantada.

\begin{tabular}{c|c|c} 
& Não cantado & Cantado \\
\hline mean & 6.90 & 15.30 \\
std & 16.04 & 22.71 \\
min & 0.04 & 0.02 \\
$25 \%$ & 0.66 & 3.44 \\
$50 \%$ & 1.48 & 7.40 \\
$75 \%$ & 4.43 & 17.54 \\
$\max$ & 148.74 & 237.82
\end{tabular}

Tabela 3.1: Resumo da distribuição dos tamanhos de trechos, em segundos, no conjunto de dados utilizado

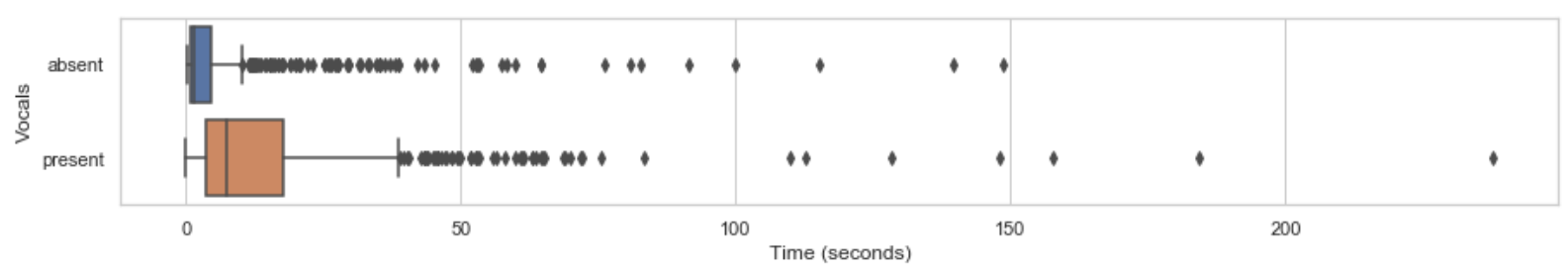

Figura 3.1: Boxplots apresentando a distribuição dos tamanhos, em segundos, dos trechos do conjunto de dados

\footnotetext{
${ }^{1}$ https://github.com/marl/medleydb
} 


\subsection{Experimentos preliminares}

Nestes experimentos preliminares, comparamos o uso de um descritor comumente usado em detecção de voz cantada, o MFCC (ver subseção 2.2.1), com o descritor VGGish embeddings (ver seção 2.4), que ainda não havia sido utilizado para esta tarefa pela comunidade de MIR.

\section{Desenho experimental}

O código para os experimentos foi desenvolvido em Python utilizando as bibliotecas librosa ${ }^{2}$ (para processamento de áudio e cálculo de alguns descritores) e scikit-learn ${ }^{3}$ [Pedregosa et al., 2011] (para treinar e utilizar os classificadores). Usamos a versão 3.6 da linguagem Python para a maioria dos códigos, com exceção do cálculo dos VGGish embeddings, que exigem Python 3.5. A visualização dos resultados foi realizada em Jupyter Notebooks ${ }^{4}$.

A metodologia para avaliar o descritor VGGish seguiu os seguintes passos:

- escolha de um conjunto de dados;

- separação dos conjuntos de treinamento, validação e teste;

- cálculo dos descritores de áudio;

- classificação com modelos estatísticos aprendidos;

- análise e discussão dos resultados.

Selecionamos todo o conjunto de faixas com conteúdo de voz cantada do MedleyDB. Este conjunto foi dividido em três partes (treino, validação e teste), de acordo com as seguintes proporções: $20 \%$ foram reservadas para teste, e as outras $80 \%$ foram separadas em $80 \%$ treino e $20 \%$ validação (ou $64 \%$ e $16 \%$ do conjunto original, respectivamente). Para evitar o aprendizado de características de artistas específicos, utilizamos a API do MedleyDB, realizando a separação condicionada por artista, isto é, o mesmo artista não pode estar presente simultaneamente no conjunto de treino e de teste.

Os descritores de áudio usados para treinar os classificadores tomaram como base segmentos de 0.96 segundos, de acordo com os parâmetros originais dos descritores VGGish embeddings, usando sobreposição de 0.48 segundos entre janelas sucessivas (ou seja, metade da duração da janela). Os descritores MFCC foram calculados com 40 bandas de frequências e 13 coeficientes em pequenas janelas de $10 \mathrm{~ms}$ e depois resumidos nos mesmos blocos de 0.96 segundos $(96 * 10 \mathrm{~ms}$ ) usados no VGGish. Para resumir os segmentos de áudio, calculamos diversas estatísticas associadas a cada coeficiente do MFCC (média, desvio padrão, máximo e mediana, além de médias e desvios padrões das diferenças (deltas) de primeira e segunda ordem), ilustradas na figura a seguir.

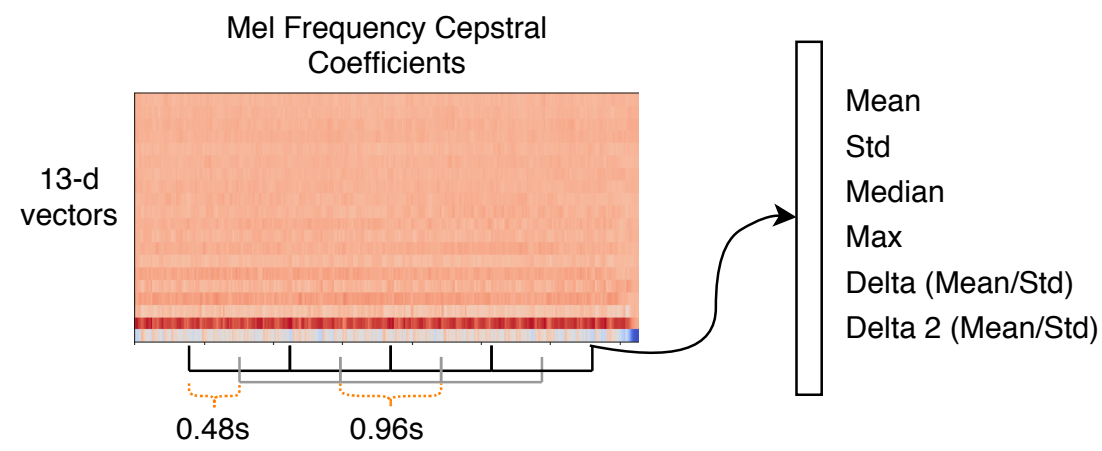

Figura 3.2: Estatísticas usadas do descritor $M F C C$

\footnotetext{
${ }^{2}$ https://librosa.github.io/librosa/

${ }^{3}$ https://scikit-learn.org/

${ }^{4}$ https://jupyter.org/
} 
Para o cálculo dos rótulos destes descritores (se continham ou não continham voz cantada) foram usadas as ativações de voz (instrument activation) de cada faixa. Para cada música com conteúdo vocal, consideramos como contendo voz cantada os segmentos que possuíam pelo menos uma voz (feminina, masculina, coral ou vocalistas), presentes em mais de $50 \%$ da duração do trecho de áudio (esse critério foi revisado nos experimentos subsequentes).

Utilizando as referências de resultados de Rocamora e Herrera [2007] e de Lehner et al. [2014] como ponto de partida, selecionamos dois algoritmos de aprendizado de máquinas (SVM e RF veja seção 2.3) para observar o comportamento de modelos gerados por estes algoritmos quando treinados com MFCC (descritor frequentemente usado) e VGGish embeddings (novo descritor na literatura). Utilizando o subconjunto de validação, foram selecionados os classificadores e parâmetros que obtiveram melhor acurácia, isto é, que obtiveram maior taxa de acerto na saída. A avaliação consistiu em verificar a acurácia do classificador sobre o subconjunto de teste. Por fim, fizemos uma análise qualitativa/subjetiva dos erros de classificação, ouvindo os sinais de áudio e investigando os trechos mal-classificados, a fim de observar as características do conteúdo de sinal que produziam mais confusões no classificador.

Foi utilizado como referência de performance um classificador dummy que atribui a presença voz cantada para todos os frames. Os resultados deste experimento, na tabela 3.2, indicam a distribuição de segmentos cantados e o valor mínimo (piso) que os classificadores treinados deveriam atingir em relação à acurácia.

Tabela 3.2: Valores minimos de acurácia

\begin{tabular}{|c|c|c|c|}
\hline & treino & validação & teste \\
\hline Acurácia & 0.6882 & 0.6878 & 0.7150 \\
\hline
\end{tabular}

\section{Modelagem: SVM e Random Forest}

Usando o classificador Suport Vector Machine do scikit-learn, variando o parâmetro C e mantendo os demais parâmetros com os valores default

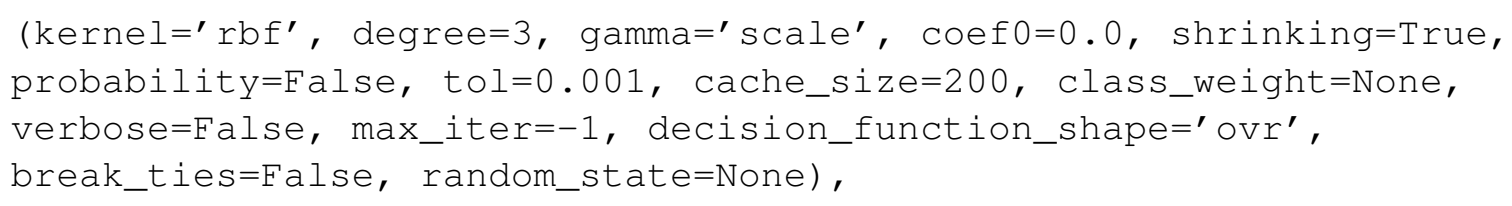

obtivemos os resultados apresentados na Figura 3.3a. Da mesma forma, ao utilizar o classificador Random Forest também com parâmetros default

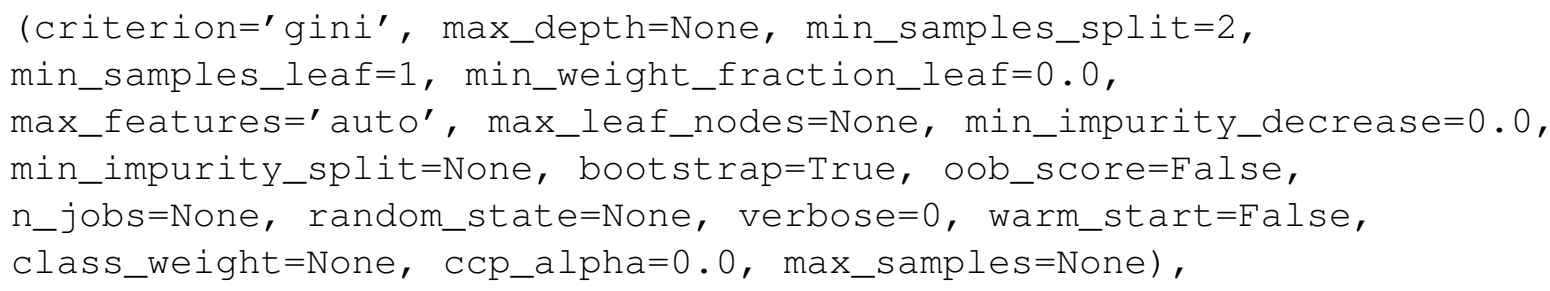

do scikit-learn, variando a quantidade de estimadores, obtivemos os resultados apresentados na tabela 3.3b.

O gráfico 3.3a indica que existe um ganho na performance do modelo gerado pelo algoritmo SVM ao reduzir o valor de C até 0.1 ; abaixo disso, a acurácia do modelo é pior para realizar a detecção de voz cantada, independentemente do descritor utilizado para a avaliação.

Por sua vez, o gráfico 3.3a apresenta estabilidade na performance do modelo gerado por RF utilizando cada vez mais árvores de decisão. Neste caso, percebemos que é melhor usar um modelo que custe menos, computacionalmente, ou seja, que utilize o menor número de árvores de decisão (100 estimadores). 

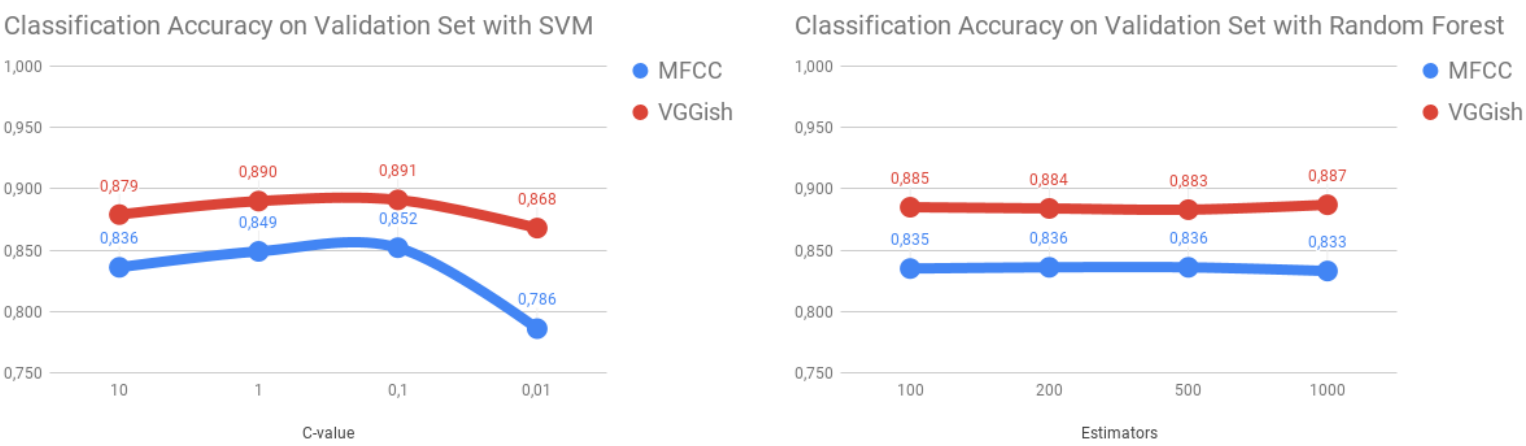

(a) Resultados usando diferentes valores de $C(\mathbf{b})$ Resultados para diferentes números de estimausando $S V M$ dores usando Random Forest

Figura 3.3: Resultados usando os nossos modelos treinados no conjunto de dados de validação

\subsubsection{Avaliações experimentais}

Após a realização do treinamento e seleção dos parâmetros que aumentam a acurácia no conjunto de validação ( $C=0.1$ para $S V M$ e 100 estimadores para $R F$ ), aplicamos estes modelos nos dados de teste a fim de verificarmos sua acurácia. Ao observar os resultados na Figura 3.4, constatamos que tanto o uso de coeficientes MFCC quanto o uso de VGGish embeddings para treinar modelos de aprendizado de máquina são capazes de superar a performance de referência (piso ou baseline) do classificador dummy.

Notamos também na tabela 3.3 que o uso de VGGish embeddings aumenta consideravelmente a acurácia em relação ao uso de MFCC (entre 0.07 e 0.08 de diferença). Além disso, os modelos de aprendizado de máquina treinados com MFCC, e também com VGGish, possuem resultados relativamente próximos entre si. Isto pode sugerir que as diferenças entre os algoritmos de classificação não influenciam no poder discriminativo dos dados de entrada, e que o uso de VGGish embeddings apresenta maior poder de diferenciação dos trechos de voz cantada do que o uso de estatísticas sobre os coeficientes MFCC.

Tabela 3.3: Resultados para os melhores classificadores treinados no conjunto de dados de teste

\begin{tabular}{|c|c|c|}
\hline Classificador & MFCC & VGGish \\
\hline Baseline & 0.71 & 0.71 \\
\hline Best SVM & 0.76 & 0.83 \\
\hline Best RF & 0.75 & 0.83 \\
\hline
\end{tabular}

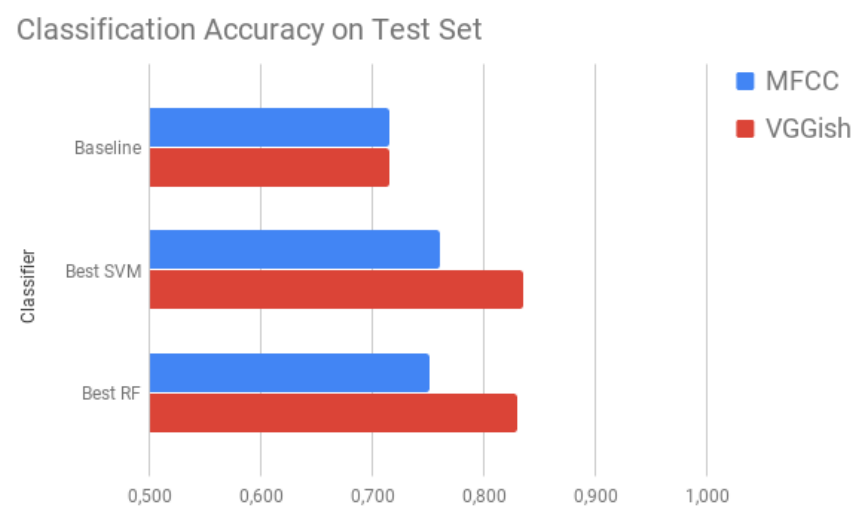

Figura 3.4: Resultados para os melhores classificadores treinados no conjunto de dados de teste 
Para observar o comportamento do classificador SVM utilizando MFCC e VGGish, geramos 10 divisões diferentes do conjunto de dados e utilizamos os parâmetros de C-value iguais a 10, 1, 0.1, 0.01. Quanto menor o parâmetro, maior a distância da margem para o hiperplano que divide as classes. O gráfico 3.5a apresenta o comportamento de variação de acurácia nos conjuntos de validação para cada parâmetro de C-value nas 10 diferentes divisões do conjunto de músicas.

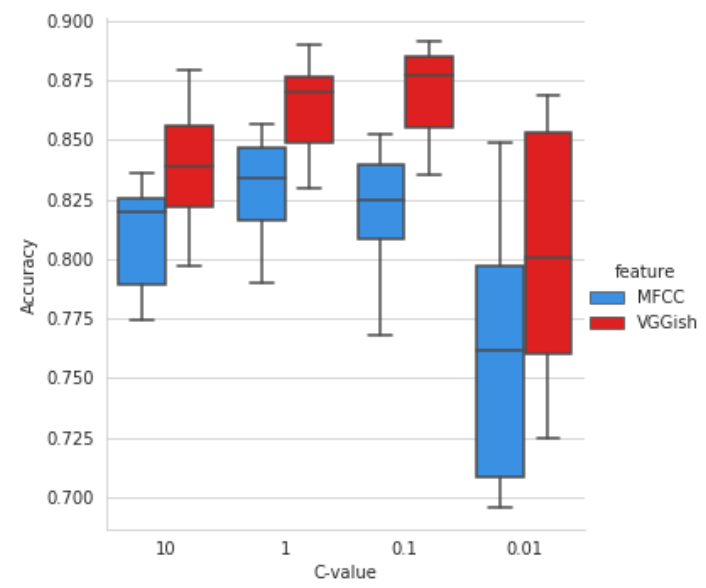

(a) Conjunto de validação

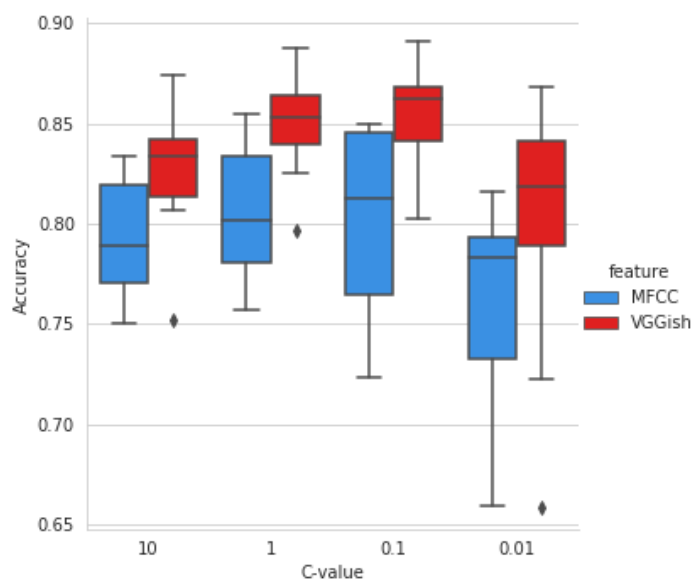

(b) Conjunto de teste

Figura 3.5: Variação da acurácia para os 10 splits criados com 61 músicas do MedleyDB

O gráfico 3.5b apresenta o comportamento de variação de acurácia nos conjuntos de teste para cada parâmetro de C-value nas 10 diferentes divisões do conjunto de músicas. Avaliando estes modelos treinados nos conjuntos de teste, nota-se que o comportamento médio é semelhante ao comportamento da classificação nos conjuntos de teste. Porém, os resultados usando VGGish possuem menos variação em torno da média com relação aos resultados usando MFCC.

\section{Análise de erros}

Para realizar uma avaliação qualitativa, observamos músicas com diferentes acurácias de classificação utilizando o modelo SVM treinado com MFCC e VGGish.

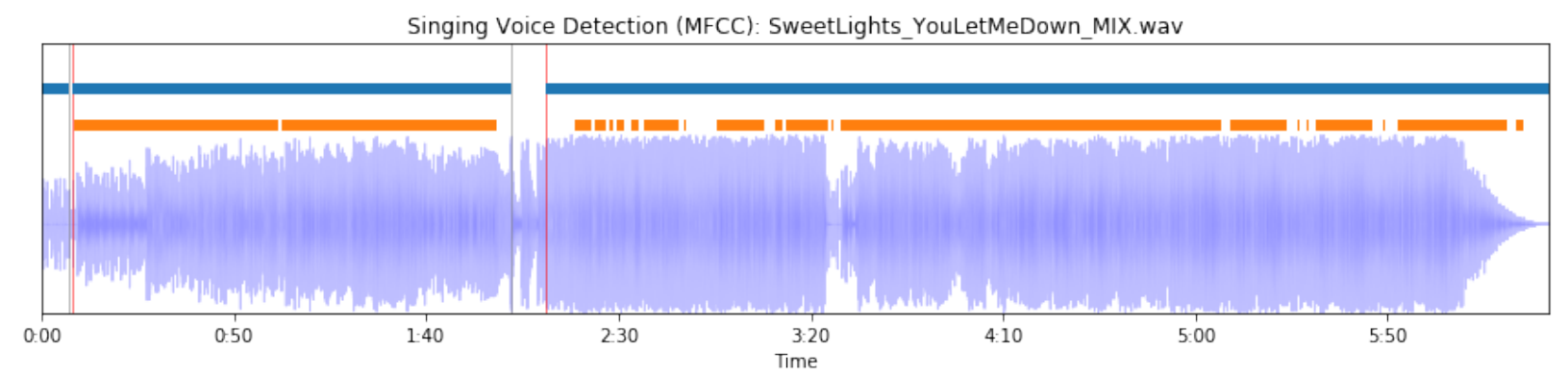

Singing Voice Detection (VGGish): SweetLights_YouLetMeDown_MIX.wav

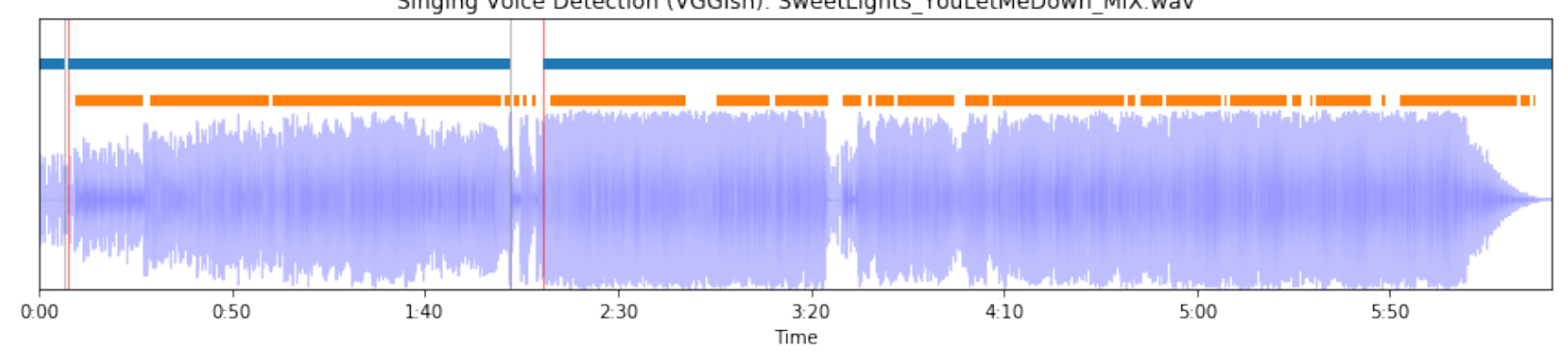

Figura 3.6: You Let Me Down - Análise de erros: SVM utilizando MFCC (acima) e VGGish (abaixo). Ground-truth (azul), saída do classificador (laranja) 
A música You Let Me Down (artista Sweet Lights) obteve resultados semelhantes em ambos os modelos classificadores. A Figura 3.6 (acima) apresenta os resultado de classificação desta peça do modelo SVM treinado a partir de descritores MFCC, enquanto a Figura 3.6 (abaixo) apresenta os resultados do modelo treinado com descritores VGGish para a mesma música. As marcações em azul indicam o rótulo dos trechos do sinal em que há voz cantada, e as marcações em laranja indicam onde o classificador apontou que havia voz cantada.
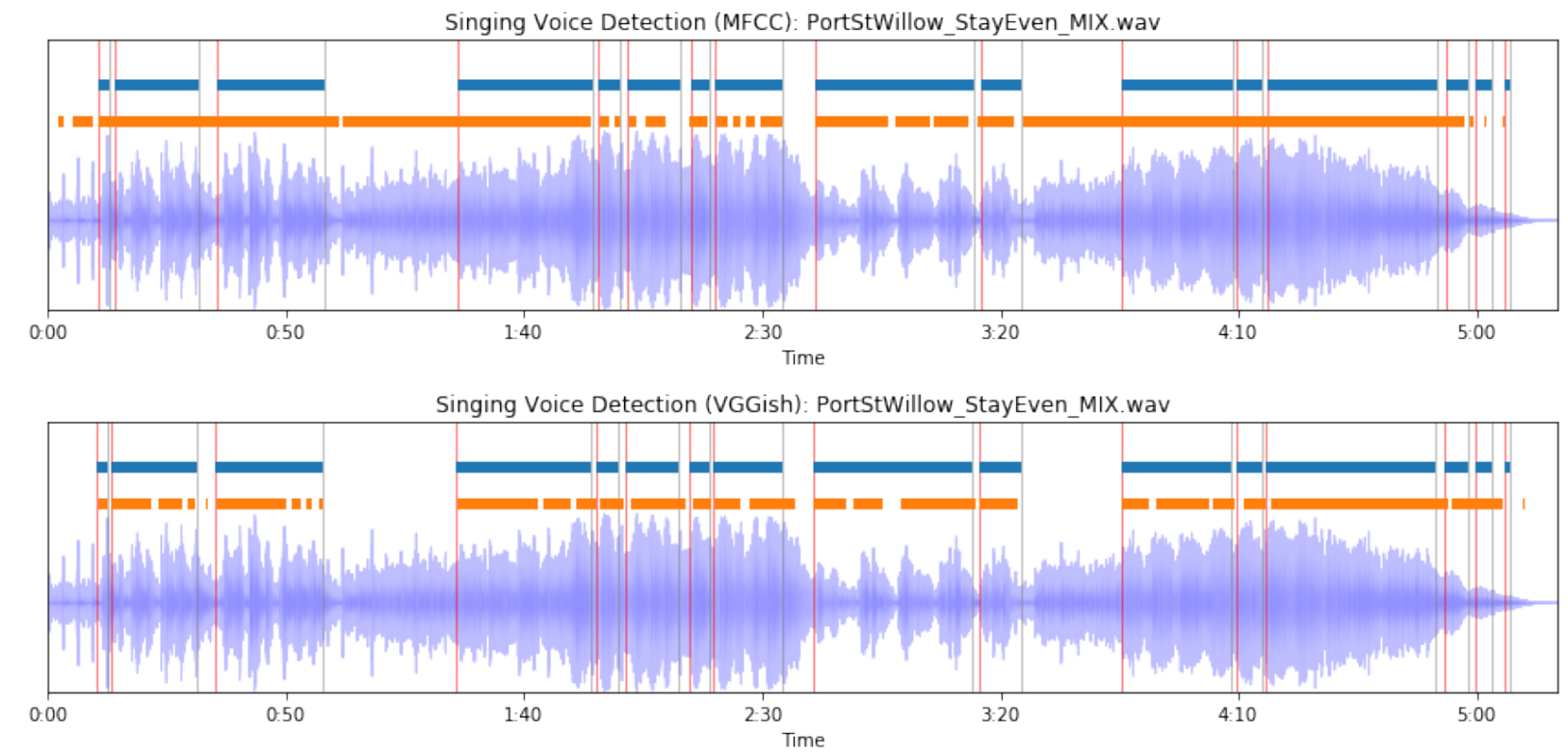

Figura 3.7: Stay Even - Análise de erros: SVM utilizando MFCC (acima) e VGGish (abaixo). Ground-truth (azul), saída do classificador (laranja)

Observando os resultados de classificação da música Stay Even (artista Port St Willow) percebemos a diferença na classificação entre os dois modelos. Vemos que a Figura 3.7 (acima) apresenta os resultado de classificação partir de descritores MFCC contendo muitos falsos positivos, enquanto a Figura 3.7 (abaixo), com descritores VGGish, apresenta pouquíssimos falsos positivos, mas alguns falsos negativos não existentes na classificação com MFCC.
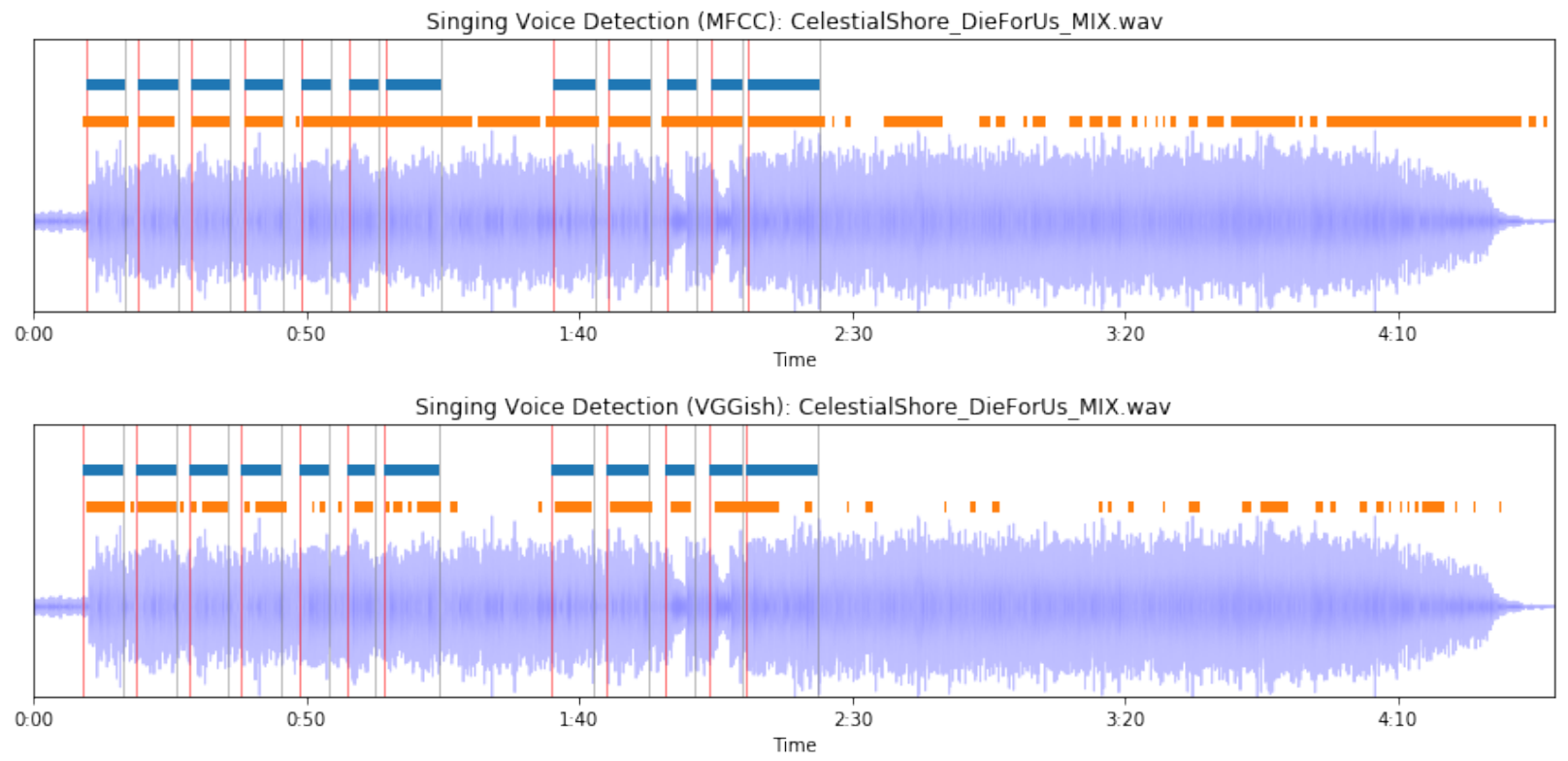

Figura 3.8: Die For Us - Análise de erros: SVM utilizando MFCC (acima) e VGGish (abaixo). Groundtruth (azul), saída do classificador (laranja) 
A música com menos acertos no conjunto de teste era Die For Us (artista Celestial Shore). Avaliamos a Figura 3.8 (acima) que apresenta os resultado de classificação, na música Die For Us, do modelo SVM treinado a partir de descritores MFCC, enquanto a Figura 3.8 (abaixo) apresenta os resultados do modelo treinado com descritores VGGish para a mesma música.

A música Die For Us se destacou por possuir muitos falsos positivos, ou seja, muitos trechos classificados como voz cantada que não continham voz. Nestes trechos, a fonte sonora presente era um sintetizador realizando variações rápidas de frequência, como glissandos.

Notamos que, usando VGGish embeddings, o número de falsos positivos diminuiu, porém os falsos negativos aumentaram. A voz cantada não é identificada em alguns trechos contendo fontes percussivas.

\subsubsection{Discussão}

A principal discussão levantada sobre este tema é a aplicação de conhecimento prévio para realizar a classificação. Uma vez que se faz o treinamento com aprendizado supervisionado, sem restrições nos dados de entrada, não é possível controlar o que será aprendido pelo classificador. Se forem usados no treinamento muitos exemplos de voz e piano, o classificador pode "aprender" que piano faz parte do que se deseja encontrar, logo associaríamos o piano à voz humana cantada, o que não deveria acontecer. É possível fornecer entradas ao classificador e dizer o que é esperado, mas não é possível definir exatamente o que ele vai capturar daquela entrada. Por isso, existe a necessidade de se intuir e entender quais características do descritor de entrada são responsáveis por influenciar positivamente na classificação do trecho como contendo ou não voz cantada.

Lehner et al. [2014] discutem o fato de falsos positivos serem constantes em sistemas de detecção de voz cantada, dadas as características de variação de altura de algumas fontes sonoras. Uma vez compreendidas as principais influências, podemos acrescentar esta informação ao classificador ou destacar a informação no dado de entrada, permitindo um aumento na qualidade da classificação.

Schlüter [2016] apresenta um sistema de anotação com poucas informações, isto é, com informações menos granulares. O próprio Schlüter desenvolveu uma aplicação on-line ${ }^{5}$ na qual se pode experimentar o efeito de criar variações contínuas de altura (glissandos) em um espectro polifônico, provocando a detecção de voz em trechos onde ela não existe. Intuitivamente, acredita-se que o sistema aprende apenas a detectar variações contínuas na frequência, e não necessariamente características da voz humana, como seria esperado.

Estes experimentos preliminares nos motivaram a realizar experimentos adicionais utilizando outras versões da mesma música com menos instrumentos na mixagem (usando a API do medleydb para criar as remixagens). Os resultados destes experimentos adicionais não foram satisfatórios, mas se encontram registrados no apêndice A deste trabalho.

Os resultados favoráveis com relação aos VGGish embeddings nos levaram a desenvolver outros experimentos de comparação, utilizando mais descritores de áudio, além dos coeficientes MFCC, visando reproduzir o modelo mais recente de detector de voz cantada com arquitetura de feature engineering Lehner et al. [2014].

\footnotetext{
${ }^{5}$ Veja a aplicação de Schluter em: https://jobim.ofai.at/singinghorse/
} 


\subsection{Experimento de comparação de descritores de áudio}

Os experimentos preliminares nos permitiram identificar a possibilidade de aumentar a qualidade da detecção de voz cantada em sinais polifônicos através do uso de VGGish deep embeddings como descritores de áudio. Desenvolvendo esta ideia, estruturamos experimentos de comparação do uso de descritores de áudio projetados para destacar o conteúdo específico da voz e dos descritores aprendidos automaticamente, a fim de observar a qualidade da classificação e o comportamento dos detectores de voz cantada treinados. Desta forma, comparamos o uso de descritores de áudio com resultados apresentados anteriormente em Lehner et al. [2014] e o uso de VGGish embeddings para a tarefa de deteç̧ão de voz cantada.

Todos os experimentos foram escritos em Python. Utilizamos o scikit-learn e seu algoritmo de aprendizagem Random Forest. Para o cálculo dos descritores, utilizamos a biblioteca Librosa, os códigos $^{6}$ em Matlab de Lehner et al. [2014] e o código de extração das features VGGish ${ }^{7}$ disponibilizados pelos autores de Gemmeke et al. [2017]. Os experimentos e resultados relatados neste trabalho estão disponíveis em um repositório no Github ${ }^{8}$.

\section{Experimento de reprodução de Lehner et al. [2014]}

Adotamos a estrutura de modelagem de sistema detector de voz cantada apresentada no artigo Lehner et al. [2014], que até o momento em que este texto foi escrito era considerado um dos modelos estado-da-arte em detecção de voz cantada com arquitetura de feature engineering, segundo Lee et al. [2018]. Os dados de entrada para o modelo classificador conta com os descritores de áudio MFCC, Vocal Variance, Fluctogram, Spectral Flatness e Spectral Contraction.

Calculamos alguns dos descritores (MFCC, Fluctogram, $S F, S C$ ) por meio do código disponibilizado pelos autores, para todas as peças que contém voz cantada do conjunto de dados MedleyDB. O descritor Vocal Variance foi calculado separadamente, seguindo as instruções de cálculo presentes em Lehner et al. [2014]. Assim, para cada janela de 200 milissegundos de áudio, construímos um vetor de características com os valores de cada descritor.

Ajustamos e atribuímos os rótulos cantado/não cantado para cada vetor de descritores de acordo com o tamanho de janela usado. Os trechos de áudio que não possuíam rotulação pura (100\% de frames anotados como contendo voz/não-voz) foram anotados como não voz, uma vez que as janelas possuíam apenas 200ms de áudio (ver seção 1.2).

Para garantir que todas as peças cantadas disponíveis fossem avaliadas, utilizamos a MedleyDB API para dividir as peças em 10 conjuntos de treino e teste, com tamanhos de aproximadamente $70 \%$ e 30\% respectivamente. Acrescentamos a restrição de que o mesmo artista não estivesse presente em ambos os subconjuntos (como referido na subseção 3.3, separação condicionada por artista). Por fim, observamos que cada peça que contém voz cantada aparecia pelo menos uma vez em algum dos conjuntos de teste.

Desta vez, automatizamos a busca por hiperparâmentros para os modelos. A biblioteca scikitlearn fornece o objeto GridSearchCV. Este objeto é capaz de receber um conjunto de parâmetros, treinar modelos, e selecionar o modelo com melhor desempenho de acordo com uma métrica específica, testando todas as combinações de hiperparâmetros. Utilizando esta ferramenta, realizamos uma busca em grade com validação cruzada em 5 folds sobre o primeiro conjunto de treinamento com o algoritmo Random Forest, tendo como métrica de erro a Precisão ("precision"). Os parâmetros da busca em grade foram:

'n_estimators': [10, 35, 60, 85, 110], 'max_depth': [10, 20, 30, 40],
'max_features': ['auto', 'sqrt'], 'bootstrap': [True, False]

e todos os outros parâmetros do algoritmo Random Forest foram definidos com os valores default (reportados na seção anterior).

\footnotetext{
${ }^{6}$ Código para extração de features vocais: https://www.dropbox.com/s/nqv388coriklely/svd2018.7z?dl=0

${ }^{7}$ Código para extração de VGGish embeddings: https://github.com/tensorflow/models/tree/master/research/ audioset/vggish

${ }^{8}$ Experimentos deste trabalho disponíveis em github.com/shayenne/vocaldetection
} 
A utilização dos 5 folds e desta série de parâmetros contendo 80 combinações diferentes resultou em 400 modelos treinados e comparados entre si para identificar os hiperparâmetros que garantiam o melhor desempenho. Esta busca devolveu o modelo que obteve melhor resultado dentre todos, para o primeiro conjunto de treino e teste. Treinamos um modelo de Random Forest com os parâmetros encontrados neste primeiro conjunto para cada um dos 10 conjuntos de treino e teste divididos anteriormente. Para cada modelo, obtemos três diferentes resultados de rotulação:

- output: a classificação original do modelo

- majority vote: suavização das probabilidades em janelas de $800 \mathrm{~ms}$ com voto de maioria de 1 segundo (proposto pelo artigo Lehner et al. [2014]);

- optimal binarization: binarização otimizada das probabilidades (limiar sobre as probabilidades otimizado a partir dos dados de treinamento). A binarização otimizada foi realizada através da busca pelo melhor threshold de probabilidade utilizando o índice de Youden (vide seção 2.6).

\section{Experimento VGGish}

Para avaliar um descritor de áudio gerado por aprendizado profundo, utilizamos os VGGish embeddings como entrada para os modelos de aprendizado de máquina. Para cada música, calculamos os vetores com janela de tamanho padrão de cálculo dos vetores de VGGish (960ms), com hop size de metade da janela (480ms). Neste experimento, para os trechos de áudio que possuíam menos que $300 \mathrm{~ms}$ de voz anotados foram classificados como não contendo voz cantada (vide 1.2).

Seguindo os mesmos passos do experimento anterior, usamos os mesmos 10 conjuntos de treino e teste e calculamos os hiperparâmetros que apresentavam o modelo com melhor desempenho sobre o primeiro split de treino e testes, a partir da busca em grade. Treinamos modelos de Random Forest com os parâmetros encontrados para cada um dos 10 conjuntos de treino e teste. Como no experimento anterior, obtemos três diferentes resultados de rotulação:

- output: a classificação original do modelo

- majority vote: média das probabilidades em duas janelas consecutivas com threshold igual à 0.5 (adaptando a ideia de voto de maioria apresentado no experimento anterior);

- optimal binarization: binarização otimizada das probabilidades.

\subsection{Resultados}

Deste ponto em diante, iremos utilizar LEHNER para nos referirmos ao experimento baseado nos descritores apresentados por Lehner et al. [2014] e VGGISH para nos referirmos ao experimento com VGGish embeddings.

A busca em grade sobre os hiperparâmetros definidos na seção 3.4 para o experimento LEHNER e para o experimento VGGISH produziram a lista de valores a seguir, com os quais os classificadores obtiveram melhor desempenho. Os valores dos hiperparâmetros selecionados pela busca em grade foram idênticos para ambos os experimentos:

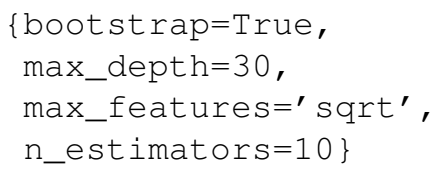

o que significa que cada modelo gerado pelo algoritmo de Random Forests utilizando estes hiperparâmetros usará bootstrap (fará uma amostra aleatória dos dados de entrada, com reposição, para realizar o treinamento), as árvores terão profundidade máxima de 30 nós, cada árvore de decisão usará, no máximo, a raiz quadrada do número de features de entrada para o split no treinamento e serão geradas apenas 10 árvores de decisão. 


\section{Métricas dos conjuntos de teste}

Em ambos os experimentos (LEHNER e VGGISH), tomamos 10 splits treino/teste e geramos 10 modelos de Random Forest (um para cada split). As métricas a seguir se referem aos resultados da classificação para cada modelo gerado sobre seu próprio conjunto de teste. Nos gráficos do tipo boxplot apresentados na Figura 3.9 apresentamos os resultados de ambos os experimentos, considerando as três diferentes rotulações:

- saída original do classificador;

- voto de maioria (proposto por Lehner et al. [2014] e adaptado para o VGGISH);

- binarização otimizada das probabilidades.

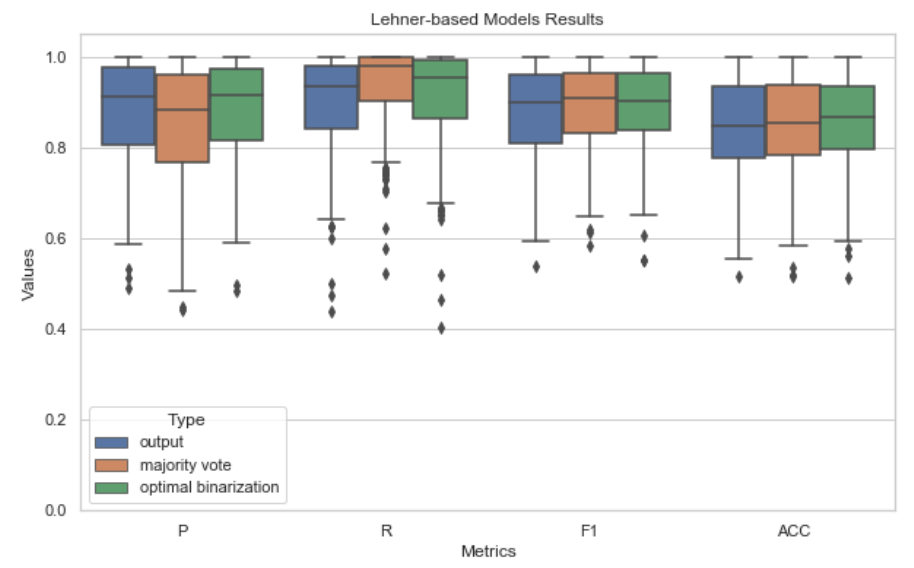

(a) Métricas dos modelos baseados em Lehner et al. [2014]

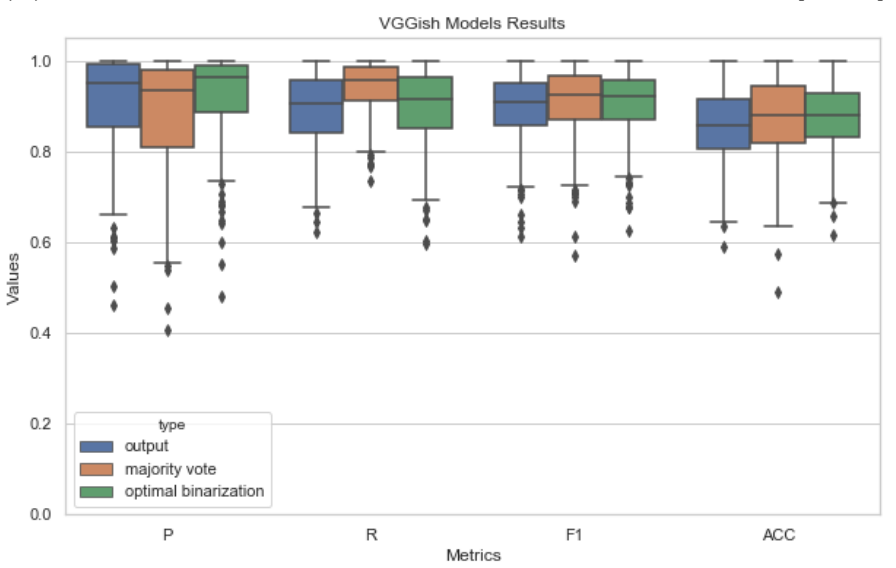

(b) Métricas dos modelos baseados em VGGish embeddings

Figura 3.9: Métricas dos diferentes tipos de abordagem em Detecção de Voz Cantada experimentados. Cada boxplot representa a dispersão dos resultados dos 10 conjuntos de teste avaliados.

Os gráficos na Figura 3.9 contém métricas agrupadas de todas as peças em todos os conjuntos de teste. Estes gráficos nos permitem comparar visualmente a qualidade geral da detecção de voz cantada entre as diferentes abordagens (uso de descritores de áudio baseados em Lehner et al. [2014] e uso de VGGish embeddings).

O gráfico da Figura 3.9b destaca-se por trazer quase todas as métricas com valores de mínimos quantílicos maiores que 0.6. Em comparação com o gráfico da Figura 3.9a, os modelos VGGISH apresentam métricas superiores em média, exceto pela métrica Recall, que é maior entre os resultados pós-processados do experimento LEHNER. Além disso, as médias de todas as métricas da abordagem usando VGGish embeddings estão próximas ou acima de 0.9 , o que indica alta capacidade de acerto desse classificador nas peças que não faziam parte do conjunto de treinamento. 
Além da análise das métricas dos detectores de voz cantada treinados nestes experimentos, investigamos outras características dos modelos a partir da sua construção. O algoritmo Random Forest nos permite verificar facilmente quais features, no nosso caso descritores de áudio, foram mais importantes para a classificação em uma classe ou outra.

Observando os 5 descritores mais importantes dentre todos os grupos de treino e teste, percebemos que o coeficiente 0 do MFCC está sempre entre os 3 primeiros mais importantes no experimento LEHNER.

No experimento VGGISH, notamos que o décimo terceiro elemento do vetor de VGGish embeddings (VGGish[12]) aparece na maioria dos splits como feature mais importante, sendo que nos outros casos fica em segundo lugar. Podemos observar quais elementos aparecem nas 5 primeiras posições de cada experimento na Figura 3.10. Esta figura contém um histograma de contagem das features que aparecem entre as cinco mais importantes em cada modelo.

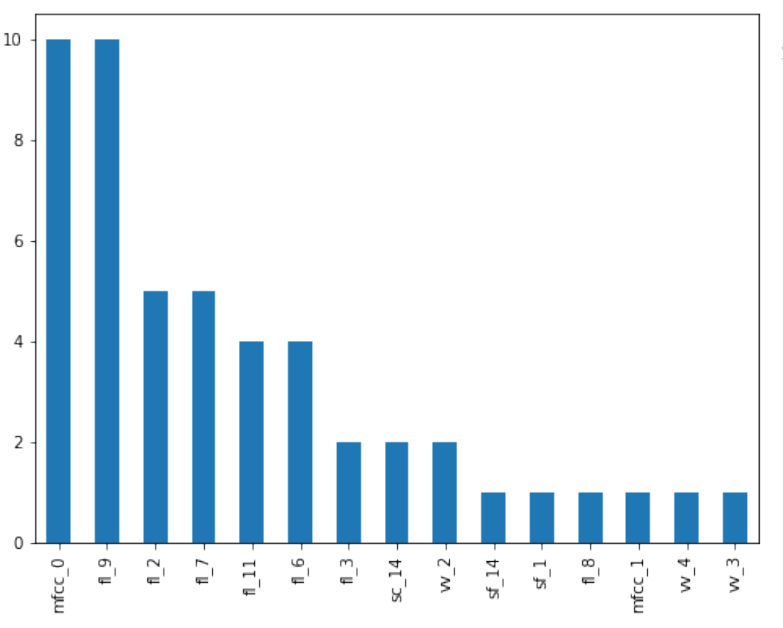

(a) Experimento Lehner

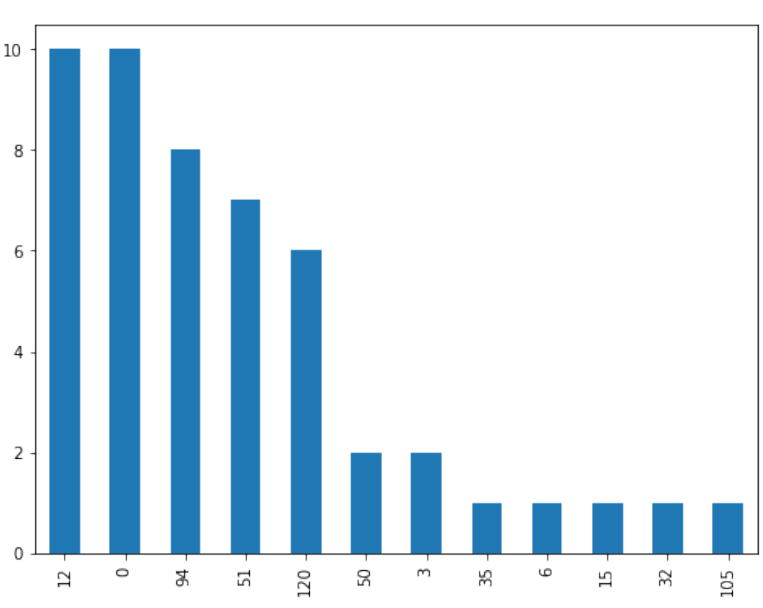

(b) Experimento VGGish

Figura 3.10: Histogramas de elementos que aparecem entre os 5 mais importantes para cada experimento.

Para aprofundar a observação sobre as features mais importantes para cada um dos experimentos, observamos a distribuição dos seus valores para cada classe alvo (lembrando que 1 indica presença de voz cantada, e 0 indica ausência de voz cantada). A Figura 3.11 indica uma separabilidade razoável dos valores da feature VGGish[12] para as classes alvo, enquanto os valores de MFCC[0] não indicam uma separação clara.

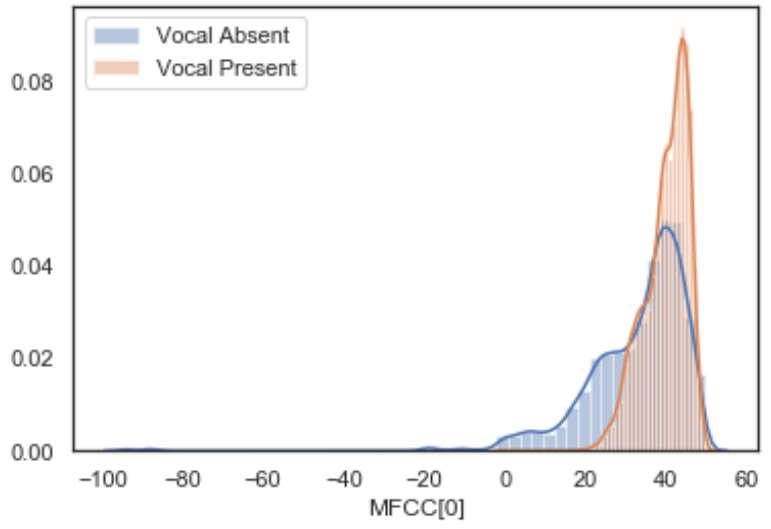

(a) $M F C C[0]$

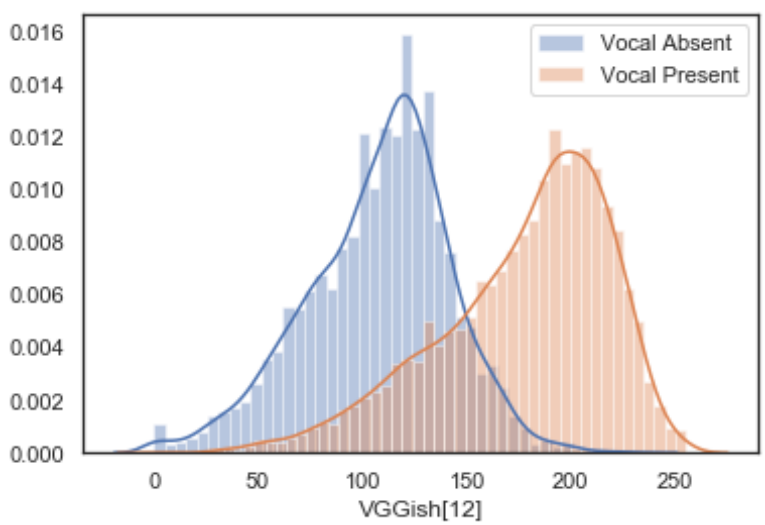

(b) VGGish[12]

Figura 3.11: Distribuição de valores das features mais importantes para todas as peças em cantado (classe 1) e não-cantado (classe 0) 
A Figura 3.12 contém o exemplo de uma peça do conjunto de dados apresentando. Esta peça era a que apresentava menores resultados de classificação em todos os modelos. Podemos visualizar o comportamento dos rotuladores nos trechos de confusão. Notamos nessa figura que as probabilidades de presença de voz no trecho instrumental da música apresentada são maiores na Figura 4.4b que na Figura 4.4a, o que indica que o uso das features perceptualmente motivadas acrescentou informações ao modelo que não haviam no uso de VGGish embeddings. Acreditamos que o fato de os VGGish embeddings possuírem maior quantidade de conteúdo musical afete a qualidade da detecção em trechos muito ruidosos, como é o caso desta música.

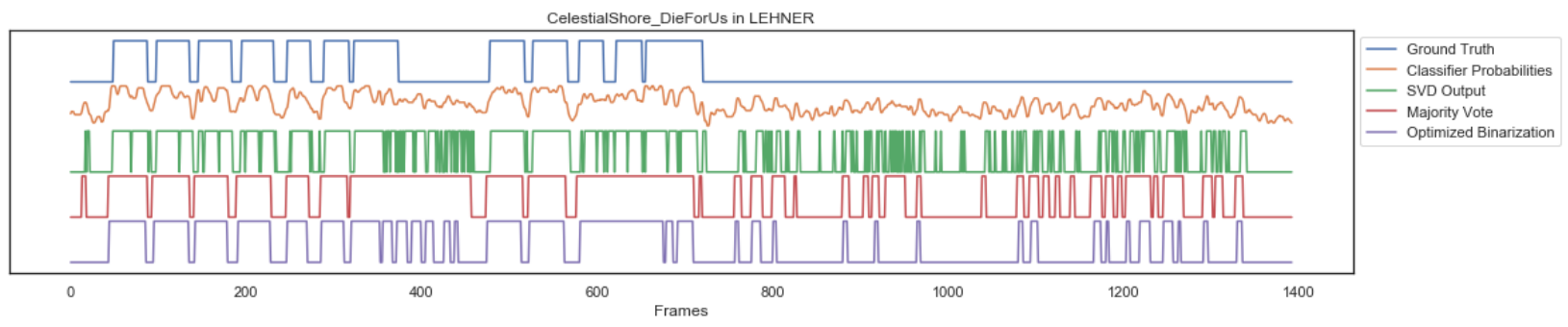

(a) Lehner

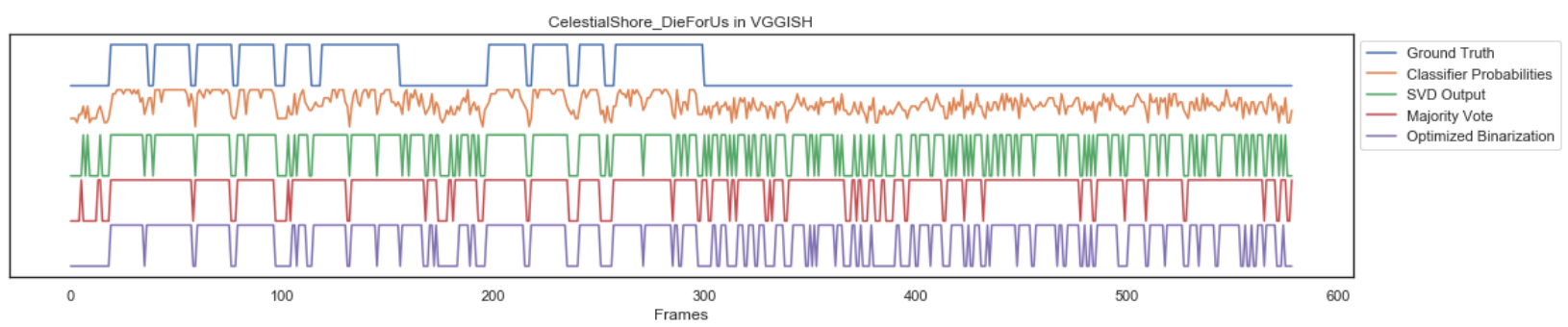

(b) VGGish

Figura 3.12: Resultados de detecção de voz cantada para a peça Die For Us, Celestial Shore. Em azul, no topo, temos as anotações originais da peça indicando a presença de voz, quando acima, e a ausência de voz, quando abaixo. (Os gráficos foram sobrepostos para evitar conflitos na visualização). Em laranja, segunda linha, temos as probabilidades da presença de voz cantada de acordo com o modelo treinado. Em verde, linha central, temos a saída original do detector de voz. Em vermelho, quarta linha, temos as probabilidades filtradas e binarizadas com o voto de maioria. Em roxo, mais abaixo, temos as probabilidades filtradas e binarizadas com o limiar ótimo.

\subsection{Discussão}

Após reproduzir a estrutura de Lehner et al. [2014] com os descritores calculados utilizando o código do autor e realizando o agrupamento seguindo suas instruções, notamos que a classificação com este método é comparavelmente menos acurada do que a classificação utilizando apenas os VGGish embeddings como descritores de entrada.

Analisando as importâncias relativas dos descritores, verificamos que o coeficiente 0 do MFCC aparece em primeiro lugar no experimento LEHNER, seguido de alguns coeficientes do descritor Fluctogram.

O MFCC[0] representa a quantidade média de energia presente no espectro do sinal, e observar que este coeficiente foi um dos elementos mais importantes na detecção de voz reflete o que foi relatado por Schlüter e Lehner [2018]. A intensidade do sinal de voz normalmente é maior que a intensidade das fontes sonoras que fazem parte do acompanhamento. Este efeito é, de maneira geral, propositalmente criado durante a mixagem da peça. Portanto, notamos que os detectores treinados no experimento LEHNER possuem este viés de loudness.

Os autores de Schlüter e Lehner [2018] abordam uma forma de evitar este efeito do loudness no áudio usando redes convolucionais, realizando uma convolução com média zero na primeira camada da rede convolucional. Um possível futuro passo de investigação é verificar se esta abordagem de 
redes convolucionais que resolve o viés de loudness possui melhores resultados que o uso de VGGish embeddings.

Por outro lado, analisando os valores dos "coeficientes" dos VGGish embeddings, notamos que o décimo terceiro coeficiente (VGGish[12]) é um elemento que consegue diferenciar as classes razoavelmente bem a partir dos seus valores (está sempre entre os 2 primeiros descritores em ordem de importância). Como se pode notar no gráfico de distribuições da Figura 3.11b, quanto maior o valor deste coeficiente, maior a probabilidade do frame ser voz cantada. Por se tratar de um descritor aprendido automaticamente, não sabemos exatamente como este coeficiente é calculado e como ele se relaciona com a intensidade do sinal; por isso, um trabalho futuro seria avaliar se o viés de loudness se aplica a este descritor, avaliando a qualidade da deteç̧ão de voz cantada utilizando VGGish embeddings em diferentes escalas de loudness.

Notamos também que os resultados do experimento VGGISH possuem comparativamente mais falsos negativos que o experimento LEHNER. A primeira justificativa é o fato de que as janelas de análise do VGGISH são 5 vezes maiores que as janelas de análise do LEHNER, o que pode diminuir a qualidade da classificação em trechos muito pequenos, e aglutinar trechos não cantados pelo fato do classificador estar analisando um trecho maior do sinal.

Porém, por causa do modo com que os VGGish embeddings são gerados, a granularidade da análise é diferente deste com relação às features propostas por Lehner et al. [2014]. Enquanto o experimento LEHNER tem 5 amostras por segundo (cada amostra corresponde a 200ms), os $V G$ Gish embeddings correspondem a quase um segundo inteiro por amostra (960ms). Isto impede o alinhamento das features, mas não impede a comparação dos resultados de classificação.

Os VGGish embeddings também sofrem pelo excesso de contexto (janelas de 960ms e saltos de $480 \mathrm{~ms}$ ), fazendo com que muito conteúdo musical seja analisado ao mesmo tempo, o que pode influenciar seu desempenho, especialmente em trechos de áudio que possuem fontes sonoras não vocais mais proeminentes.

Calculamos os tamanhos dos trechos de áudio contendo e não contendo voz cantada a fim de verificar a perda de conteúdo de sinal relacionada ao tamanho da janela de avaliação da feature que usamos. Agrupamos os trechos de duração menor que $200 \mathrm{~ms}$, entre $200 \mathrm{~ms}$ e $960 \mathrm{~ms}$ e maiores que 960ms. A Tabela 3.4 abaixo apresenta esses percentuais.

$\begin{array}{lccc}\text { Trechos de áudio } & <200 \mathrm{~ms} & <960 \mathrm{~ms} & >=960 \mathrm{~ms} \\ \text { Sem voz cantada } & 1.6 \% & 17 \% & 32 \% \\ \text { Com voz cantada } & 0.5 \% & 2.4 \% & 47 \%\end{array}$

Tabela 3.4: Porcentagens de tamanhos trechos de áudio contendo e não contendo voz cantada sobre todo o conjunto de dados utilizado.

É possível concluir da tabela que, utilizando features de tamanho 200ms, confundiríamos pelo menos $4 \%$ de todo o conjunto de dados por conter frames mistos (onde não se pode afirmar que possuem ou não voz cantada em toda sua duração); por causa da intersecção dos frames de áudio, um trecho pode conter parte da voz cantada menor que 200ms. Por este motivo, para trechos que possuíam voz mas eram menores que $200 \mathrm{~ms}$ ajustamos a anotação para não cantado. No entanto, usando features de $960 \mathrm{~ms}$ esse número sobe para $21 \%$ (somando a quantidade de trechos com e sem voz cantada que são menores que $960 \mathrm{~ms}$ ).

Os VGGish embeddings têm sido usados também para processamento em tempo real. O MTG (Music Technology Group) da Universidad Pompeo Fabra, Espanha, adicionou os VGGish embeddings em sua principal biblioteca Essentia ${ }^{9}$ e os utiliza para tarefas de reconhecimento de gênero e mood, entre outras tarefas.

\footnotetext{
${ }^{9}$ https://mtg.github.io/essentia-labs/
} 


\section{Capítulo 4}

\section{Detecção de voz cantada usando separação de fontes}

Depois de explorar diferentes abordagens para a tarefa de deteç̧ão de voz cantada e verificar que o conteúdo dos descritores de áudio com os quais alimentamos os algoritmos de aprendizado de máquina realmente influencia no resultado final, queremos comparar os resultados de detecção de voz utilizando outra tarefa relacionada: separação de fontes.

A separação de fontes sonoras de um sinal de áudio polifônico tem como objetivo gerar faixas de áudio com as fontes segregadas derivadas da mistura de fontes original.

Para detectar os trechos que contêm voz cantada e o acompanhamento na mistura sonora, podemos usar, como passo inicial, a separação de fontes, a partir de um sistema capaz de segregar o sinal de voz. Desta forma, podemos avaliar a qualidade da detecção de voz cantada nos trechos separados por um sistema que, intrinsecamente, realiza a distinção entre conteúdo vocal e não vocal, porém sob a perspectiva de conteúdo sonoro do sinal (ao invés da perspectiva da segmentação temporal).

Os objetivos desta parte do trabalho são:

- Gerar um detector de voz cantada a partir da separação de fontes automática;

- Comparar os resultados de detecção utilizando separação de fontes e os modelos gerados no capítulo anterior.

\subsection{Metodologia}

A metodologia para realizar este experimento propõe a utilização de um sistema separador de fontes que seja capaz de gerar pelo menos uma faixa de áudio contendo os trechos cantados do sinal original, isto é, separar a fonte da voz cantada dentre a mistura polifônica.

Realizamos o cálculo do RMS (ver subseção 2.1) da faixa de voz separada, em janelas de 200ms, para cada peça do conjunto de dados que contém voz cantada. A justificativa do uso do RMS está relacionada com as características da separação de fontes. Quando o conteúdo cantado é segregado em uma nova faixa de áudio, o novo sinal associado à fonte "voz" contém mais energia em trechos onde existe a voz cantada e pouca ou nenhuma energia em trechos onde o sistema considera que não existe voz cantada (isso também é válido para a separação das outras fontes sonoras).

Usamos RMS ao invés da amplitude instantânea para que picos de amplitude gerados por falsos positivos sejam amenizados no intervalo de cálculo do RMS (trechos que contenham sinal intenso, mas que são muito curtos para que sejam parte do sinal de voz). O tamanho da janela foi escolhido através da comparação de resultados com janelas de tamanho $20 \mathrm{~ms}$ e $200 \mathrm{~ms}$. Encontramos maiores valores de $F$-measure para os resultados obtidos usando janelas de $200 \mathrm{~ms}$.

Calculamos um limiar (threshold ótimo) sobre o RMS presente no sinal da faixa de voz das peças determinadas para o treinamento (conjunto de treino) para determinar a presença de voz "estimada" pelo separador. Este limiar é encontrado a partir de anotações de presença de voz 
cantada disponíveis juntamente com as peças do conjunto de dados, através da maximização do índice de Youden (ver subseção 2.6).

Avaliamos os resultados de deteç̧ão de voz cantada a partir de peças do conjunto de teste, classificando-as com o threshold encontrado em seu respectivo conjunto de treinamento. Comparamos a performance final da detecção de voz sobre as faixas vocais separadas.

Por fim, comparamos os resultados de detecção de voz cantada entre os modelos, o que foi gerado a partir da separação de fontes e todos os modelos gerados anteriormente a partir da utilização de descritores de áudio relacionados a voz e deep embeddings.

\subsection{Conjunto de dados}

O conjunto de dados utilizado é o mesmo do capítulo anterior, MedleyDB, seguindo a mesma configuração de 10 splits treino/teste. As peças contendo voz cantada foram processadas pelo separador Spleeter (veja seção 2.5) e utilizamos os resultados dos processamentos (faixas de áudio contendo vocais) para realizar a detecção de presença de voz cantada.

Dividimos o conjunto de dados em vários conjuntos de treino e teste, sempre levando em conta que o mesmo artista não esteja simultaneamente no treinamento e no teste. As separações em conjuntos de treino/teste são realizadas a fim de que todas as peças apareçam em um conjunto de teste, pelo menos uma vez. Os conjuntos de divisões entre treino e teste usados foram os mesmos do capítulo anterior.

\subsection{Separação de fontes}

Para utilizar a ferramenta Spleeter e separar todas as peças do conjunto de dados, seguimos as instruções de instalação presentes no repositório do código fonte do sistema disponível no Github ${ }^{1}$. Após a instalação, utilizamos o ambiente pré-configurado spleeter-gpu e, para cada música do nosso conjunto de dados, realizamos a separação em duas faixas: vocais e acompanhamento.

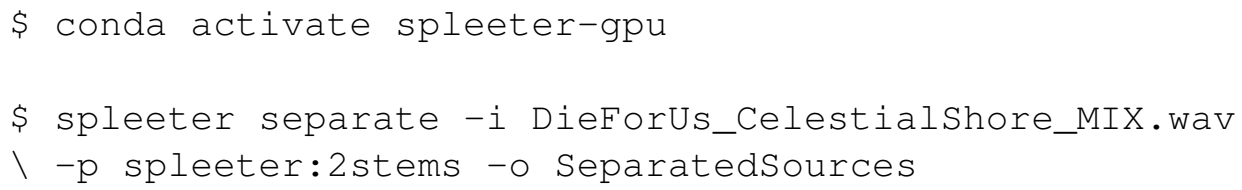

Exemplo de execução do sistema Spleeter para separação de fontes. As faixas resultantes da separação da peça "Die for us" são armazenadas no diretório "SeparatedSources".

Por padrão, o sistema cria um diretório com o nome da peça original processada e, dentro deste diretório, armazena os arquivos de áudio resultantes da separação. Uma vez tendo todas as peças separadas em faixas de voz e acompanhamento, calculamos os valores de RMS para todas as faixas denominadas "vocals". Utilizamos as faixas denominadas "vocals.wav" que o separador Spleeter havia considerado como contendo voz como referência para identificar os trechos de voz cantada nas peças.

Encontramos um valor ótimo de threshold para os valores de RMS das peças a partir dos rótulos de presença de voz para cada split de treinamento, utilizando o índice de Youden, tomando como referência os valores de RMS das peças dos conjuntos de treinamento e seus rótulos. Com os thresholds encontrados a partir dos conjuntos de treinamento, avaliamos os conjuntos de teste calculando as métricas sobre os resultados gerais do modelo e individuais das peças. Por fim, comparamos os resultados dos classificadores modelados no capítulo anterior com os resultados provenientes do separador Spleeter, e discutimos os resultados obtidos.

\footnotetext{
${ }^{1}$ https://github.com/deezer/spleeter
} 


\subsection{Resultados}

Após utilizar o Spleeter para separar as peças em faixas de vocal e acompanhamento, utilizamos o sinal da faixa vocal e calculamos o seu RMS. A Figura 4.1 apresenta um exemplo de sinal RMS da faixa vocal extraída pelo Spleeter.

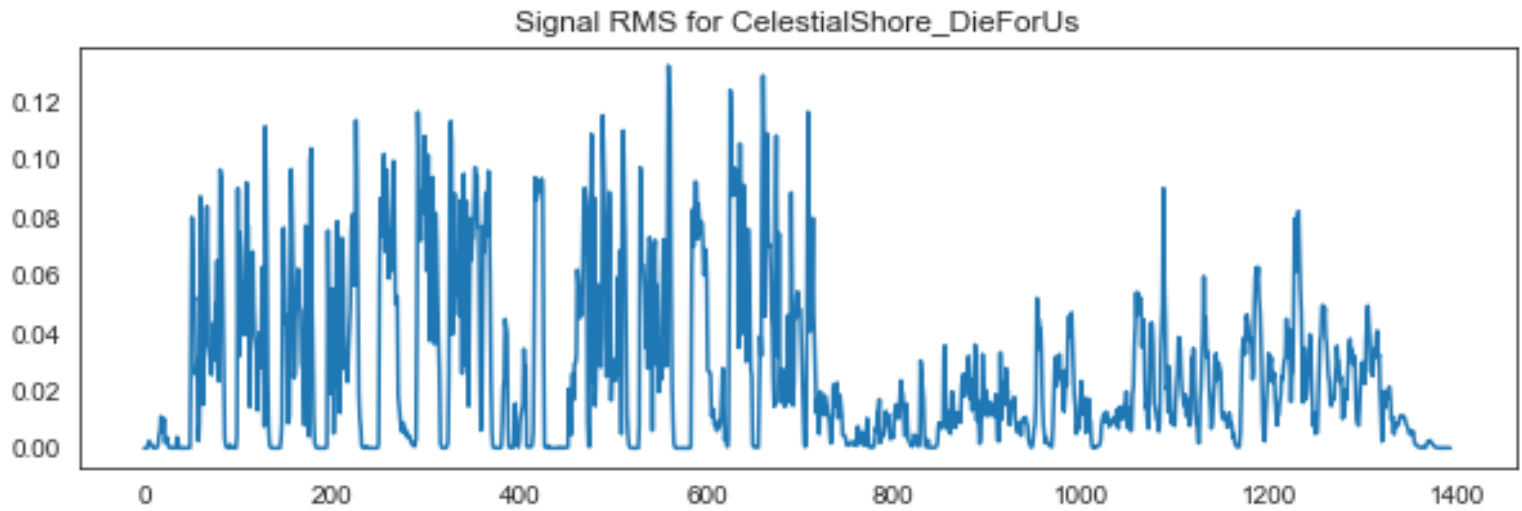

Figura 4.1: Sinal RMS da faixa cantada extraída da peça Die For Us, Celestial Shore

Normalizamos todas as peças de treinamento, para que o sinal RMS abrangesse o intervalo $[0,1]$. Cada peça foi associada às anotações de presença de voz cantada. A Figura 4.2 apresenta o resultado da normalização e a associação com os rótulos do conjunto de dados (o trecho laranja é o sinal que contém voz cantada).

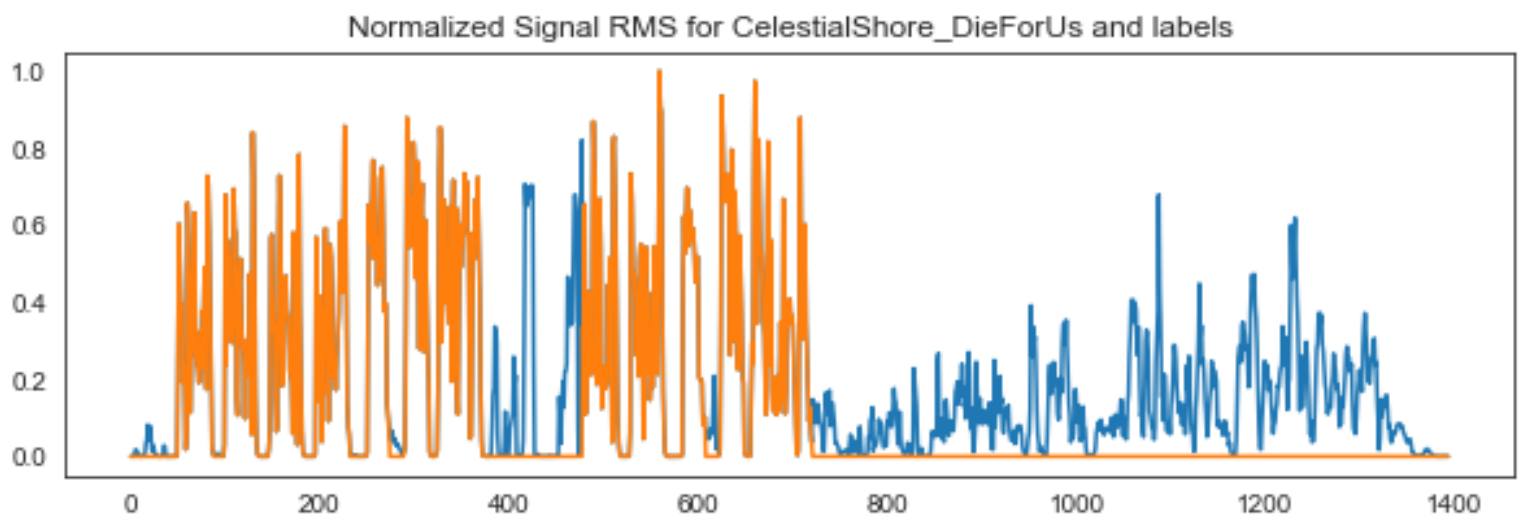

Figura 4.2: Sinal RMS da faixa com voz cantada extraída da peça Die For Us, Celestial Shore

Utilizando os valores do trecho cantado (marcado em laranja) de todas as peças do conjunto de treinamento, calculamos um threshold ou limiar ótimo, isto é, aquele que produz uma maior taxa de acerto quando utilizado. O sinal RMS do áudio é então binarizado utilizando este limiar ótimo encontrado a fim de produzir os rótulos da detecção de voz $(0=$ não voz e $1=$ voz).

Os gráficos em 4.3 nos permitem comparar visualmente a qualidade geral da detecção de voz cantada entre as diferentes abordagens (uso de descritores de áudio baseados em Lehner et al. [2014], uso de deep embeddings e separação de fontes).

O gráfico $4.3 \mathrm{~b}$ destaca-se por trazer todas as métricas com valores de mínimos quantílicos maiores que 0.6. Comparado com o gráfico 4.3a, todos os modelos apresentam médias superiores em todas as métricas. Podemos notar que nos resultados dos VGGish embeddings existe uma peça cujo Precision no modelo de Threshold probabilities é menor que 0.4, o que não acontece ao usar os descritores propostos por Lehner. Além disso, todas as médias de todas as métricas da abordagem usando VGGish embeddings estão próximas ou acima de 0.9 , o que indica alta capacidade de acerto do modelo em peças que não faziam parte do conjunto de treinamento. 


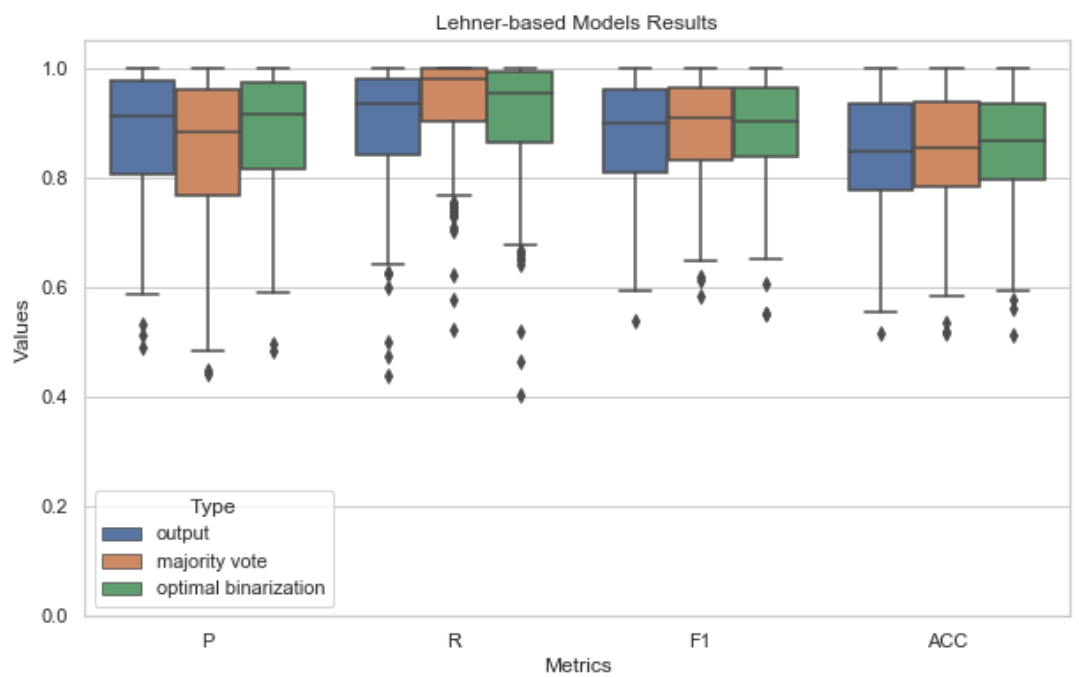

(a) Métricas dos modelos baseados em Lehner et al. [2014]

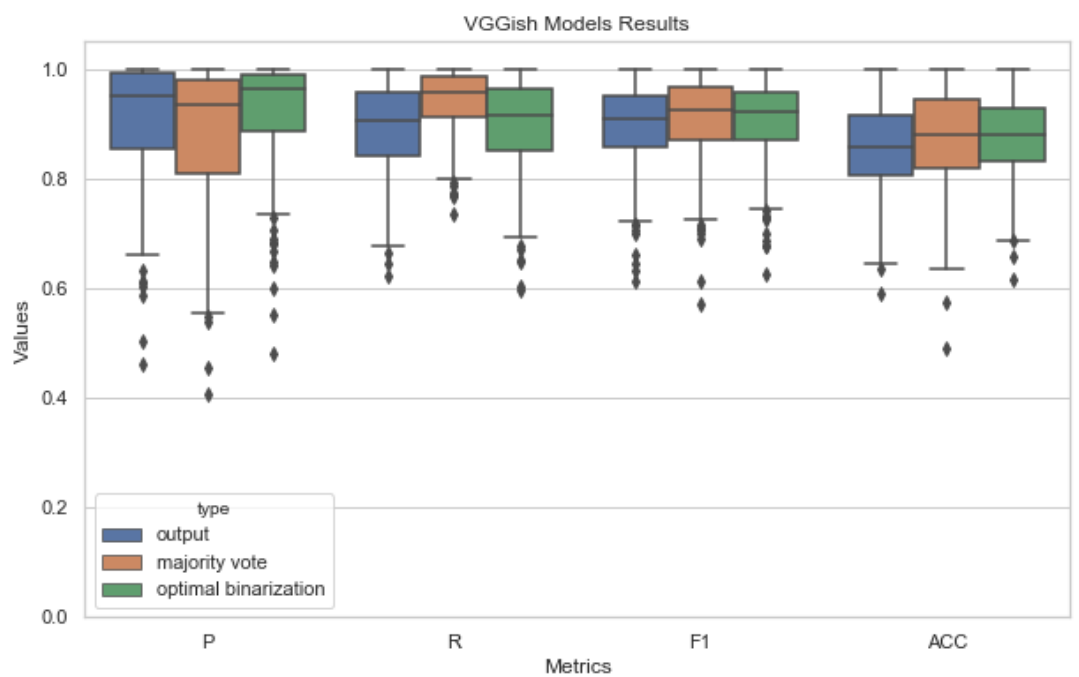

(b) Métricas dos modelos baseados em VGGish embeddings

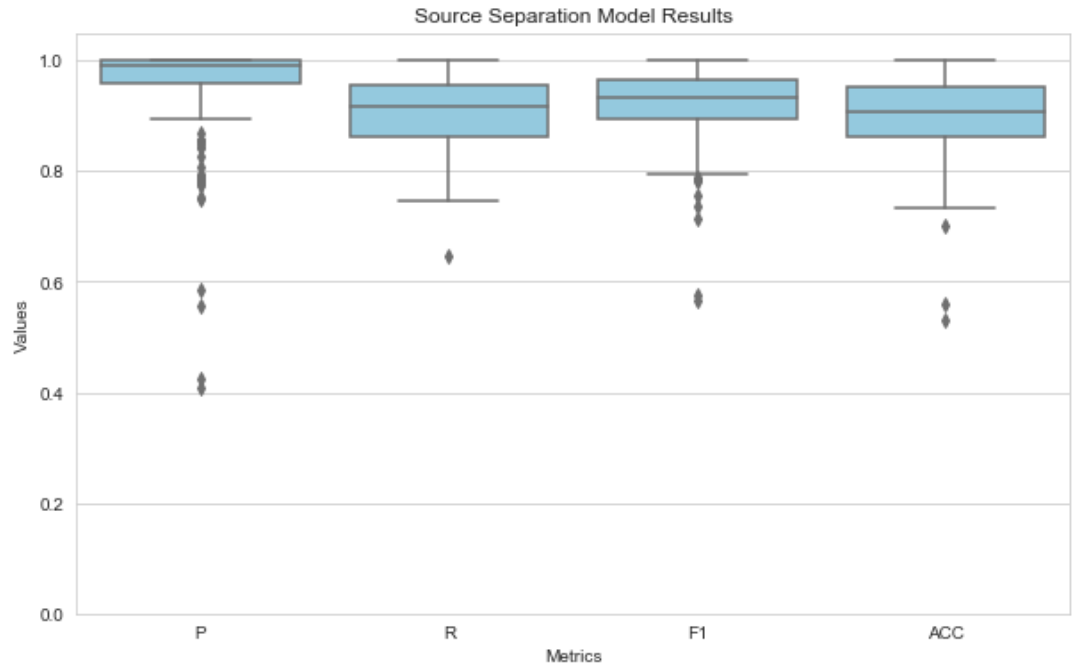

(c) Métricas do modelo de separação de fontes

Figura 4.3: Métricas dos diferentes tipos de abordagem em Deteç̧ão de Voz Cantada experimentados. Cada boxplot representa a dispersão dos resultados dos 10 conjuntos de teste avaliados. 
Em contraponto, vemos o gráfico $4.3 \mathrm{c}$ trazendo a métrica Precision muito alta, com média próxima de 1. Isto destaca a qualidade do sistema que realiza a separação de fontes, pois uma vez separada, existe muito mais chance de o conteúdo do sinal separado de fato contenha voz cantada. No entanto, a métrica Recall possui muita variação (com mínimo chegando próximo de 0.4), o que indica que o sistema pode ter deixado de separar muitos trechos com conteúdo cantado.

Retomando o exemplo do capítulo anterior com a Figura 4.4, podemos comparar agora os resultados de detecção de voz em uma peça específica do conjunto de dados.

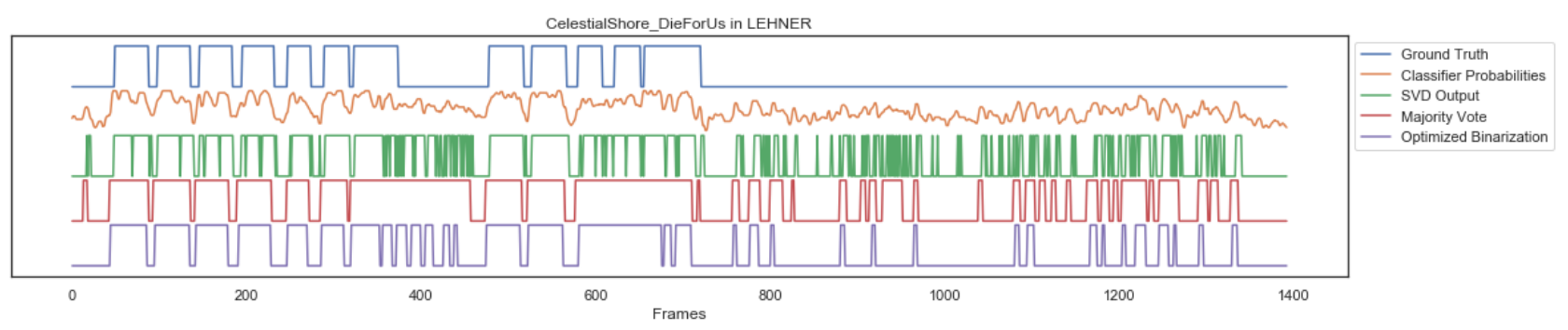

(a) Lehner

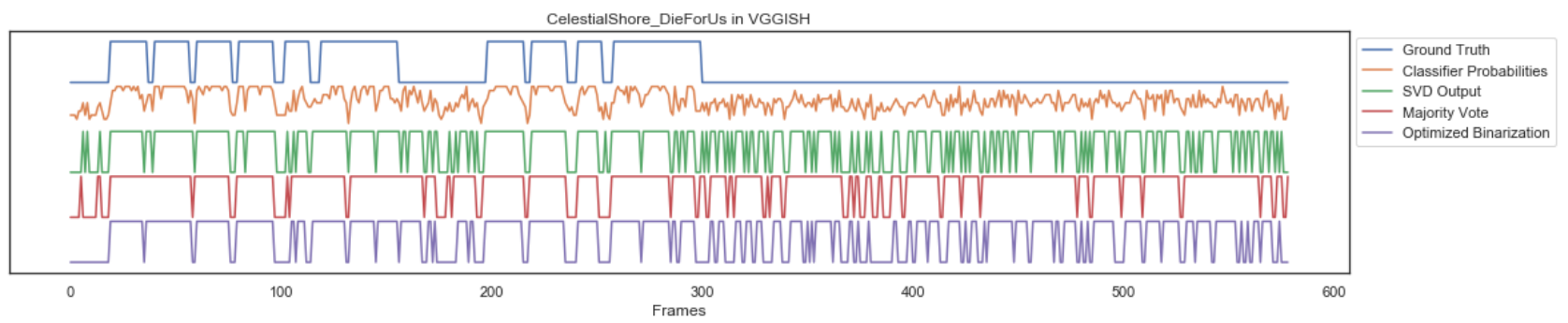

(b) VGGish

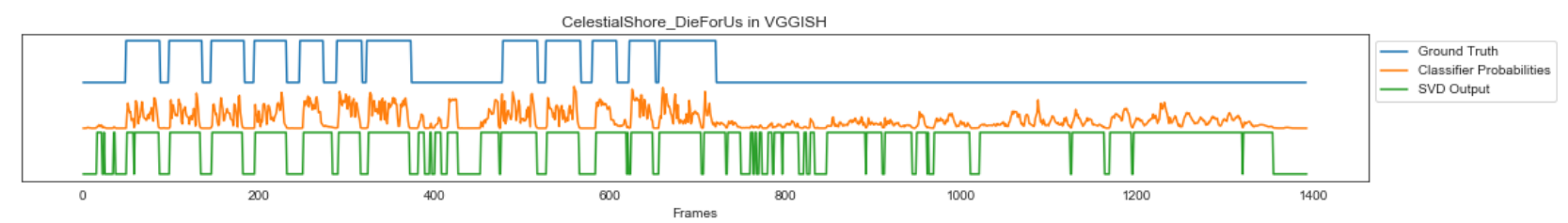

(c) Spleeter

Figura 4.4: Resultados de deteç̧ão de voz cantada para a peça Die For Us, Celestial Shore. Em azul, no topo, temos as anotações originais da peça indicando a presença de voz, quando acima, e a ausência de voz, quando abaixo. (Os gráficos foram sobrepostos para evitar conflitos na visualização). Em laranja, segunda linha, temos as probabilidades da presença de voz cantada de acordo com o modelo treinado. Em verde, linha central, temos a saída original do detector de voz. (Apenas para os gráficos 4.4a e 4.4b) Em vermelho, quarta linha, temos as probabilidades filtradas e binarizadas com o voto de maioria. Em roxo, mais abaixo, temos as probabilidades filtradas e binarizadas com o threshold ótimo.

Observando as curvas de probabilidade da presença de voz ao longo da música e comparando com a anotação da presença de voz cantada, notamos que, quando há voz no trecho, a probabilidade com VGGish é consistentemente mais estável que utilizando os descritores perceptuais. Olhando para o trecho que apresenta maior confusão (por conter sons de percussão, guitarra e sintetizadores) observamos menos picos de probabilidade alta utilizando os descritores perceptuais do que utilizando VGGish. Em contrapartida, vemos o VGGish com muita instabilidade na probabilidade neste trecho de confusão. Não conseguimos comparar diretamente a probabilidade do modelo Spleeter, mas identificamos a menor intensidade do sinal separado nos trechos confusos, o que pode indicar que o sistema separador de fontes deixou algum sinal passar, por supor ser um sinal cantado, porém com menor intensidade que o sinal original.

A Figura 4.5 traz a comparação de resultados de F-score separando os modelos por gênero. Desta forma, podemos observar a qualidade de cada tipo de detector em situações específicas. 


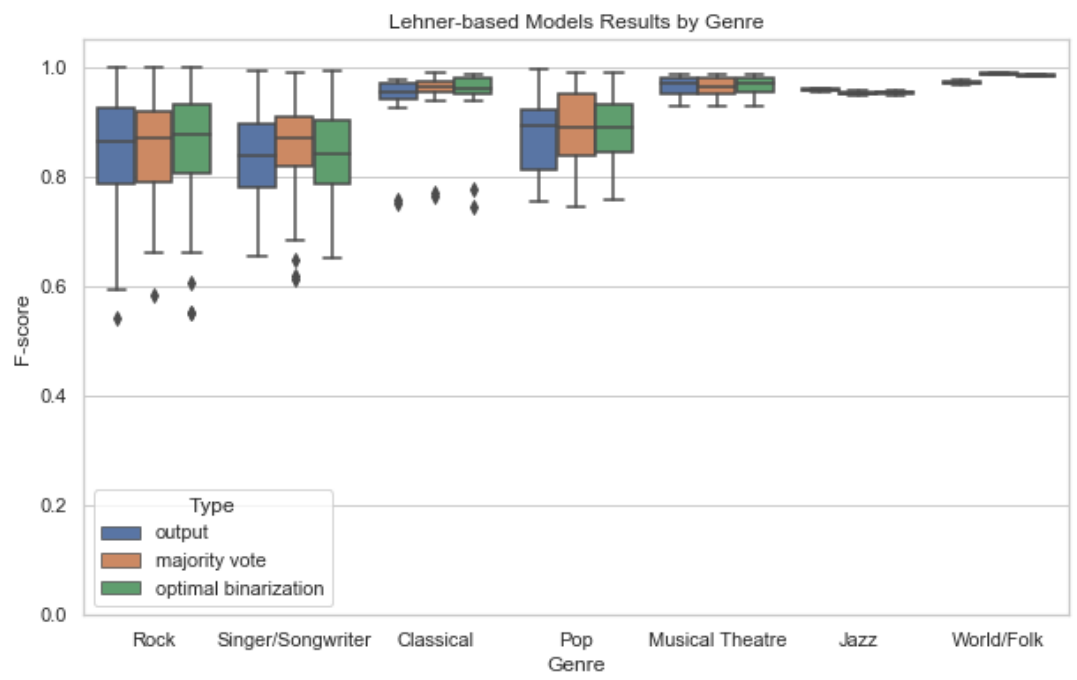

(a) F-score dos modelos baseados em Lehner et al. [2014]

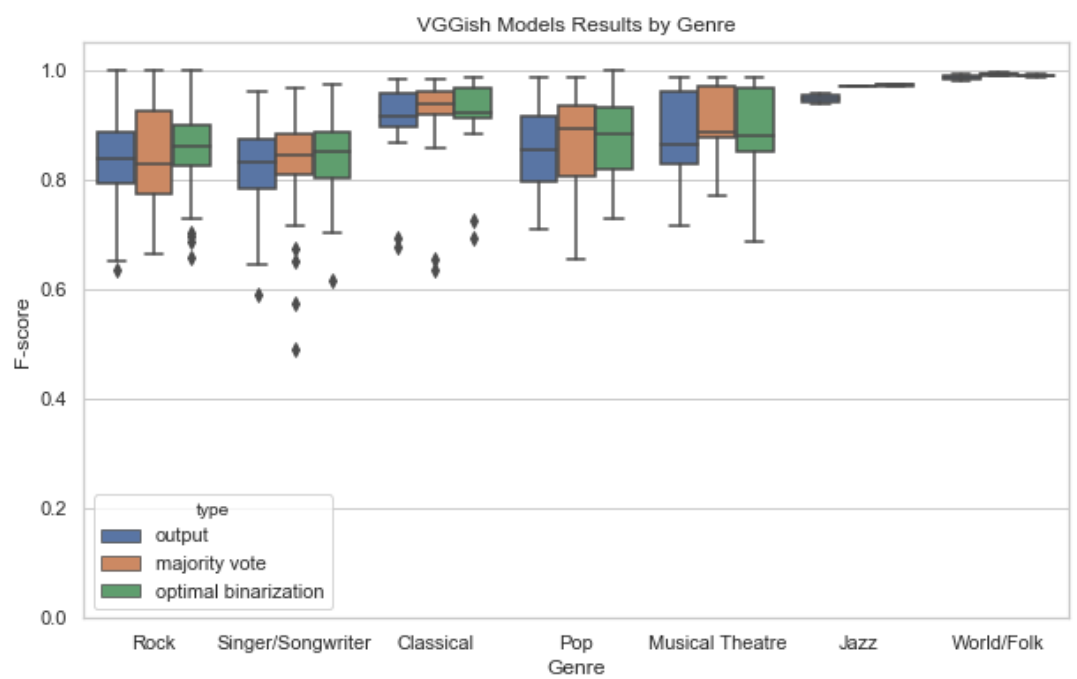

(b) F-score dos modelos baseados em VGGish embeddings

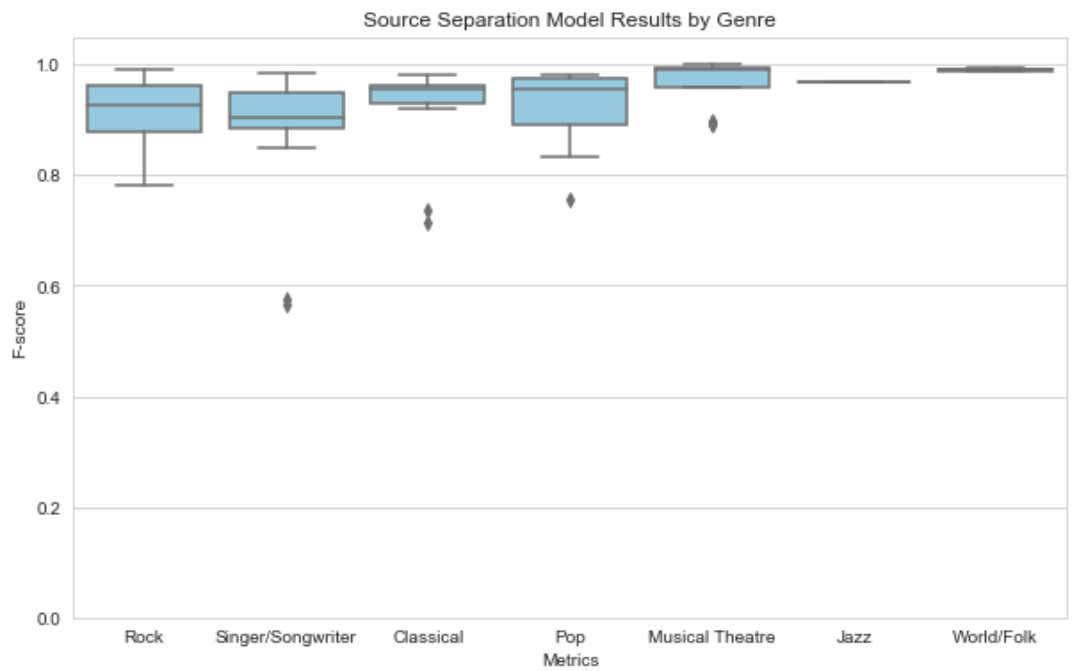

(c) F-score do modelo de separação de fontes

Figura 4.5: F-score dos diferentes tipos de abordagem em Detecção de Voz Cantada experimentados. Cada boxplot representa a dispersão dos F-scores dos 10 conjuntos de teste avaliados. 
A Tabela 4.1 apresenta as métricas resumidas em média de todos os conjuntos de teste para cada modelo. Destacamos os maiores valores de cada métrica e pudemos observar a qualidade geral da classificação dos modelos. Vemos que o modelo baseado em separação de fontes possui as maiores métricas em comparação com todos os outros, exceto pelo Recall que é maior no modelo baseado em classificação a partir dos VGGish e pós processado com o voto da maioria.

\begin{tabular}{c|ccc|ccc|c|c|c}
\multirow{2}{*}{ metrics } & \multicolumn{2}{|c|}{ LEHNER MODELS } & \multicolumn{3}{c|}{ VGGISH MODELS } & SPLEETER & \multirow{2}{*}{ metrics } \\
\cline { 2 - 9 } & output & maj vote & opt bin & output & maj vote & opt bin & output & me \\
$A C C$ & 0.84 & 0.85 & 0.86 & 0.86 & 0.87 & 0.87 & $\mathbf{0 . 9 0}$ & $A C C$ \\
$P$ & 0.88 & 0.86 & 0.88 & 0.91 & 0.88 & 0.92 & $\mathbf{0 . 9 5}$ & $P$ \\
$R$ & 0.89 & 0.94 & 0.91 & 0.89 & $\mathbf{0 . 9 4}$ & 0.90 & 0.90 & $R$ \\
$F 1$ & 0.88 & 0.89 & 0.89 & 0.89 & 0.91 & 0.90 & $\mathbf{0 . 9 2}$ & $F 1$
\end{tabular}

Tabela 4.1: Métricas resumidas para todos os conjuntos de testes e modelos

Para obter uma percepção mais apurada dos resultados de classificação, separamos as peças por gênero e escolhemos apenas um modelo por tipo de abordagem (Lehner e VGGish, binarização ótima e Spleeter, saída sem pós processamento). A Tabela 4.2 apresenta os valores das métricas de avaliação destes modelos. Destacamos aqui também os maiores valores de acurácia para cada gênero. A partir desta tabela podemos notar que mesmo possuindo maiores métricas na média geral, quando olhamos os resultados separados por gênero, notamos que o modelo de separação de fontes (Spleeter) é igual ou inferior ao modelo utilizando VGGish (com a exceção do gênero Musical Theatre, onde Spleeter alcança valores levemente superiores ao VGGish). Isso indica que ambos os métodos possuem equivalência na qualidade da classificação de trechos cantados.

\begin{tabular}{c|ccccccc} 
genre & Classical & Jazz & $\begin{array}{c}\text { Musical } \\
\text { Theatre }\end{array}$ & Pop & Rock & $\begin{array}{c}\text { Singer/ } \\
\text { Songwriter }\end{array}$ & $\begin{array}{c}\text { World/ } \\
\text { Folk }\end{array}$ \\
\hline & \multicolumn{7}{|c}{ Perceptual features models } \\
\hline ACC & $\mathbf{0 . 9 4}$ & 0.94 & $\mathbf{0 . 9 3}$ & 0.83 & 0.83 & 0.80 & 0.97 \\
P & 0.97 & 0.93 & 0.94 & 0.86 & 0.84 & 0.86 & 0.99 \\
$R$ & 0.94 & 0.98 & 0.99 & 0.93 & 0.88 & 0.87 & 0.97 \\
$F 1$ & 0.95 & 0.95 & 0.96 & 0.89 & 0.86 & 0.85 & 0.98 \\
\hline & \multicolumn{7}{|c}{ VGGish embeddings models } \\
\hline$A C C$ & 0.92 & $\mathbf{0 . 9 7}$ & 0.88 & $\mathbf{0 . 8 8}$ & $\mathbf{0 . 8 6}$ & $\mathbf{0 . 8 4}$ & $\mathbf{0 . 9 9}$ \\
$P$ & 0.96 & 0.97 & 0.97 & 0.92 & 0.90 & 0.90 & 0.99 \\
$R$ & 0.94 & 0.98 & 0.91 & 0.91 & 0.87 & 0.87 & 0.99 \\
$F 1$ & 0.95 & 0.98 & 0.93 & 0.92 & 0.88 & 0.88 & 0.99 \\
\hline & \multicolumn{7}{|c}{ Source separation model } \\
\hline$A C C$ & 0.92 & 0.96 & 0.89 & 0.88 & 0.85 & 0.84 & 0.99 \\
$P$ & 0.95 & 0.96 & 0.97 & 0.91 & 0.88 & 0.88 & 0.99 \\
$R$ & 0.95 & 0.98 & 0.92 & 0.92 & 0.88 & 0.89 & 0.99 \\
$F 1$ & 0.95 & 0.97 & 0.94 & 0.91 & 0.88 & 0.88 & 0.99
\end{tabular}

Tabela 4.2: Métricas resumidas separadas por gênero (binarização ótima)

\subsection{Discussão}

O uso de separação de fontes como indicador da presença de voz cantada possui resultados consideravelmente bons em comparação com o uso de um sistema de deteç̧ão de voz cantada baseado apenas em descritores tradicionais de áudio. A comparação mais importante torna-se a de viabilidade de uso deste indicador em termos de custo computacional e resultados esperados.

Para algumas tarefas que dependem de detecção de voz cantada, como reconhecimento de cantor, este resultado seria suficiente. A quantidade de falsos positivos é relativamente baixa, considerando as outras métricas. Para outras tarefas, como a transcrição de letras, a falta de trechos cantados 
pode influenciar na qualidade de transcrição. Neste caso, os classificadores treinados com descritores vocais possuem melhor acurácia na identificação de trechos cantados, pois são capazes de identificar, em média, mais trechos cantados.

Para exemplificar a velocidade computacional de processamento das músicas mais curta e mais longa no sistema de separação de fontes Spleeter (utilizando CPU e GPU), essas foram as medidas de tempo obtidas:

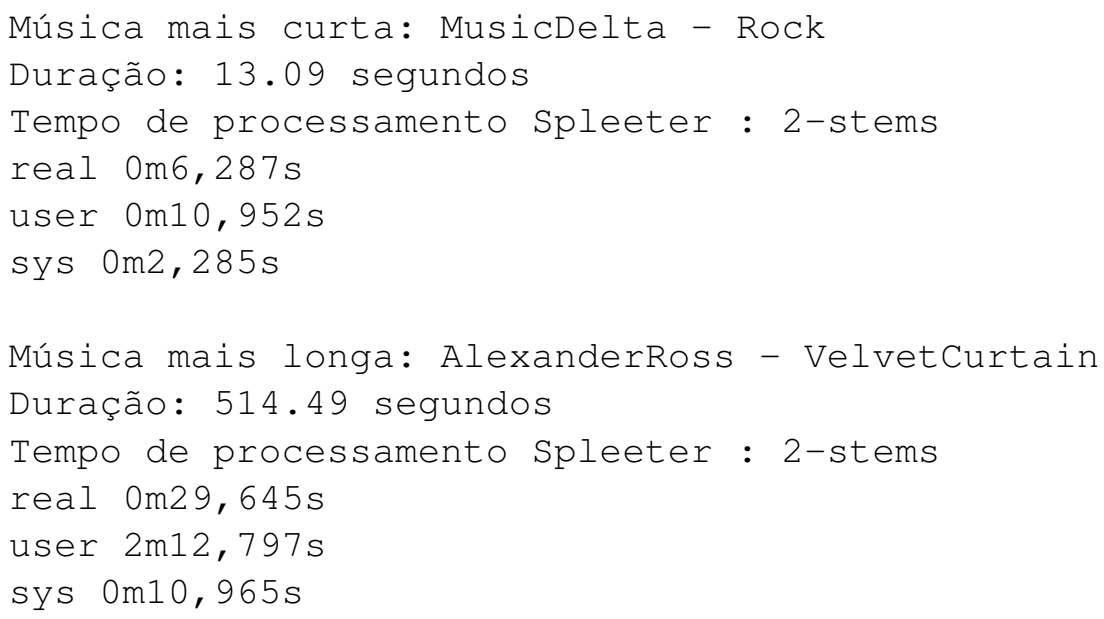

Considerando as durações das músicas, os tempos de processamento não tiveram diferença significativa. Segundo a documentação, a diferença maior no tempo de processamento acontece quando se divide em 4 faixas, mas no nosso caso dividimos apenas em 2 faixas - vocals e accompaniment).

Ainda considerando o tempo de processamento em relação às durações, verifica-se que este indicador de presença de voz pode ser usado em aplicações de tempo real (com a desvantagem da perda de contexto musical, o que diminui um pouco o seu desempenho). De fato, recentemente houve o lançamento da primeira versão de plugin VST (Visual Studio Technology) para o Spleeter ${ }^{2}$, através do qual é possível lidar com a separação de fontes em tempo real.

${ }^{2}$ https://github.com/gvne/vstSpleeter 


\section{Capítulo 5}

\section{Conclusões}

Neste trabalho revisitamos as técnicas apresentadas na literatura para tratar o problema de deteç̧ão de voz cantada em sinais de áudio polifônico, descrevemos brevemente os conceitos necessários para a elaboração de um detector automático (descritores de áudio, modelos de aprendizado de máquina e avaliadores estatísticos) e colocamos algumas questões de pesquisa em aberto. Em seguida, apresentamos uma metodologia experimental para abordar aquelas questões, apontamos as direções tomadas para alcançar os objetivos listados, e discutimos os resultados dos experimentos realizados através de análises e interpretações. Utilizamos ferramentas de aprendizado profundo disponíveis, comparando os resultados em detecção de voz cantada com o uso de descritores específicos e as possibilidades criadas pelas ferramentas de aprendizado profundo. As análises indicam que existe margem para melhoria nos sistemas de detecção de voz cantada que usam modelagem estatística clássica, através da inclusão de aprendizado profundo no processamento inicial do sinal.

\subsection{Contribuições}

Dentre as contribuições presentes nesta dissertação, devem ser destacadas: a revisão da literatura em deteç̧ão de voz; uma breve referência dos conceitos utilizados; a discussão sobre as limitações e desafios neste problema; a implementação de um sistema que detecta voz cantada; e a série de experimentos para investigação do comportamento dos diversos modelos estudados sobre um conjunto de dados anotados. Os principais eixos de articulação do processo de pesquisa foram os seguintes:

\section{Reprodução de um sistema de deteç̧ão de voz melódica}

Em um primeiro contato com o problema que não foi reportado neste trabalho, consideramos pertinente tentar reproduzir o sistema de extração de melodias descrito em Rigaud e Radenen [2016]. Este sistema possuía um módulo independente para a detecção de voz. O classificador foi implementado baseado em uma rede neural recorrente bidirecional com unidades LSTM.

Através deste processo, pudemos explorar os elementos básicos de treinamento e teste de classificadores, descritores de áudio e métricas de avaliação. O resultado desta parte do desenvolvimento foi apresentado (como pôster e apresentação oral) em um workshop ${ }^{1}$ da conferência Neural Information Processing Systems (NIPS) de 2017, em Los Angeles.

\section{Utilização de um descritor de áudio recente na literatura}

A pesquisa ganhou um recorte mais concreto com a participação da autora no programa de mentoria organizado pelo WiMIR (Women in Music Information Retrieval). No primeiro semestre de 2018, ela teve a orientação de Justin Salamon, pesquisador e professor na New York University.

\footnotetext{
${ }^{1} \mathrm{O}$ trabalho pode ser encontrado em https://mltrain.cc/events/nips-highlights-learn-how-to-code-a-paper-with-state- of-the-art-frameworks /.
} 
Durante este período, desenvolvemos um sistema de detecção de voz cantada utilizando o descritor VGGish [Hershey et al., 2017], que ainda não havia sido aplicado na tarefa de detecção de voz. Seu uso foi comparado com um descritor amplamente utilizado, o MFCC. Os principais objetivos desta parte foram verificar os resultados de classificação utilizando este novo descritor, ganhar intuição sobre o conteúdo dessa representação e avaliar a qualidade de classificação em relação ao uso do MFCC. Os resultados destes experimentos preliminares foram expostos na seção de Late Break/Demos da conferência International Society for Music Information Retrieval (ISMIR) de 2018.

\section{Sensibilidade à instrumentação de um detector de voz cantada baseado em des- critores espectrais}

Com o objetivo de detectar a voz cantada em uma mistura de fontes sonoras, avaliamos como a instrumentação afeta a detecção de voz em peças cantadas usando um descritor espectral tradicional (MFCC). Treinamos modelos Random Forest com remixes de músicas para subconjuntos específicos de fontes sonoras e os comparamos com modelos treinados com as músicas originais.

Desta forma, pudemos realizar uma análise preliminar dos resultados da precisão da classificação. Estes resultados foram publicados em um resumo expandido nos proceedings do Simpósio Brasileiro de Computação Musical de 2019, e apresentados em forma de pôster naquela conferência.

4. Comparação do uso de descritores relacionados à voz cantada com o uso de descritores aprendidos automaticamente

Tendo Lehner et al. [2014] como principal referência, realizamos experimentos para comparar os resultados de detecção de voz cantada usando descritores de áudio tradicionais e motivados perceptualmente (MFCC), em comparação com os descritores aprendidos automaticamente pela rede VGGish, os VGGish embeddings.

Esta foi a etapa mais longa de todo o processo de pesquisa, que passou por várias reformulações ao longo do tempo para abordar diversos tipos de pós-processamentos envolvidos nas comparações, definir janelas de avaliação e estruturar o formato dos experimento. Foi a partir dessa etapa que surgiu o interesse em encontrar outro uso de aprendizado profundo para a detecção de voz cantada, a partir do qual desenvolvemos a avaliação sobre a separação de fontes.

5. Avaliação da qualidade da identificação de voz cantada usando separação de fontes

A separação de fontes a partir de aprendizado profundo foi a ferramenta que nos permitiu ampliar a percepção do valor do uso de técnicas de aprendizado automático em tarefas já há muito estudadas e abordadas com ferramental estatístico clássico. Através desses experimentos, verificamos a viabilidade de obter resultados comparáveis aos obtidos anteriormente, porém usando modelos muito mais simples (sinal RMS) aplicados à fonte vocal separada, obtida por um sistema dedicado apenas à separação da voz cantada e do acompanhamento.

Mais informações sobre estes trabalhos e referências podem ser encontradas no relatório de resultados do mestrado. ${ }^{2}$

\subsection{Objetivos alcançados}

Retomando os objetivos destacados no capítulo 1, podemos visualizar com maior clareza os resultados obtidos. As questões principais a serem respondidas eram:

\footnotetext{
${ }^{2}$ https://shayennemoura.wordpress.com/2020/08/05/masters-achievements/
} 
- Descritores tradicionais e perceptualmente motivados discriminam bem os trechos de voz cantada?

Os experimentos apresentados no capítulo 3 nos permitiram notar a qualidade da deteç̧ão de voz cantada utilizando descritores relacionados à voz. Como dito anteriormente, o uso destes descritores possui desempenho razoável, com margem a melhorias.

- A utilização de descritores de áudio aprendidos automaticamente contribui para melhores resultados nesta tarefa?

Também no capítulo 3 apresentamos a utilização de um descritor recente aprendido automaticamente. Como foi relatado, o uso deste descritor contribuiu e teve resultados superiores aos resultados de detecção de voz cantada utilizando descritores tradicionais de processamento de voz.

- O tipo de acompanhamento (fontes sonoras presentes no sinal) influencia na detecção dos trechos cantados?

Até este momento, conseguimos realizar apenas experimentos preliminares de remixagem com diferentes agrupamentos de fontes sonoras. Os resultados destes experimentos estão apresentados no apêndice A.

- Qual seria a qualidade da deteçã̃o de voz cantada utilizando a saída de um separador de fontes treinado com aprendizado profundo?

A resposta para esta pergunta se encontra no capítulo 4, onde comparamos os modelos anteriormente descritos com o uso da separação de fontes para obtenção de faixas com conteúdo vocal.

\subsection{Dificuldades encontradas}

Durante o desenvolvimento deste projeto, muitas dificuldades foram encontradas, desde a definição do objeto de pesquisa, uma vez que o tema é extremamente abrangente, até a execução dos experimentos, que necessitavam de revisão constante.

Podemos destacar a pouca oferta de conjuntos de dados anotados, um problema que foi denunciado e bastante discutido nas conferências da área nos últimos anos. Tem havido um grande esforço por parte dos pesquisadores para aumentar a oferta de dados anotados consistentemente. Isso indica que os resultados de pesquisa devem se tornar mais acurados em um futuro próximo.

Outra dificuldade que muitas vezes causou impedimento na execução dos experimentos foi a pouca disponibilidade de recursos computacionais. Treinar e experimentar resultados com redes neurais em muitos dados exige equipamentos capazes para aguentar a carga de processamento e memória necessários. Assim sendo, o escopo deste projeto teve que ser adequado em função dos recursos computacionais disponíveis.

\subsection{Trabalhos futuros}

Um trabalho futuro interessante é verificar a acurácia de um separador de voz (como o Spleeter, por exemplo) recebendo os dados de saída dos detectores de voz cantada, seja como um parâmetro extra ou como um sinal filtrado, removendo os trechos que foram classificados como não contendo voz. Espera-se que os resultados sejam mais precisos, uma vez que o sistema pode ter mais contexto sobre os dados que está processando.

Outro possível desenvolvimento da investigação aqui apresentada corresponde a verificar se a abordagem de redes convolucionais que resolve o viés de loudness produz melhores resultados do que o uso de VGGish embeddings. Além disso, seria interessante descobrir se o viés de loudness se aplica também a este descritor, avaliando a qualidade da deteç̧ão de voz cantada utilizando VGGish embeddings em diferentes níveis de loudness. 
Em agosto de 2020, os organizadores do MIREX 2020 (Music Information Retrieval Evaluation eXchange) iniciaram uma nova modalidade de competição: Singing Transcription from Polyphonic $M u s i c^{3}$. O objetivo desta tarefa é indicar, para um dado sinal de áudio polifônico, a localização de onsets e offsets, bem como o sinal de pitch da voz cantada em meio ao acompanhamento. Existe uma simplificação neste caso, pois a voz cantada é monofônica para todos os áudios que serão avaliados. Os elementos apresentados neste trabalho podem servir de referência para realizar o primeiro passo, a identificação da voz cantada, e posteriormente aplicar-se algoritmos de detecção de pitch para definir a saída completa.

\footnotetext{
${ }^{3}$ https://www.music-ir.org/mirex/wiki/2020:Singing_Transcription_from_Polyphonic_Music
} 


\title{
Apêndice A
}

\section{Sensibilidade à Instrumentação de um Detector de Voz Cantada baseado em Descritores Espectrais}

\begin{abstract}
A.1 Resumo
Detectar a voz em uma mistura de fontes sonoras continua sendo uma tarefa desafiadora em Recuperação de Informação Musical. O conteúdo musical pode ser percebido de muitas maneiras diferentes conforme a instrumentação varia. Avaliamos como a instrumentação afeta a detecção de voz em peças cantadas usando um descritor espectral padrão (MFCC), treinando modelos Random Forest com remixagens de músicas para subconjuntos específicos de fontes sonoras e comparando-os com os modelos treinados com as músicas originais. Assim, apresentamos uma análise preliminar dos resultados da precisão da classificação.
\end{abstract}

\section{A.2 Introdução}

A detecção de voz cantada, também chamada de Singing Voice Detection ou Vocal Detection, é a tarefa de identificar segmentos de voz em um trecho de áudio contendo uma mistura de fontes sonoras. Essa tarefa é uma etapa intermediária dentre muitas outras tarefas relacionadas à recuperação de informação musical, entre elas a separação de voz cantada [Li e Wang, 2005] e a transcrição de melodia [Salamon e Gómez, 2012].

Existem várias abordagens na literatura para identificar segmentos com voz cantada [Lee et al., 2018]. Neste trabalho, usamos a abordagem de feature engineering, ou seja, usamos descritores comumente relacionados a tarefas de processamento de voz como entrada para algoritmos de aprendizado de máquina para criar um modelo classificador. Este é um experimento preliminar que utiliza a aumentação de dados com base em modelos de treinamento com diferentes remixagens de peças, no qual apresentamos uma avaliação da precisão da classificação usando essa abordagem.

\section{A.3 Metodologia}

Nosso objetivo é comparar a sensibilidade dos modelos classificadores aos remixes instrumentais, usando um descritor padrão (MFCC) para realizar a detecção de voz cantada. Usamos o conjunto de dados MedleyDB [Bittner et al., 2014], que contém peças de voz cantadas com faixas separadas para cada fonte instrumental e criamos remixes alternativos combinando subconjuntos das faixas instrumentais originais.

Definimos quatro famílias para esses remixes, com progressivamente menos instrumentos: (1) o mix original; (2) todos os instrumentos monofônicos mais percussão; (3) todos os instrumentos monofônicos; e (4) apenas instrumentos tocando a melodia principal. Isso cria um conjunto de 
dados aumentado no qual podemos medir o desempenho dos detectores de voz cantada. Note que todas as famílias incluem todas as faixas vocais, e a motivação é verificar se esses novos remixes facilitariam a detecção da voz do cantor, bem como proveriam mais dados para o treinamento. Uma quinta família, composta por remixes puramente instrumentais, ou seja, mixagens originais sem voz, também foi considerada para fornecer mais dados de treinamento sem voz cantada, na tentativa de contrabalançar a taxa de $71 \%$ de exemplos positivos (ou seja, segmentos contendo voz cantada) nos dados originais.

O ground-truth foi baseado nas ativações de instrumentos, conforme anotadas no conjunto de dados MedleyDB. Consideramos que um segmento de $960 \mathrm{~ms}$ possui voz de canto se pelo menos $50 \%$ de seu comprimento (não necessariamente contíguo) possui voz cantada. Os tipos de voz incluídos em nosso conjunto de dados são: male singer, female singer, male speaker, female speaker, male rapper, female rapper e vocalists.

Os descritores de áudio são calculados usando segmentos de 0,96 segundo, com sobreposição de 0,48 segundo (parâmetros compatíveis com o experimento com VGGish descrito no corpo da dissertação). Especificamente, usamos o Librosa [McFee et al., 2015] versão 0.6.0 para obter MFCCs de 40 coeficientes usando segmentos de $10 \mathrm{~ms}$, dos quais retivemos os 13 primeiros coeficientes (excluindo o coeficiente 0); agregamos cada sequência de 96 segmentos (96* $10 \mathrm{~ms}$ ) usando as seguintes estatísticas: média, desvio padrão, mediana, delta e delta duplo, a fim de preservar o contexto temporal (a dimensionalidade do recurso é $13^{*} \mathrm{n}$ _estatísticas).

Nos experimentos, utilizamos classificadores Random Forest com 100 estimadores, depois de considerar como alternativas 10, 20, 50, 100 e 150 estimadores, porque 100 estimadores produziram consistentemente os melhores resultados em todos os cenários experimentais preliminares. Para avaliar a sensibilidade da detecção, realizamos um primeiro experimento para comparar a precisão da classificação dos modelos treinados e avaliados em cada família de remixes. Em um segundo experimento, queríamos verificar se os modelos treinados se generalizaram bem, aumentando progressivamente os dados do treinamento: (A) treinando apenas com as misturas originais (família 1); (B) treinamento com mixagens originais mais remixes alternativos que incluem vocais (famílias 1 $+2+3+4$ ); e (C) treinamento com mixagens originais e todos os remixes alternativos (famílias $1+2+3+4+5$ - incluindo remixes puramente instrumentais).

\section{A.4 Avaliação}

\section{A.4.1 Dataset}

Os experimentos foram baseados no conjunto de dados MedleyDB [Bittner et al., 2014]. Selecionamos todas as 61 faixas com voz de canto e as dividimos em subconjuntos de treinamento e teste. A divisão foi definida da seguinte forma: $80 \%$ para o subconjunto de treinamento e $20 \%$ para o subconjunto de teste, deixando 48 e 13 músicas para os subconjuntos de treinamento e teste, respectivamente. Isso resulta em 21.368 e 3.874 segmentos de áudio de 960 ms para treinamento e teste, respectivamente.

Para evitar o efeito artista/álbum [Whitman et al., 2001] em nossos experimentos de classificação, usamos a MedleyDB API ${ }^{1}$ para garantir que os subconjuntos não compartilhem os mesmos artistas, ou seja, se um artista está presente no subconjunto de treinamento, todas as suas músicas estarão no mesmo subconjunto.

\section{A.4.2 Resultados}

Utilizamos a precisão para avaliar o desempenho dos modelos treinados. A figura A.1 apresenta os resultados em cada uma das quatro famílias de remix, ou seja, treinando e testando os modelos em uma única família de remix. Podemos verificar que a detecção de voz cantada se torna mais precisa ao treinar e avaliar com um subconjunto reduzido de fontes sonoras, em comparação com o uso de todas as fontes nas peças originais.

\footnotetext{
${ }^{1}$ https://github.com/marl/medleydb
} 


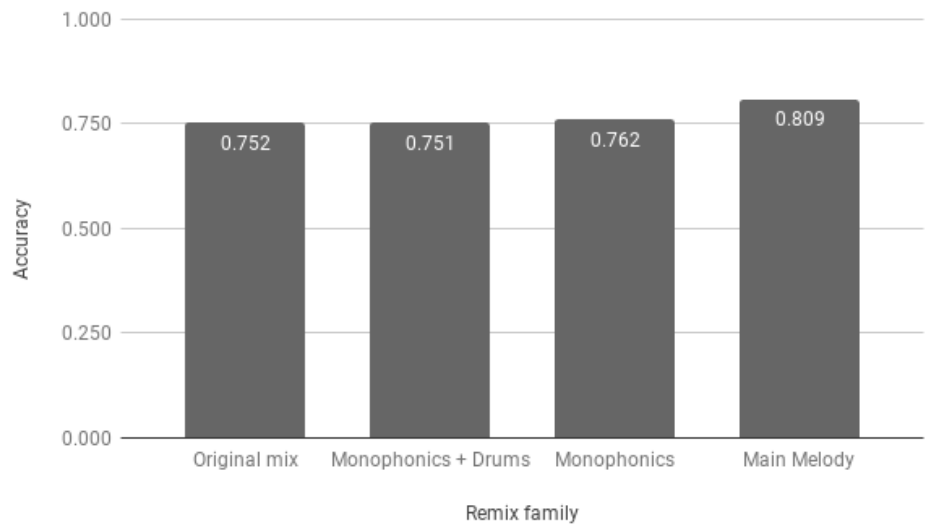

Figura A.1: Acurácia usando famílias de remix

Os resultados da generalização de nossos modelos são apresentados na figura A.2. Neste experimento, treinamos os modelos usando os três grupos de dados de treinamento discutidos na seção anterior, ou seja, (A) apenas mixagens originais, (B) remixes originais + alternativos com vocais e (C) originais + todos os remixes alternativos. A avaliação foi feita no conjunto de validação das músicas originais.

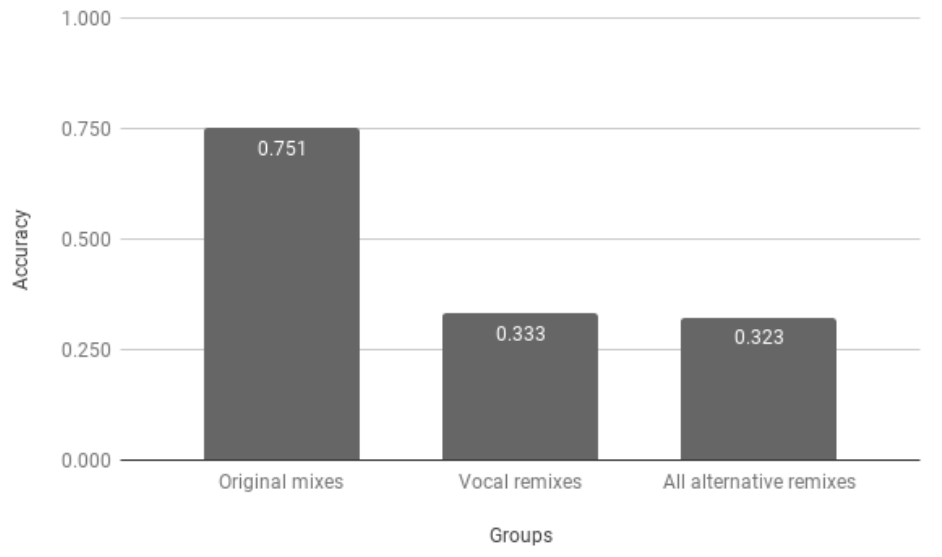

Figura A.2: Acurácia na generalização de conjuntos de treinamento aumentados

Vemos na figura A.2 que a acurácia diminuiu cerca de $42 \%$ ao usar um conjunto de treinamento aumentado, incluindo remixes alternativos vocais, em comparação ao uso apenas das peças originais no conjunto de treinamento. Os resultados da precisão da classificação, treinando o modelo com todos os remixes alternativos, diminuíram um pouco mais.

Nossa hipótese para explicar esses resultados negativos é que, mesmo que os remixes alternativos criem contextos específicos nos quais a deteç̧ão de voz é um pouco mais fácil do que no contexto original (uma interpretação endossada pela figura A.1), esses contextos estão possivelmente introduzindo muita dispersão nos MFCCs gerados (que são conhecidos por refletir aspectos do timbre).

A matriz de confusão do último grupo, por exemplo, mostra que o classificador tornou-se substancialmente inclinado para rotular segmentos como não cantados (cerca de $67 \%$ de todos os segmentos correspondem a falsos negativos), sugerindo que os MFCCs da classe não-cantada se sobrepunha à maioria dos segmentos de voz cantada nesse espaço de representação. Portanto, se o aumento de dados através da diversificação da variedade instrumental será útil na deteç̧ão de voz cantada, outros descritores de áudio, mais diretamente relacionados à presença de voz, terão necessariamente de ser incluídos. 
Outra observação derivada desses resultados é o fato de que a adição de peças sem exemplos vocais no conjunto de treinamento (na tentativa de equilibrar os exemplos positivo/negativo) realmente diminuiu a capacidade do modelo de classificar com precisão os segmentos cantados/não-cantados.

Como trabalho futuro com relação às técnicas de aumentação de dados para deteç̧ão de voz cantada, além de incluir descritores de áudio relacionados à voz mais específicos no espaço de representação, consideramos o treinamento dos modelos com diferentes misturas de músicas (por exemplo, fontes de sopro e fontes de cordas) e usando outros modelos de classificação (como SVM e Neural Networks), dentro de um conjunto específico de instrumentos ou estilo/gênero musical a ser avaliado.

\section{A.5 Conclusões}

Neste texto, relatamos resultados preliminares de nossos experimentos sobre a avaliação do uso de diferentes remixes instrumentais como uma técnica de aumentação de dados para detecção de voz no canto. Utilizamos modelos de Random Forests para classificar os segmentos de voz cantados do conjunto de dados MedleyDB, usando um descritor de áudio padrão (MFCC). Nossos resultados mostram que os remixes não foram capazes de aumentar a precisão da classificação em comparação com o uso das peças originais, mas forneceram algumas ideias para melhorias futuras, como avaliar os modelos treinados com outros grupos de remixes com base em famílias instrumentais e combinar MFCCs com outros descritores de áudio relacionados à voz. 


\section{Referências Bibliográficas}

Belin et al.(2004) Pascal Belin, Shirley Fecteau e Catherine Bedard. Thinking the voice: neural correlates of voice perception. Trends in cognitive sciences, 8(3):129-135. Citado na pág. 4

Berenzweig et al.(2002) A. L. Berenzweig, D. P. W. Ellis e S. Lawrence. Using voice segments to improve artist classification of music. Em 22nd Int. Conf.: Virtual, Synthetic, and Entertainment Audio. Audio Engineering Society. Citado na pág. 3, 4, 5

Berenzweig e Ellis(2001) Adam L Berenzweig e Daniel PW Ellis. Locating singing voice segments within music signals. Em Applications of Signal Processing to Audio and Acoustics, 2001 IEEE Workshop on the, páginas 119-122. IEEE. Citado na pág. 4

Bittner et al.(2014) R. M. Bittner, J. Salamon, M. Tierney, M. Mauch, C. Cannam e J. P. Bello. Medleydb: A multitrack dataset for annotation-intensive mir research. Em 15th International Society for Music Information Retrieval Conference, páginas 155-160, Taipei, Taiwan. Citado na pág. $22,47,48$

Bregman(1994) Albert S Bregman. Auditory scene analysis: The perceptual organization of sound. MIT press. Citado na pág. 2

Breiman(2001) Leo Breiman. Random forests. Machine learning, 45(1):5-32. Citado na pág. 15

Cherry(1953) E Colin Cherry. Some experiments on the recognition of speech, with one and with two ears. The Journal of the acoustical society of America, 25(5):975-979. Citado na pág. 2

Cook(1991) Perry Raymond Cook. Identification of Control Parameters in an Articulatory Vocal Tract Model, with Applications to the Synthesis of Singing. Tese de Doutorado, Stanford, CA, USA. UMI Order No. GAX91-15756. Citado na pág. 3

Cover(1965) T. M. Cover. Geometrical and statistical properties of systems of linear inequalities with applications in pattern recognition. IEEE Transactions on Electronic Computers, EC-14(3): 326-334. Citado na pág. 14

Dittmar et al.(2015) Christian Dittmar, Bernhard Lehner, Thomas Prätzlich, Meinard Müller e Gerhard Widmer. Cross-version singing voice detection in classical opera recordings. Em ISMIR, páginas 618-624. Citado na pág. 4, 5

Gemmeke et al.(2017) Jort F Gemmeke, Daniel PW Ellis, Dylan Freedman, Aren Jansen, Wade Lawrence, R Channing Moore, Manoj Plakal e Marvin Ritter. Audio set: An ontology and humanlabeled dataset for audio events. Em 2017 IEEE International Conference on Acoustics, Speech and Signal Processing (ICASSP), páginas 776-780. IEEE. Citado na pág. 16, 29

Hennequin et al.(2019) Romain Hennequin, Anis Khlif, Felix Voituret e Manuel Moussallam. Late-breaking/demo: Spleeter: a fast and state-of-the art music source separation tool with pretrained models. Citado na pág. 17, 18

Hershey et al.(2017) Shawn Hershey, Sourish Chaudhuri, Daniel P. W. Ellis, Jort F. Gemmeke, Aren Jansen, Channing Moore, Manoj Plakal, Devin Platt, Rif A. Saurous, Bryan Seybold, 
Malcolm Slaney, Ron Weiss e Kevin Wilson. Cnn architectures for large-scale audio classification. Em International Conference on Acoustics, Speech and Signal Processing (ICASSP). URL https: //arxiv.org/abs/1609.09430. Citado na pág. 44

Hsu e Jang(2010) Chao-Ling Hsu e Jyh-Shing Roger Jang. On the improvement of singing voice separation for monaural recordings using the mir-1k dataset. IEEE Transactions on Audio, Speech, and Language Processing, 18(2):310-319. Citado na pág. 2, 3

Humphrey et al.(2017) Eric J Humphrey, Nicola Montecchio, Rachel M Bittner, Andreas Jansson e Tristan Jehan. Mining labeled data from web-scale collections for vocal activity detection in music. Em 18th International Society for Music Information Retrieval Conference, páginas 709715. Citado na pág. 5

Knees e Schedl(2016) P. Knees e M. Schedl. Music Similarity and Retrieval: An Introduction to Audio- and Web-based Strategies. The Information Retrieval Series. Springer Berlin Heidelberg. ISBN 9783662497227. URL https://books.google.com.br/books?id=sXlBDAAAQBAJ. Citado na pág. 2

Lee et al.(2018) Kyungyun Lee, Keunwoo Choi e Juhan Nam. Revisiting singing voice detection: a quantitative review and the future outlook. Em 19th International Society for Music Information Retrieval Conference, Paris, France. Citado na pág. 3, 4, 5, 29, 47

Leglaive et al.(2015) Simon Leglaive, Romain Hennequin e Roland Badeau. Singing voice detection with deep recurrent neural networks. Em Acoustics, Speech and Signal Processing (ICASSP), 2015 IEEE International Conference on, páginas 121-125. IEEE. Citado na pág. 4, 5

Lehner et al.(2014) Bernhard Lehner, Gerhard Widmer e Reinhard Sonnleitner. On the reduction of false positives in singing voice detection. Em Acoustics, Speech and Signal Processing (ICASSP), 2014 IEEE International Conference on, páginas 7480-7484. IEEE. Citado na pág. 2, 4, $5,6,12,14,24,28,29,30,31,33,34,37,38,40,44$

Lehner et al.(2018) Bernhard Lehner, Jan Schluter e Gerhard Widmer. Online, loudness-invariant vocal detection in mixed music signals. IEEE/ACM Transactions on Audio, Speech and Language Processing (TASLP), 26(8):1369-1380. Citado na pág. 4, 6, 13, 14

Li e Wang(2005) Yipeng Li e DeLiang Wang. Separation of singing voice from music accompaniment for monaural recordings. Relatório técnico, Ohio State University Columbus United States. Citado na pág. 47

Li e Wang(2007) Yipeng Li e DeLiang Wang. Separation of singing voice from music accompaniment for monaural recordings. IEEE Transactions on Audio, Speech, and Language Processing, 15(4):1475-1487. Citado na pág. 2, 3, 4, 5

Logan et al.(2000) Beth Logan et al. Mel frequency cepstral coefficients for music modeling. Em ISMIR, volume 270, páginas 1-11. Citado na pág. 11

Lorena e de Carvalho(2007) Ana Carolina Lorena e André CPLF de Carvalho. Uma introdução às support vector machines. Revista de Informática Teórica e Aplicada, 14(2):43-67. Citado na pág. 14

Mauch et al.(2011) Matthias Mauch, Hiromasa Fujihara, Kazuyoshi Yoshii e Masataka Goto. Timbre and melody features for the recognition of vocal activity and instrumental solos in polyphonic music. Em 12th International Society for Music Information Retrieval Conference, páginas 233238. Citado na pág. 6

McFee et al.(2015) B. McFee, C. Raffel, D. Liang, D. P. W. Ellis, M. McVicar, E. Battenberg e O. Nieto. librosa: Audio and music signal analysis in python. Em Proc. 14th python in science conference, páginas 18-25. Citado na pág. 48 
Moura(2018) Shayenne Moura. Singing voice detection using vggish embeddings. Em Extended abstract of 19th International Society for Music Information Retrieval Conference, Paris, France. Citado na pág. 16

Muller et al.(2011) Meinard Muller, Daniel PW Ellis, Anssi Klapuri e Gaël Richard. Signal processing for music analysis. IEEE Journal of Selected Topics in Signal Processing, 5(6):10881110. Citado na pág. 11

Pedregosa et al.(2011) F. Pedregosa, G. Varoquaux, A. Gramfort, V. Michel, B. Thirion, O. Grisel, M. Blondel, P. Prettenhofer, R. Weiss, V. Dubourg, J. Vanderplas, A. Passos, D. Cournapeau, M. Brucher, M. Perrot e E. Duchesnay. Scikit-learn: Machine learning in Python. Journal of Machine Learning Research, 12:2825-2830. Citado na pág. 23

Peeters et al.(2011) Geoffroy Peeters, Bruno L Giordano, Patrick Susini, Nicolas Misdariis e Stephen McAdams. The timbre toolbox: Extracting audio descriptors from musical signals. The Journal of the Acoustical Society of America, 130(5):2902-2916. Citado na pág. 11

Ramona et al.(2008) Mathieu Ramona, Gaël Richard e Bertrand David. Vocal detection in music with support vector machines. Em 2008 IEEE International Conference on Acoustics, Speech and Signal Processing, páginas 1885-1888. IEEE. Citado na pág. 6

Regnier e Peeters(2009) Lise Regnier e Geoffroy Peeters. Singing voice detection in music tracks using direct voice vibrato detection. Em Acoustics, Speech and Signal Processing, 2009. ICASSP 2009. IEEE International Conference on, páginas 1685-1688. IEEE. Citado na pág. 2, 4, 5

Rigaud e Radenen(2016) François Rigaud e Mathieu Radenen. Singing voice melody transcription using deep neural networks. Em ISMIR, páginas 737-743. Citado na pág. 43

Rocamora e Herrera(2007) M. Rocamora e P. Herrera. Comparing audio descriptors for singing voice detection in music audio files. Em Brazilian Symposium on Computer Music, 11th. Sao Paulo, Brazil, volume 26, página 27. Citado na pág. 3, 4, 5, 24

Salamon e Gómez(2012) J. Salamon e E. Gómez. Melody extraction from polyphonic music signals using pitch contour characteristics. IEEE Transactions on Audio, Speech, and Language Processing, 20(6):1759-1770. doi: 10.1109/TASL.2012.2188515. Citado na pág. 47

Schlüter(2016) Jan Schlüter. Learning to pinpoint singing voice from weakly labeled examples. Em 17th International Society for Music Information Retrieval Conference, páginas 44-50. Citado na pág. $4,5,28$

Schlüter e Lehner(2018) Jan Schlüter e Bernhard Lehner. Zero-mean convolutions for levelinvariant singing voice detection. Em 19th Int. Soc. for Music Info. Retrieval Conf., Paris, France. Citado na pág. 33

Sonnleitner et al.(2012) Reinhard Sonnleitner, Bernhard Niedermayer, Gerhard Widmer e Jan Schlüter. A simple and effective spectral feature for speech detection in mixed audio signals. Em Proceedings of the 15th International Conference on Digital Audio Effects (DAFx'12). Citado na pág. 12

Stöter et al.(2019) Fabian-Robert Stöter, Stefan Uhlich, Antoine Liutkus e Yuki Mitsufuji. Openunmix-a reference implementation for music source separation. Citado na pág. 17

Sundberg(1977) Johan Sundberg. The acoustics of the singing voice. Scientific American, 236 (3):82-91. Citado na pág. 3

Swaminathan e Lerch(2019) R. V. Swaminathan e A. Lerch. Improving singing voice separation using attribute-aware deep network. Em 2019 International Workshop on Multilayer Music Representation and Processing (MMRP), páginas 60-65. Citado na pág. 4, 6 
Vembu e Baumann(2005) Shankar Vembu e Stephan Baumann. Separation of vocals from polyphonic audio recordings. Em 6th International Society for Music Information Retrieval Conference, páginas 337-344. Citeseer. Citado na pág. 6

Wang e Brown(2006) D.L. Wang e G.J. Brown. Computational Auditory Scene Analysis: Principles, Algorithms, and Applications. Wiley. ISBN 9780471741091. URL https://books.google. com.br/books?id=q58eAQAAIAAJ. Citado na pág. 2

Whitman et al.(2001) B. Whitman, G. Flake e S. Lawrence. Artist detection in music with minnowmatch. Em Proc. of the 2001 IEEE Signal Processing Society Workshop, páginas 559568. IEEE. Citado na pág. 48

Zhang(2003) Tong Zhang. Automatic singer identification. Em Multimedia and Expo, 2003. ICME'03. Proceedings. 2003 International Conference on, volume 1, páginas I-33. IEEE. Citado na pág. 4 